\title{
Production and Cost Assessment of a Potential Application of Surface Miners in Coal Mining in West Virginia
}

Timothy A. Nolan

West Virginia University

Follow this and additional works at: https://researchrepository.wvu.edu/etd

\section{Recommended Citation}

Nolan, Timothy A., "Production and Cost Assessment of a Potential Application of Surface Miners in Coal Mining in West Virginia" (2012). Graduate Theses, Dissertations, and Problem Reports. 3337.

https://researchrepository.wvu.edu/etd/3337

This Thesis is protected by copyright and/or related rights. It has been brought to you by the The Research Repository @ WVU with permission from the rights-holder(s). You are free to use this Thesis in any way that is permitted by the copyright and related rights legislation that applies to your use. For other uses you must obtain permission from the rights-holder(s) directly, unless additional rights are indicated by a Creative Commons license in the record and/ or on the work itself. This Thesis has been accepted for inclusion in WVU Graduate Theses, Dissertations, and Problem Reports collection by an authorized administrator of The Research Repository @ WVU. For more information, please contact researchrepository@mail.wvu.edu. 


\title{
Production and Cost Assessment of a Potential Application of Surface Miners in Coal Mining in West Virginia
}

\author{
Timothy A. Nolan \\ Thesis submitted to the \\ At West Virginia University \\ in partial fulfillment of the requirements \\ for the degree of \\ Master of Science \\ in \\ Mining Engineering \\ Vladislav Kecojevic, Ph.D., Chair \\ Brijes Mishra, Ph.D. \\ Keith A. Heasley, Ph.D. \\ Department of Mining Engineering
}

Benjamin M. Statler College of Engineering and Mineral Resources

\author{
Morgantown, West Virginia \\ 2012
}

Keywords: Surface Mining; Surface Miner; Bituminous Coal;

West Virginia; Analytical Hierarchy Process;

Copyright 2012 Timothy A. Nolan 


\title{
ABSTRACT \\ Production and Cost Assessment of a Potential Application of Surface Miners in Coal Mining in West Virginia
}

\author{
Timothy A. Nolan
}

The broad objective of this research was to improve current mining practices and reduce negative environmental impact of surface coal mining in West Virginia (WV). The specific objectives were to (i) build the production and cost models to determine if conventional surface mining unit operations such as drilling, blasting, digging, loading, and crushing can be replaced with one mining machine called a surface miner (SM), (ii) apply the analytical hierarchy process (AHP) to help select the optimal mining method, and (iii) determine the extent of which the SM would benefit surface coal mining in WV, particularly by reducing some of the negative environmental impacts associated with current extraction practices.

The entire production and cost models were developed in MS Excel. The design and the procedures used for achieving the objectives involved six interrelated modules. Module \#1 includes rock properties of sandstone, shale, which are the predominant overburden and interburden materials in $\mathrm{WV}$, and sub-bituminous coal. Module \#2 considers drilling and blasting operations. Module \#3 includes digging and loading of overburden material. It specifically addresses mining equipment such as electric and hydraulic shovels and front-end wheel loaders. Interburden material also includes sandstone and shale, and the two unit operations involved are ripping and pushing by bulldozers and loading by hydraulic backhoe shovel. Module \#4 covers coal extraction by hydraulic backhoe shovel and the crushing operation. Module \#5 focuses on the SM, while Module \#6 is used to conduct comparative analyses among all mining unit operations for overburden, interburden, and coal. The resulting production rates, ownership, and operating costs were also presented. The analytical hierarchy process (AHP) was used to help select the optimal mining method based on both qualitative and quantitative factors.

Based on the results of this research, application of SM would benefit coal extraction in surface mining operations in WV. The estimated cost of coal extraction is lower than with conventional mining methods, and the machine is able to work selectively with high separation accuracy. Thin seams of coal and overburden can be mined separately, thus preventing dilution with interburden material. Rising operating costs for the SM become an issue as the quantity of material being extracted increases and higher values of unconfined compressive strength are encountered. Cutting tools on the drum wear out faster and require more changes and, at a certain point, the SM becomes unfeasible because of the time and cost involved in changing cutting tools. A significant advantage of SM, where applicable, is the elimination of the negative environmental impacts associated with blasting. 


\title{
PRODUCTION AND COST ASSESSMENT OF A POTENTIAL APPLICATION OF SURFACE MINERS IN COAL MINING IN WEST VIRGINIA
}

\author{
Timothy A. Nolan \\ Thesis submitted to the \\ Benjamin M. Statler College of Engineering and Mineral Resources \\ At West Virginia University \\ in partial fulfillment of the requirements \\ for the degree of \\ Master of Science \\ in \\ Mining Engineering \\ Department of Mining Engineering \\ APPROVAL OF THE EXAMINING COMMITTEE
}

Vladislav Kecojevic, Ph.D., Chair

Brijes Mishra, Ph.D.

Date

Keith A. Heasley, Ph.D. 


\section{Table of Contents}

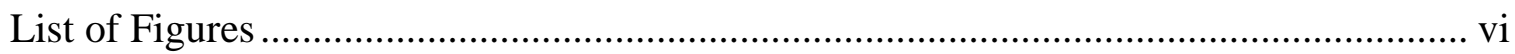

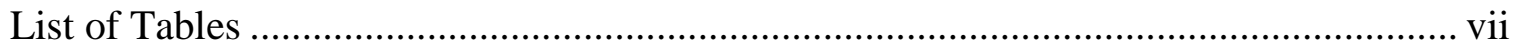

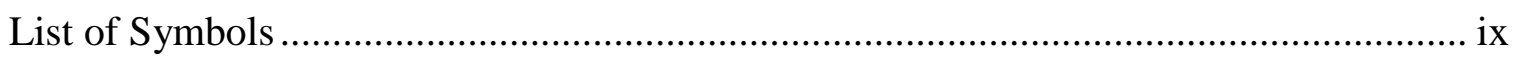

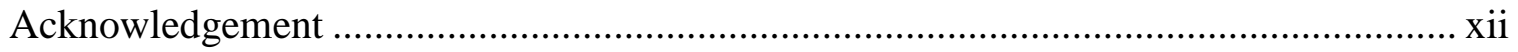

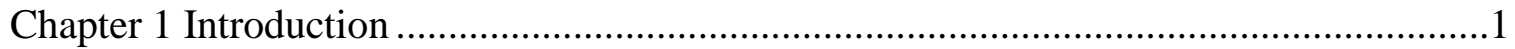

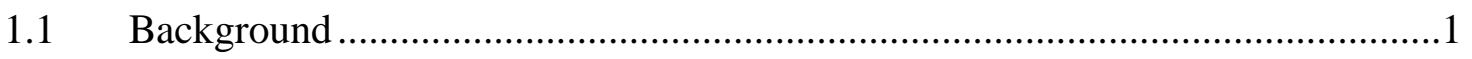

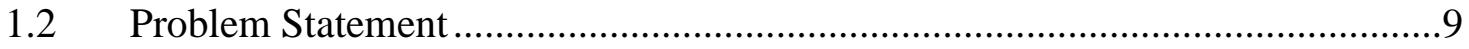

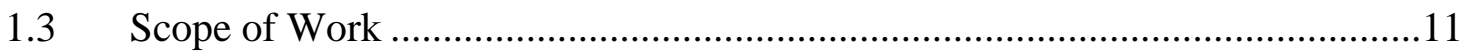

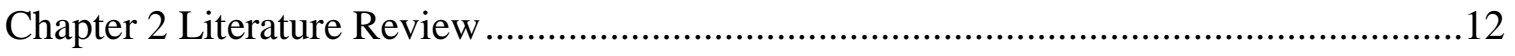

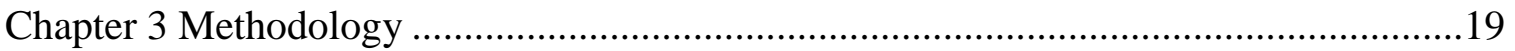

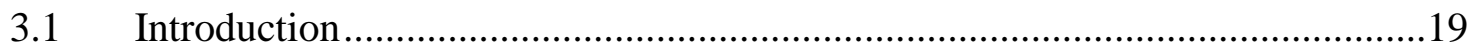

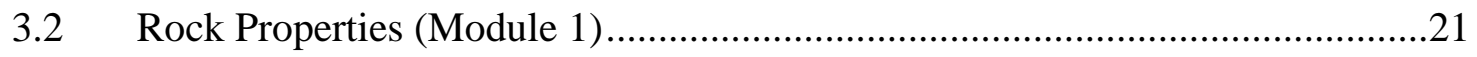

3.3 Drilling and Blasting Operations (Module 2) ...........................................22

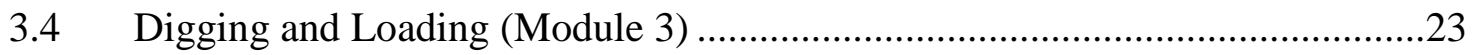

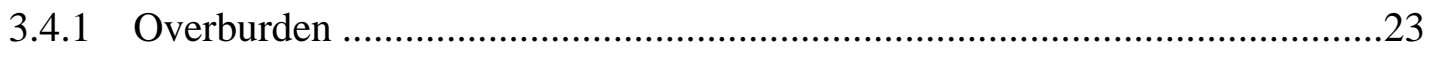

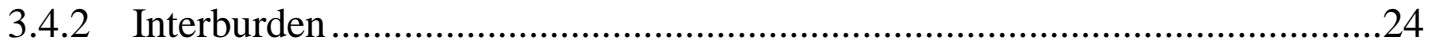

3.5 Coal Extraction \& Crushing (Module 4) ......................................................25

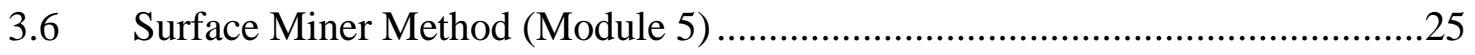

3.7 Comparison of Mining Methods (Module 6) ................................................44

3.7.1 Analytical Hierarchy Process for the Selection of the Optimal Mining

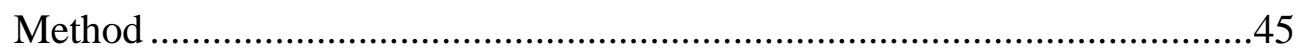

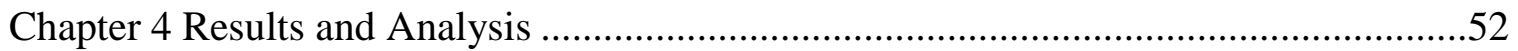

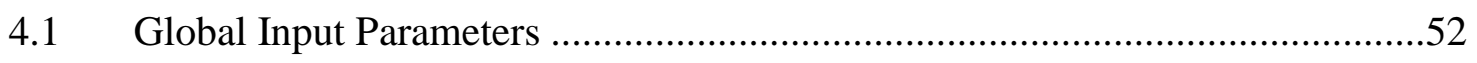

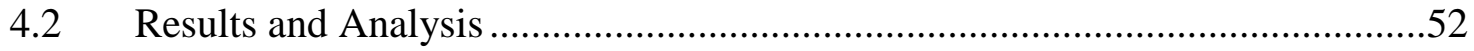

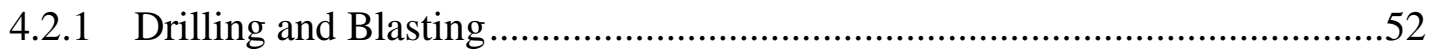

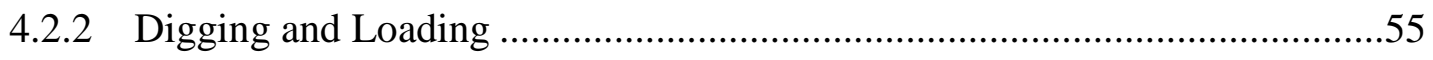

4.2.3 Conventional Coal Extraction and Crushing ..............................................63

4.2.4 Surface Miner Method .............................................................................66

4.2.5 Comparison of Mining Methods ........................................................... 76 


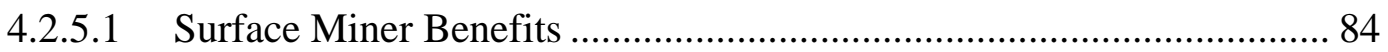

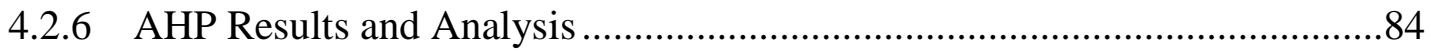

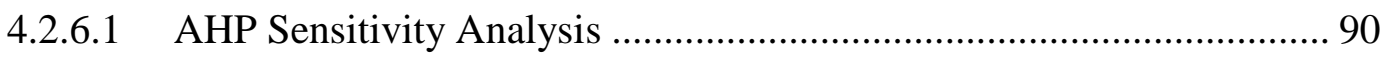

Chapter 5 Conclusions and Recommendations for Future Research.............................98

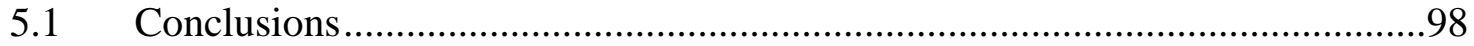

5.3 Recommendations for Future Research ......................................................99

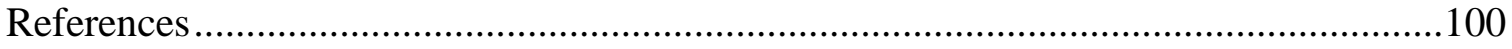




\section{List of Figures}

Figure 1-1 Conventional Surface Mining Process (Image Sources:

Atlas Copco, Terex, Caterpillar, Kecojevic, Hitachi, and Liebherr) ………………..... 3

Figure 1-2 Surface Coal Mine in WV (Kecojevic, 2006) ............................................................ 4

Figure 1-3 Surface Miner (Wirtgen, 2010) ……………..................................................... 5

Figure 1-4 Surface Miner Diagram (Wirtgen, 2010) ................................................................ 6

Figure 1-5 Rotating Drum and Carbide-Tipped Cutting Tools (Wirtgen, 2010)............................ 7

Figure 1-6 Selective Extraction of Coal by SM (Kecojevic, 2006) .............................................. 8

Figure 3-1 Mining Method Selection Algorithm ..................................................................... 20

Figure 3-2 Example Mining Sequence of a Surface Miner (Wirtgen, 2008).............................. 26

Figure 3-3 Typical Mining Sequence of a Surface Miner (Wirtgen, 2008)................................... 27

Figure 3-4 AHP Model for Selection of Optimal Mining Method .............................................. 46

Figure 3-5 Example AHP Model ......................................................................................... 48

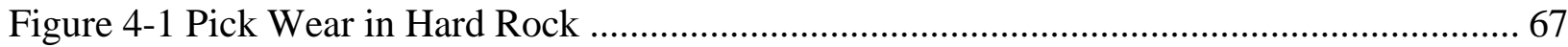

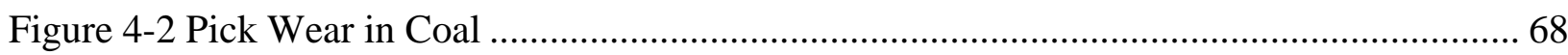

Figure 4-3 Conventional vs. SM Mining Method Comparison in Sandstone Overburden ........... 76

Figure 4-4 Conventional vs. SM Mining Method Comparison in Shale Overburden ................... 78

Figure 4-5 Conventional vs. SM Mining Method Comparison in Sandstone Interburden ............ 79

Figure 4-6 Conventional vs. SM Mining Method Comparison in Shale Interburden .................... 81

Figure 4-7 Conventional vs. SM Mining Method Comparison in Coal ....................................... 82

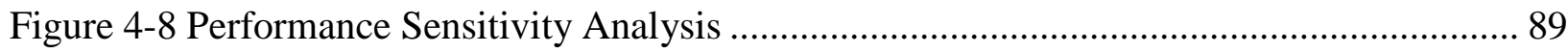

Figure 4-9 Sensitivity Analysis (Conventional Blasting Rating: Fair) ........................................ 94

Figure 4-10 Sensitivity Analysis (SM Blasting Rating: Good) ……………………………........ 95

Figure 4-11 Sensitivity Analysis (Conventional Blasting Rating: Fair,

SM Blasting Rating: Good) .............................................................................. 96 


\section{List of Tables}

Table 2-1 Rating of the Parameters of New Rockmass Cuttability Classification

Table 2-2 Applicability of Surface Miner Based on Excavatability Index

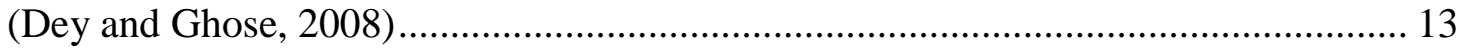

Table 3-1 Average Values of Coal and Rock Properties in WV ............................................ 22

Table 3-2 Pick Wear Equations for Hard Rock .............................................................. 31

Table 3-3 Pick Wear Equations for Coal ....................................................................... 31

Table 3-4 The Fundamental Scale of Absolute Numbers (Saaty, 2008) ................................. 47

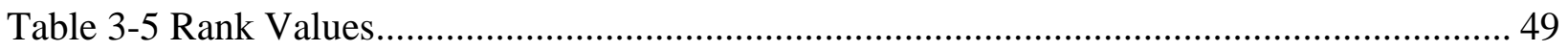

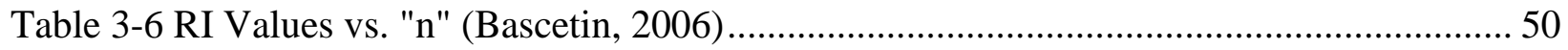

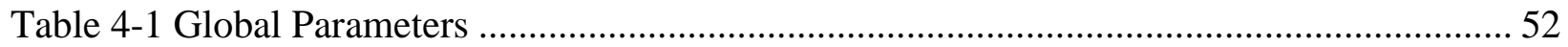

Table 4-2 Drilling and Blasting Parameters.................................................................. 53

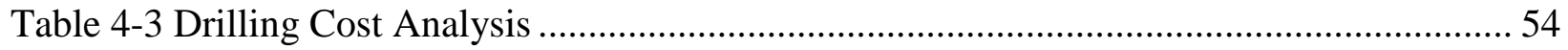

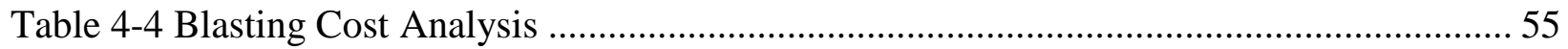

Table 4-5 Overburden Hydraulic Shovel Parameters ......................................................... 56

Table 4-6 Overburden Hydraulic Shovel Cost Analysis..................................................... 57

Table 4-7 Overburden Electric Shovel Parameters........................................................... 58

Table 4-8 Overburden Electric Shovel Cost Analysis ....................................................... 58

Table 4-9 Overburden Front-End Wheel Loader Parameters .................................................. 59

Table 4-10 Overburden Front-End Wheel Loader Cost Analysis ........................................... 59

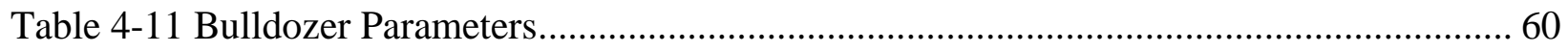

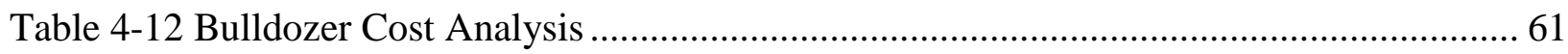

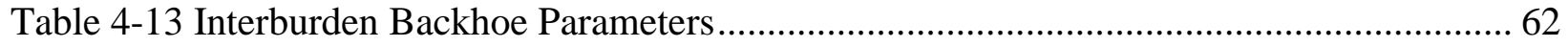

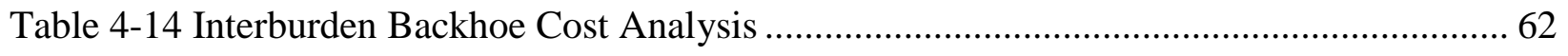

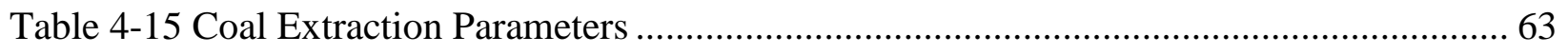

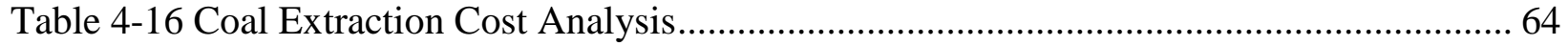

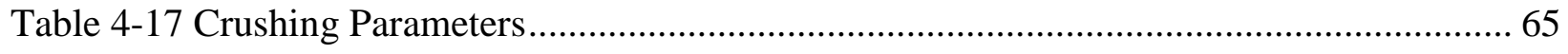

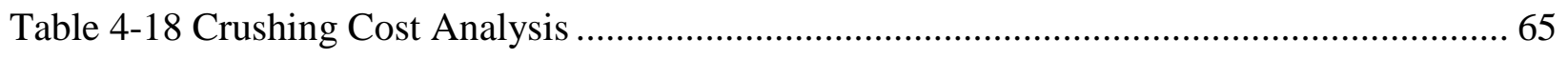

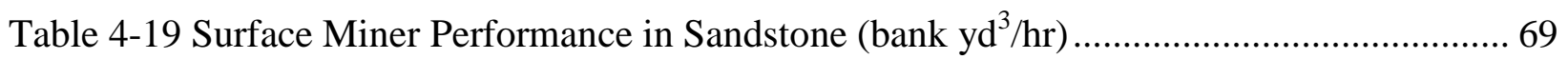




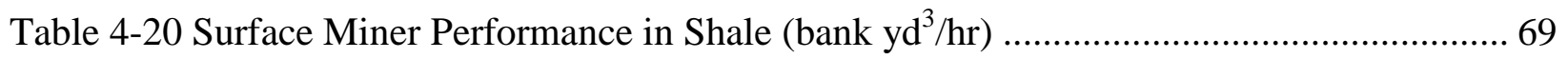

Table 4-21 Surface Miner Performance in Coal (tons/hr) .......................................................... 70

Table 4-22 Surface Miner Parameters for Overburden.............................................................. 70

Table 4-23 Surface Miner Cost Analysis for Overburden .......................................................... 71

Table 4-24 Surface Miner Parameters for Interburden .................................................................. 72

Table 4-25 Surface Miner Cost Analysis for Interburden …………….................................... 73

Table 4-26 Surface Miner Parameters for Coal ......................................................................... 74

Table 4-27 Surface Miner Cost Analysis for Coal............................................................... 75

Table 4-28 Total Cost of SM per Cubic Yard in Sandstone Overburden ...................................... 77

Table 4-29 Total Cost of SM per Cubic Yard in Shale Overburden .......................................... 78

Table 4-30 Total Cost of SM per Cubic Yard in Sandstone Interburden ...................................... 80

Table 4-31 Total Cost of SM per Cubic Yard in Shale Interburden .......................................... 81

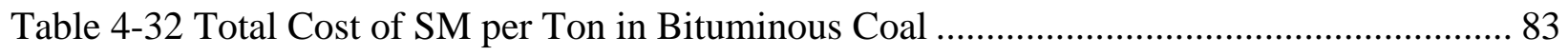

Table 4-33 Pairwise Comparison Judgment Matrices for the

Selection of the Optimal Mining Method.................................................................. 86

Table 4-34 Composite Priority Weights for Critical Factors.......................................................... 87

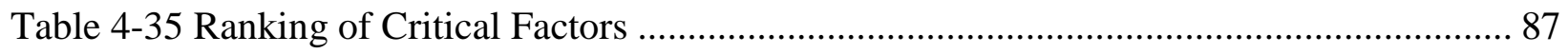

Table 4-36 Application of the AHP Model to Mining Method Selection ..................................... 88

Table 4-37 Production and Cost Sensitivity Analysis ................................................................. 91

Table 4-38 Environmental and Cost Sensitivity Analysis ....................................................... 91

Table 4-39 Environmental and Production Sensitivity Analysis .................................................. 92

Table 4-40 Sensitivity Analysis on Final Criteria...........................Error! Bookmark not defined. 


\section{List of Symbols}

AHP

ANFO

$\mathrm{CC}$

CI

CR

CTR

D

DR

DV

FC

FLC

GC

$\mathrm{HCI}$

$\mathrm{HO}$

INS

INSR

INT

INTR

LBC

LC

MP

NCT

NPC

OC

$\mathrm{OHY}$

$\mathrm{OP}$
Analytical Hierarchy Process

Ammonium Nitrate + Fuel Oil

Capital Cost

Consistency Index

Consistency Ratio

Cuttability Index

Cutting Depth

Depreciation Rate

Depreciation Value per Year

Fuel Cost

Full Load Fuel Consumption

Grease Cost

Hydraulic Oil Change Time Interval

Hydraulic Oil Cost

Insurance Cost

Insurance Rate

Interest Cost

Interest Rate

Labor Cost

Lube Cost

Maximum Production

Non-Cutting Time

Number of Pick Changes per Row

Ownership Cost

Operating Hours per Year

Operating Years 
OPC

P

PC

PCT

PCY

PPS

PQ

PTC

PW

Q

RC

RCT

RCT\%

RI

RL

ROHY

RP

RV

$\mathrm{RV} \%$

SM

SP

SS

ST

TS

TSL

TT

TX

TXR

UP
Operating Cost

Power

Purchasing Cost

Pick Changing Time

Pick Consumption per Year

Picks per Set

Practical Cutting Performance

Pick Cost

Pick Wear

Cutting Performance

Repair Cost

Real Cutting Time

Real Cutting Time Percent

Randomly Generated Reciprocal Matrices

Row Length

Real Operating Hours per Year

Required Production

Residual Value

Residual Value Percent

Surface Miner

Spare Parts

Sumping Speed

Sump Time

Traveling Speed

Total Sump Time

Turning Time

Tax Cost

Tax Rate

Usable Production 
V

VHO

VR

W

WC

WP

WV
Cutting Velocity Volume of Hydraulic Oil Tank Value to be Recovered Through Work Width

Water Cost Wear Parts

West Virginia 


\section{Acknowledgement}

I would like to express my sincere thanks to my advisor, Dr. Vladislav Kecojevic. His guidance, support, and patience with this research have allowed me to produce this thesis. It was an honor to have an experienced, very knowledgeable person assisting me through research and methodology.

I am also grateful to the thesis committee members, Dr. Brijes Mishra, and Dr. Keith A. Heasley. The comments and suggestions helped me to improve my research and thesis.

I would like to show my gratitude to the Department of Mining Engineering for the support and opportunity to study in the graduate program. I owe my deepest gratitude to the Coal and Energy Research Bureau for providing the financial support during my studies.

I would like to thank the people working for the mining companies that provided me with data that allowed for this research.

Finally, I would like thank my family Gary Nolan, Marybeth Nolan, and Elizabeth Nolan as well as friends and colleagues for their continued support and collaboration. 


\section{Chapter 1}

\section{Introduction}

\subsection{Background}

Coal mining is the backbone of West Virginia's economy. The state produced roughly 143 million tons of coal in 2011 (WV Coal, 2011). Approximately 50 million tons or $35 \%$ of total coal production came from surface mines.

The current surface mining practices in West Virginia (WV) consist of conventional mining unit operations including: drilling, blasting, digging, loading, haulage, and disposal (Figure 1.1). Draglines are used in some mines for stripping and direct disposal of overburden material into excavated areas. Coal crushing is the final conventional mining unit operation.

WV used almost 465,000 tons or 930 million lb of explosives in the mining, quarrying, and construction industries in 2008 (Apodaca, 2010). The state ranks second in the nation for explosives consumption. Almost $85 \%$ or 790.5 million lbs were used in surface coal mining. Considering an average price of blasting agents (bulk emulsions, slurry and ANFO) of $\$ 0.52$ per $\mathrm{lb}$, the surface coal mines in WV spent $\$ 411$ million for explosives alone. This does not include additional blasting accessories such as detonators, boosters, detonating cords, lead lines, additional costs for labor, explosives truck-delivery, and shot services. The addition of the drilling, digging, loading, and 
hauling costs for the blasted material amounts to a significant overall cost to mine operators. 


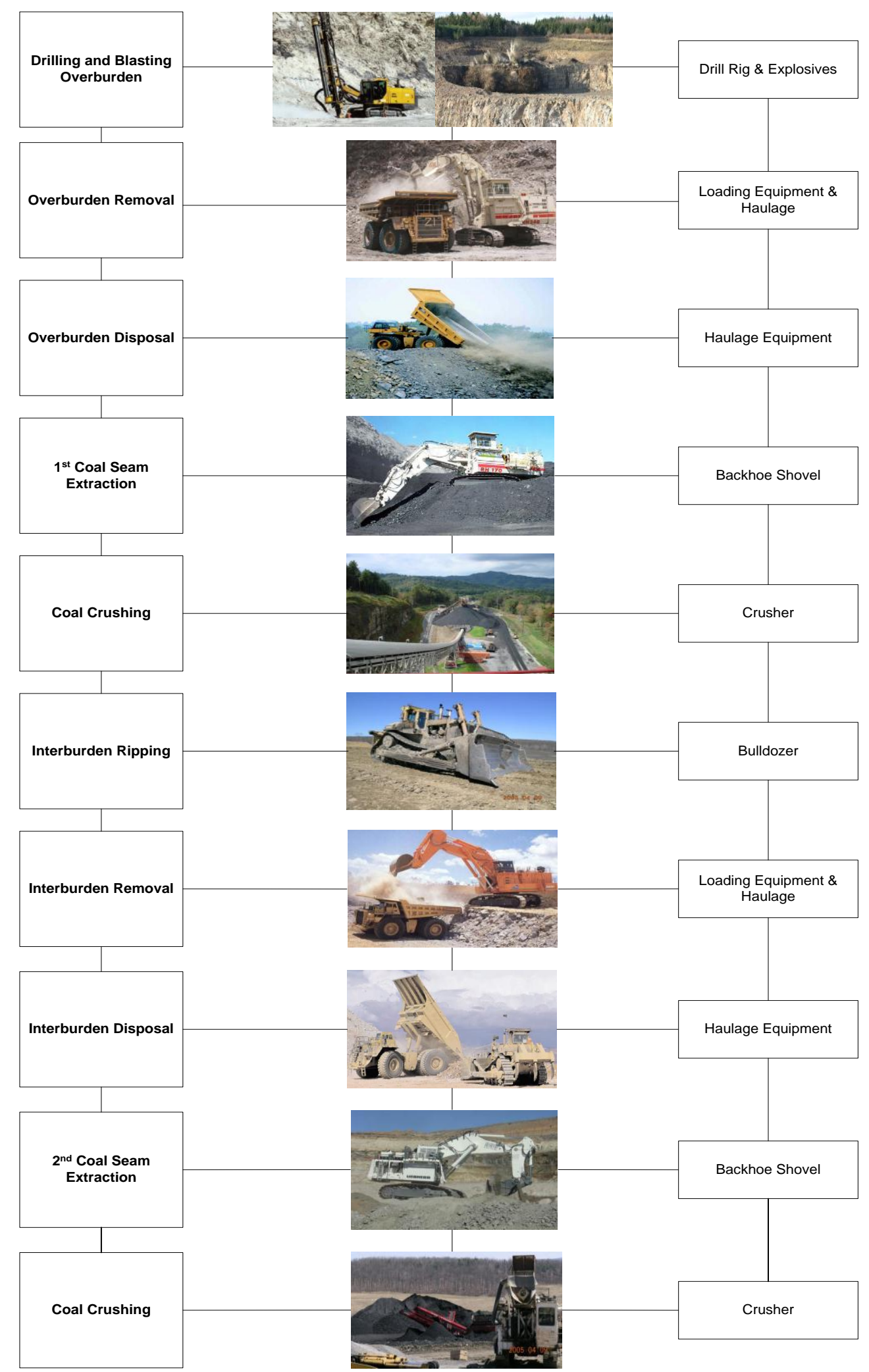

Figure 1-1 Conventional Surface Mining Process

(Image Sources: Atlas Copco, Terex, Caterpillar, Kecojevic, Hitachi, and Liebherr) 
Current blasting methods, if not properly designed and executed, can create hazards like flyrock, toxic fumes, ground vibration, and surface vibration created by air-blast. Blasting methods have been refined and are performed in a safer manner but the hazards still remain.

It is required that coal seams, overburden, and interburden be mined separately, thus preventing dilution of the coal with non-coal material. This is particularly important for the surface coal mines in WV where most of the seams are interspersed with interburden layers (Figure 1.2). The capability of the extraction systems to work selectively provides a better quality of the coal, less dilution, and higher utilization of the coal deposits.

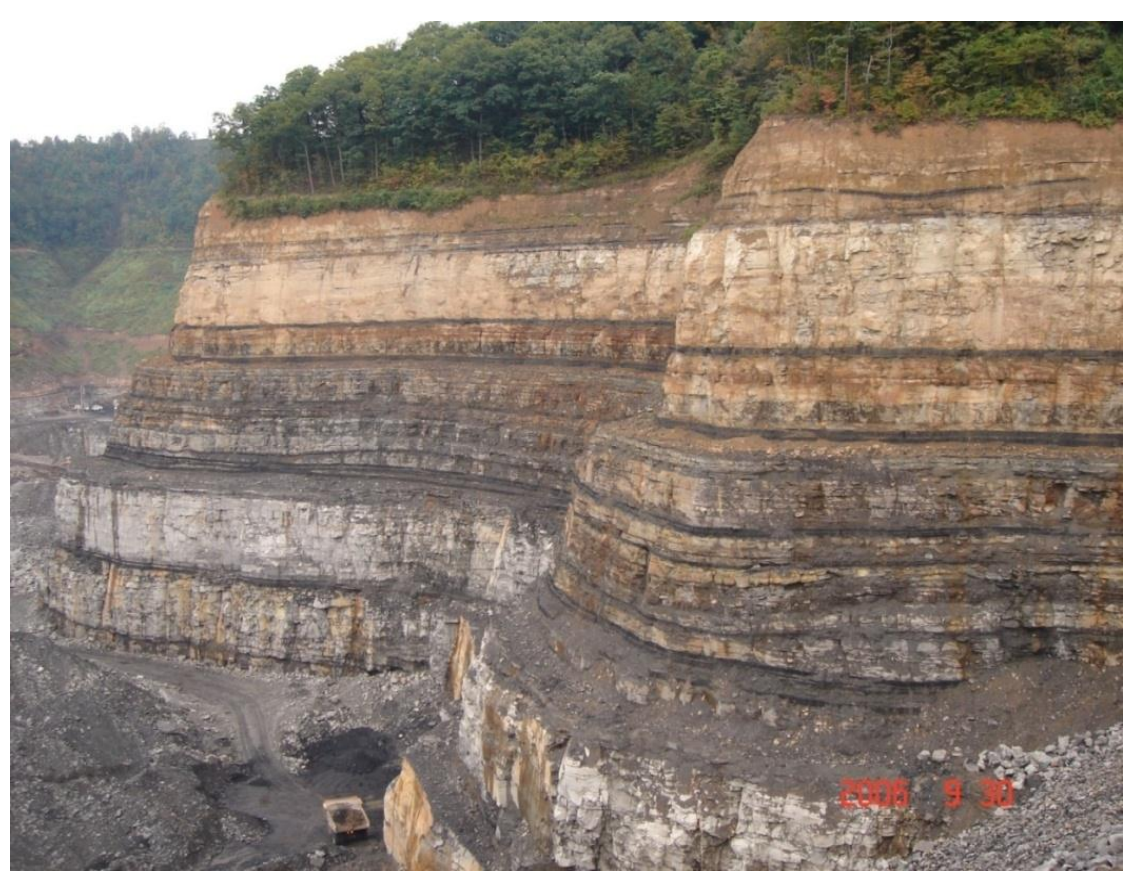

Figure 1-2 Surface Coal Mine in WV (Kecojevic, 2006) 
The Surface Miner (SM) is a multi-purpose production machine that integrates cutting, crushing, and loading (Figures 1.3 and 1.4). It is applied in numerous coal and quarry mining operations around the world. The SM is capable of continuously mining materials with compressive strengths up to $180 \mathrm{MPa}$ or 26,100 psi (Wirtgen, 2010). The largest SMs have achieved a production rate of 5,300 loose $\mathrm{yd}^{3}$ per hour and can excavate layers of up to three feet of material in one step.

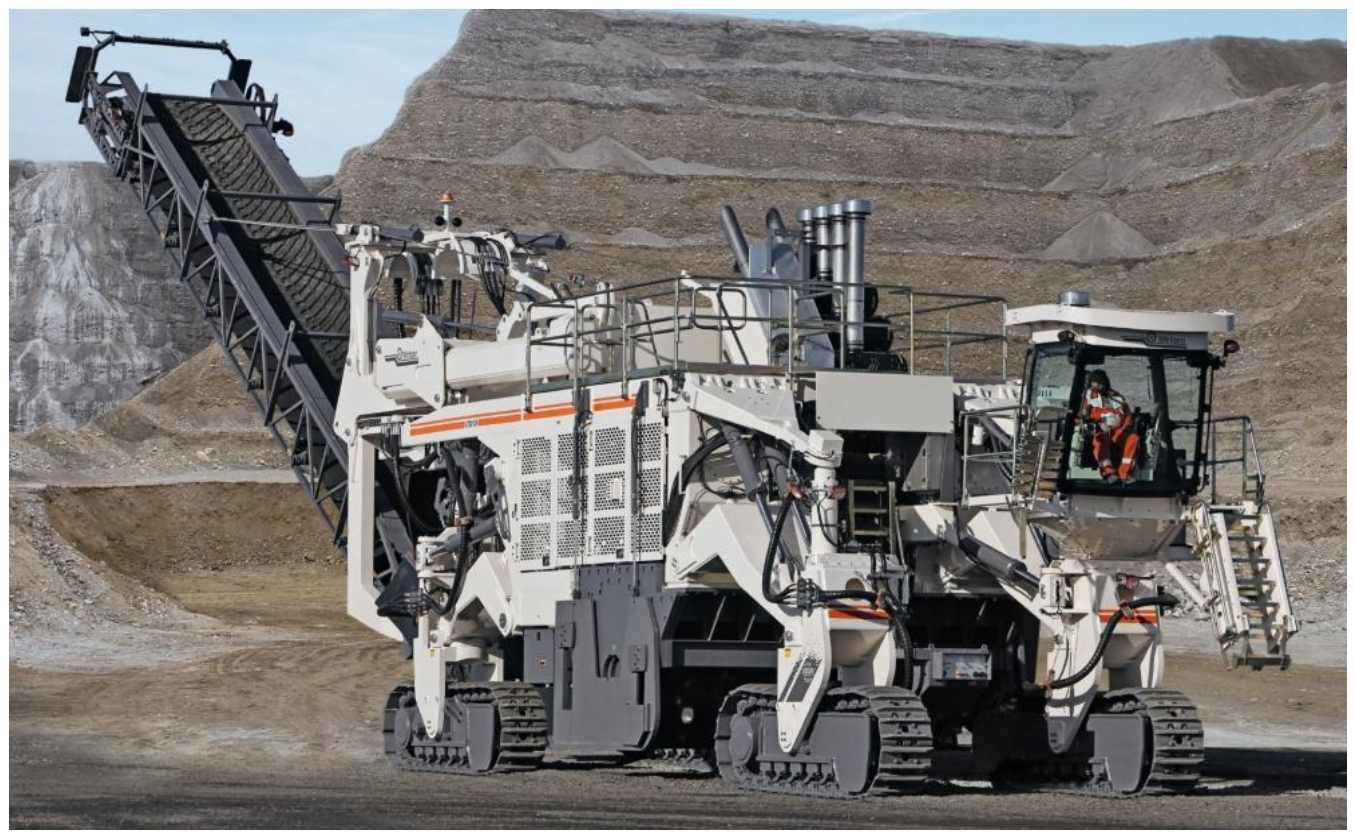

Figure 1-3 Surface Miner (Wirtgen, 2010) 


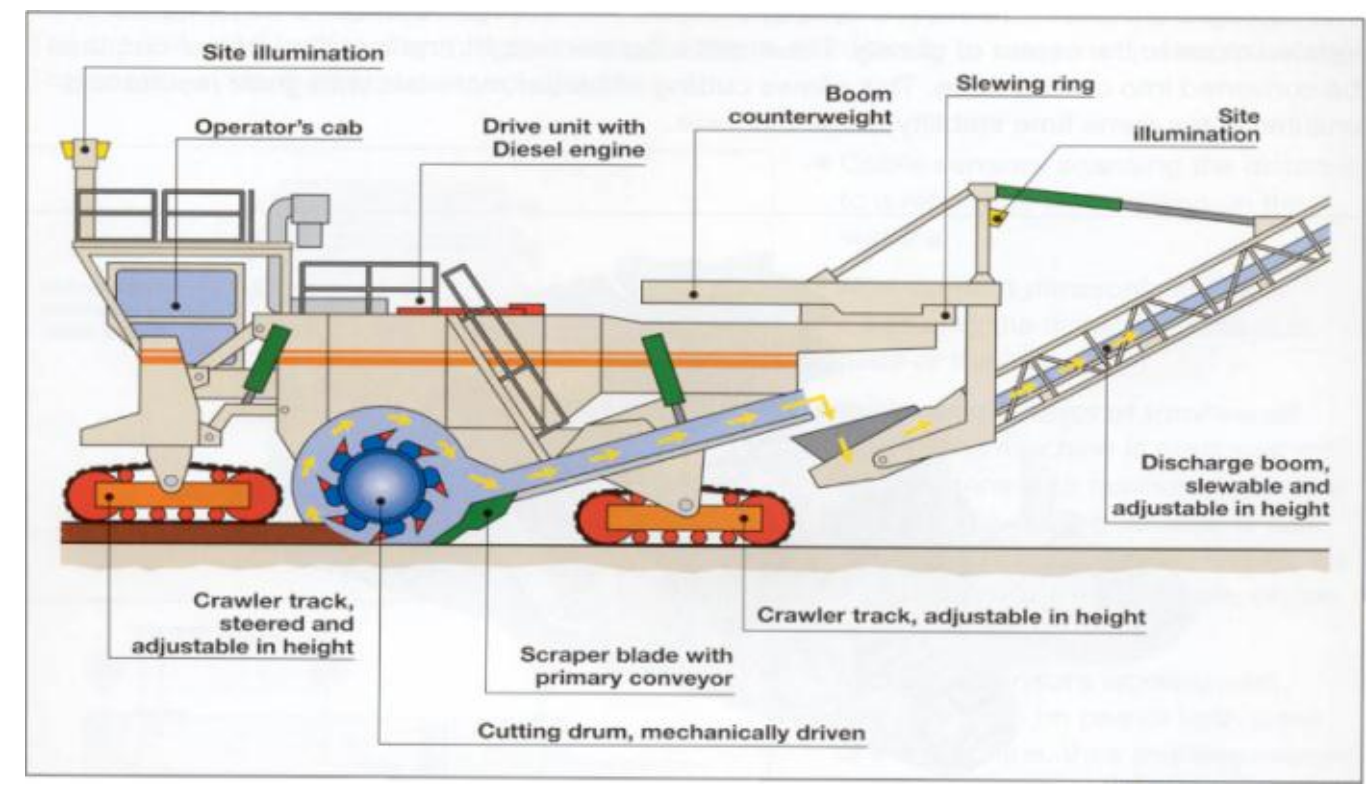

Figure 1-4 Surface Miner Diagram (Wirtgen, 2010)

The SM is mounted on four crawler tracks with an almost infinite adjustability. As the machine advances, a rotating drum studded with carbide-tipped cutting tools (Figure 1.5) cuts the material to sizes suitable for haulage. The cutting drum rotates upwards, i.e. the helically arranged cutting tools on the drum transport the material towards the center of the drum from where it is transferred by the primary belt to the secondary discharge belt. 


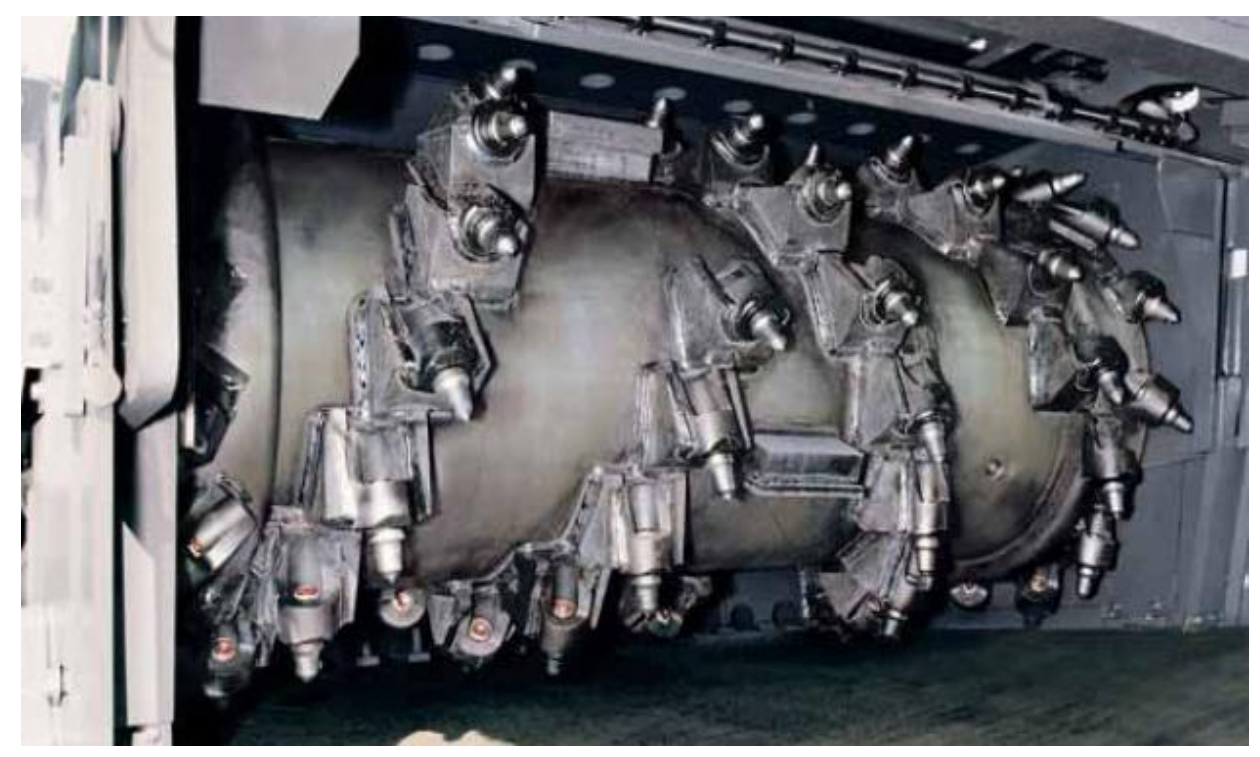

Figure 1-5 Rotating Drum and Carbide-Tipped Cutting Tools (Wirtgen, 2010)

The SM can be used for the following operations: i) cutting, crushing, and loading of overburden, interburden, and coal into haulage units such as trucks or belt conveyors; ii) cutting, crushing, and side casting; and iii) cutting, crushing, and windrowing. Therefore, one single machine can replace several conventional surface mining unit operations including drilling, blasting, digging, loading, and crushing. Since only one machine is used for several unit operations, it has a significant potential to reduce capital and operating costs, reduce manpower, and simplify coordination and planning of the mining process.

SMs are either equipped with wire rope sensors connected with side plates or sonic sensors which measures the distance from the ground and adjust the cutting depth accordingly. When a GPS receiver is connected to the automatic cutting depth controller, predefined profiles can be cut after programming the receiver. The ability to selectively 
mine results in better quality of the mined coal, less dilution, and higher recovery of the coal deposits. Figure 1.6 shows the selective work of the SMs in a coal mine in the U.S.

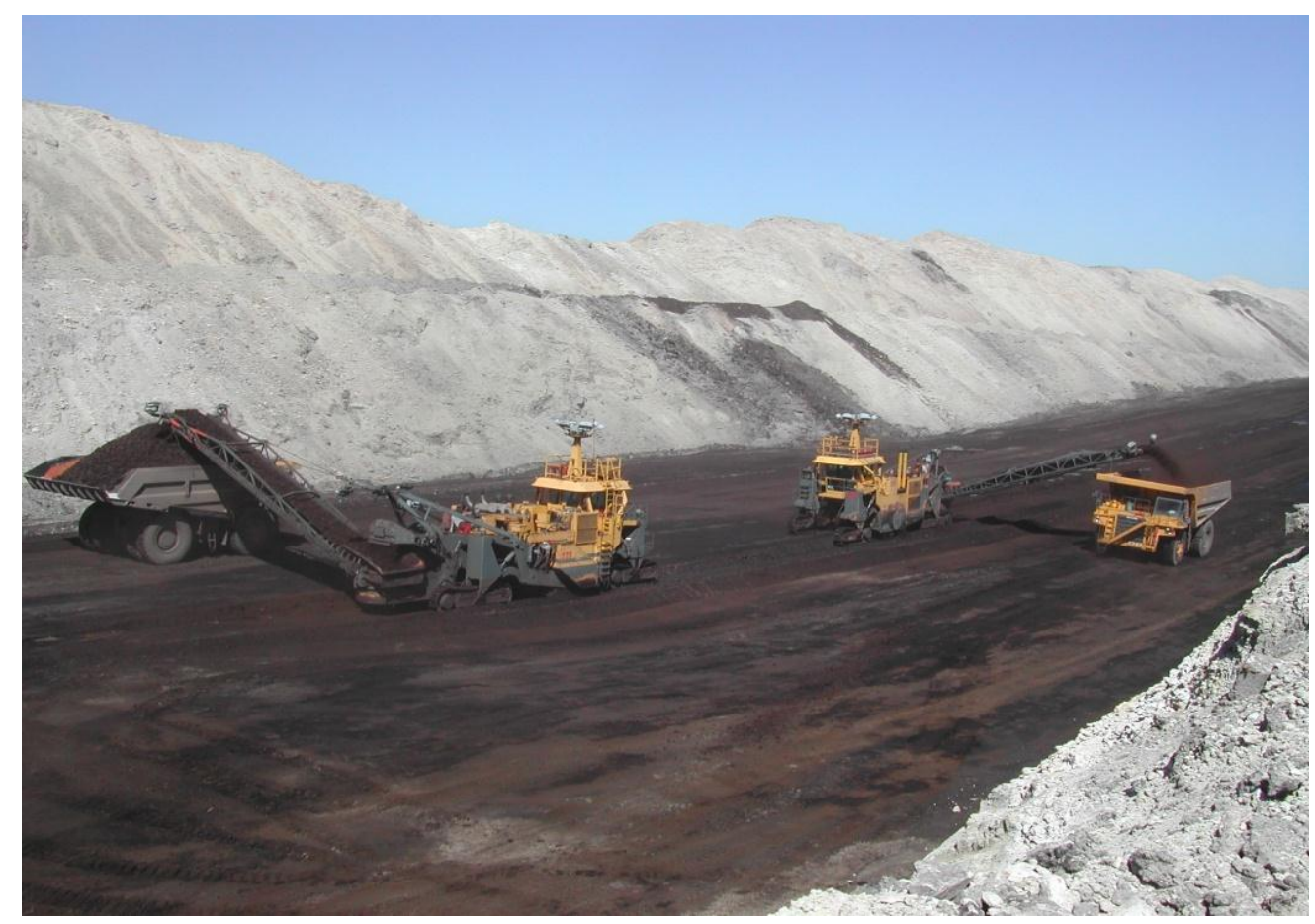

Figure 1-6 Selective Extraction of Coal by SM (Kecojevic, 2006)

Depending on the rock properties and the desired material size, the pick configuration on the cutting drum can be modified accordingly. The pick pattern (helix) on the drum remains fundamentally the same, but variations in pick type and spacing between picks will change to achieve the desired material size. The amount of picks on the cutting drum and the spacing between picks must be defined. This value is determined based on the material properties and the desired size of processed material. 


\subsection{Problem Statement}

Surface coal mining in WV faces many challenges. These challenges include more restrictive regulations, a negative public perception, and difficult geological formations. The industry as a whole has a negative image in the public eye due to, among other factors, blasting hazards involving flyrock, toxic fumes, ground vibration, and surface vibration created by air-blast. Although these hazards do not occur with every blast it only takes a few incidents to tarnish the reputation of the entire industry. Exploring and applying alternative safe and environmentally friendly technology provides the potential to minimize if not eliminate these hazards.

The geologic formations in WV consist of overburden and multiple layers of sandstone and shale rock types with bituminous coal seams of varying thicknesses interspersed between layers of interburden. Overburden and interburden layers must be removed before the coal is extracted. Depending on the thickness of the interburden layers, various methods are used for its removal. Layers with a thickness of generally less than five feet are ripped by a bulldozer. If the rock is ripped, additional loading is required to load and haul the material. If the interburden is too thick or too hard to rip, drilling and blasting is required to loosen the rock. The process of ripping or blasting continues with each interburden layer that is encountered in the mine. Once the coal seam is exposed, a shovel or front-end wheel loader digs and loads the coal into haulage equipment, typically dump trucks. The use of this type of loading equipment generates issues with the coal quality. Loading coal with a shovel or front-end wheel loader is conducted based on the operators" "best judgment" and "experience" attributes. This approach is the 
common practices which helps distinguish between coal, overburden, and interburden material. While this approach can be effective, there is a potential for a large margin of error. Excavating coal in this manner can create quality issues, which will require additional work to clean. Technology, such as the SM, can be employed to lessen the effects created by this conventional approach to coal extraction.

More stringent governmental regulations and public pressure are forcing the mining industry to evolve and minimize its environmental impacts. Future coal mining operations will need to incorporate new design features and practices that can substantially reduce these impacts to achieve "low impact" mining. These design features and practices will be necessary to ensure that the coal industry can design, permit, build, operate, reclaim, and monitor future mines in full compliance with the increasingly stringent environmental performance standards. New mining technologies and systems can minimize environmental disturbances during overburden removal and coal extraction, while improving coal recovery. 


\subsection{Scope of Work}

The broad objective of this research was to improve current mining practices and reduce negative environmental impacts of surface coal mining in WV. The specific objectives are:

(i) Build the production and cost models to determine if conventional surface mining unit operations including drilling, blasting, digging, loading, and crushing can be economically replaced with a surface miner (SM).

(ii) Apply the analytical hierarchy process (AHP) to help select the optimal mining method based on both qualitative and quantitative factors.

(iii) Determine if the SM would benefit surface coal mining in WV, particularly by reducing the negative environmental impacts associated with the conventional mining method.

The following chapters provide a literature review of relevant studies, the methodology developed for this research, results, discussion, conclusions, and recommendations for future work. 


\section{Chapter 2}

\section{Literature Review}

One of the most comprehensive studies on the application of SMs was conducted by Dey and Ghose (2008). The authors established a Cuttability Index (CTI) to explore the applicability of the SM for various values of rock properties. The rock and machine properties including point load strength, volumetric joint count, abrasivity, direction of cutting with respect to joint directions, and machine power are given numerical values, as shown in the Table 2.1.

Table 2-1 Rating of the Parameters of New Rockmass Cuttability Classification (Dey and Ghose, 2008)

\begin{tabular}{|l|c|c|c|c|c|}
\hline \multicolumn{1}{|c|}{ Class } & I & II & III & IV & V \\
\hline Point Load Index $\left(I_{S} 50\right)$ & $<0.5$ & $0.5-1.5$ & $1.5-2.0$ & $2.0-3.5$ & $>3.5$ \\
Rating $\left(I_{S}\right)$ & 5 & 10 & 15 & 20 & 25 \\
\hline Volumetric joint count $\left(\mathrm{no}^{\prime} \mathrm{m}^{3}\right)$ & $>30$ & $30-10$ & $10-3$ & $3-1$ & 1 \\
Rating $\left(J_{V}\right)$ & 5 & 10 & 15 & 20 & 25 \\
\hline Abrasivity & $<0.5$ & $0.5-1.0$ & $1.0-2.0$ & $2.0-3.0$ & $>3.0$ \\
Rating $\left(A_{W}\right)$ & 3 & 6 & 9 & 12 & 15 \\
\hline Direction of cutting respect to & $72^{0}-90^{0}$ & $54^{0}-72^{0}$ & $36^{0}-54^{0}$ & $18^{0}-36^{0}$ & $0^{0}-18^{0}$ \\
major joint direction & & & & & 12 \\
Rating $\left(\mathrm{J}_{\mathrm{S}}\right)$ & 3 & 6 & 9 & 12 & 15 \\
\hline Machine Power $(\mathrm{kW})$ & $>1000$ & $800-1000$ & $600-800$ & $400-600$ & $<400$ \\
Rating $(M)$ & 4 & 8 & 12 & 16 & 20 \\
\hline
\end{tabular}

A summation of the values is performed to generate a CTI between 20 and 100. Based on this value, the applicability of the SM is ranked on the Excavatability Index from 
"Very Easy Excavation," if lower than 50, to "Surface Miner Should Not be Deployed" if the CTI is greater than 80 (Table 2.2).

Table 2-2 Applicability of Surface Miner Based on Excavatability Index (Dey and Ghose, 2008)

\begin{tabular}{|l|l|}
\hline \multicolumn{1}{|c|}{ Excavatability Index } & \multicolumn{1}{c|}{ Possibility of Ripping } \\
\hline$C T I<50$ & Very Easy Excavation \\
\hline $50<C T I<60$ & Easy Excavation \\
\hline $60<C T I<70$ & Limit of Economic Excavation \\
\hline $70<C T I<80$ & Difficult Excavation, May be Not Economic \\
\hline$C T I>80$ & Surface Miner Should Not be Deployed \\
\hline
\end{tabular}

Production rate is estimated by applying this rated machine capacity and a factor that considers influence from pick shape and pick spacing to the cuttability index.

The methodology developed by Dey and Ghose (2008) is used for an initial examination of the applicability of a SM. The production rate is calculated by considering only a few of many factors. This method does not account for operator influenced factors and will be marginally off when compared to the actual production rate. Additional factors such as time delays would add to the validity of the production rate calculated by this method.

Origliasso (2011) performed production and cost calculations for the SM based primarily on the power of the machine. Major aspects of the calculations, such as production rate, fuel consumption, and cutting speed, are determined based on the machine's power. The equation used to determine cutting speed is verified by the case studies performed at quarry operations. The speed is determined for the hard rock applications and may require some adjustments for a coal type operation. Origliasso's (2011) approach, with 
the integration of specific energy of the SM, is fairly sophisticated. The SM calculations estimate an actual production rate as it considers delays that are encountered. The cutting time has been built into equations as well as the machine power, rock abrasivity, and the rock's unconfined compressive strength. This method produces reasonably accurate values unless any anomalies are encountered for which a more detailed analysis of cutting time would be useful.

One of the problems that have remained when considering a SM is determining what type and size is optimal for the specific application. Pradhan and Dey (2009) explored this problem and developed software that can be applied to this situation to provide a suitable SM and the optimal mode for its operation. This technique relies on the methodology developed by Dey and Ghose (2008), in which the cuttability index and production rate are found. The software provides a quick way for mine planners and engineers to evaluate the use of a SM. The Pradhan and Dey (2009) approach to the evaluation of the applicability of SMs is again based on the cuttability index created by Dey and Ghose (2008) and will provide the same results but in a nearly instantaneous timeframe. This software provides the specifics of the SM and requires a cost model to be created by a separate process.

Schimm (1997) studied the application of a Wirtgen SM in a limestone and pegmatite mining operation. This case study occurred over a four week period during which the performance and requirements of the SM were logged. The objectives of this study were to (i) determine limestone mining costs without blasting, (ii) reduce transport cost to the 
nearby cement factory, and (iii) determine if selective mining of pegmatite was feasible. The properties of the limestone allowed for an average production rate of 210 tons per hr. The costs for operating and owning the machine during the time of the study were also observed. The transportation costs were determined for three scenarios, one with an inpit mobile crusher, one with a semi-mobile crusher, and one with the Wirtgen SM. The results of this portion of the study proved the SM to be the most economical of the three scenarios. During the mining of pegmatite, the SM was able to extract the material in a highly selective manner where the rock was not rippable. For this reason, as well as the crushed material the SM produced, the SM was again the most economical method. The study concluded that when mining in medium to hard material, the SM provides an economical alternative to conventional mining methods.

The study performed by Schimm (1997) provides a detailed breakdown of the costs associated with operating and owning a Wirtgen SM. While the study relates the use of a SM to the unconfined compressive strength of the material, many other rock parameters are not considered. The inclusion of the abrasivity of the limestone and pegmatite would have been a valuable piece of information for the considering a SM. As this is a case study, values for the SM were not calculated but observed, and the abrasivity may not have been known. However, this study provides useful information that can be expected regarding similar conditions.

The application of a SM in the Nongtrai Limestone Mine in Meghalaya, India was studied by Ghose et al. (2010). This study for a possible alternative mining method was 
performed in response to a Supreme Court order to stop all mining activities. The objective of this study was to determine if SMs could be used as an alternative mining method. The authors proceeded by applying eleven empirical approaches that have been developed by various mining professionals. The evaluation of each empirical approach would determine if the SM would be applicable, if the material could be cut by that type of machine, or if there was a SM that would be able to cut the rock. The results of the study indicated that there was no SM available that would be applicable to the studied limestone mine.

The study performed for the Nongtrai Limestone Mine in Meghalaya, India described a situation any mine could face in light of evolving litigation. The approaches used in this study varied in complexity but provided reasonable results while focusing on applicability.

SMs are built in many sizes and have various applications based on the capability of the machine. The objectives when considering any new SM technology is to lower cost of operation, reduce coal dilution, and improve coal recovery. In his research, Schroder (2011) considered the cost comparison of the larger KSM type machine from Krupp Fordertechnik. Three different applications were explored and compared to the conventional mining method. The first was a comparison of the KSM, the hydraulic shovel, and the front-end wheel loader. In a study conducted for a coal mine in India, the author indicated that the SM was the most economical option. The second study pertained to the transportation of material. It compared a SM and truck mining unit to a 
SM and belt conveyor mining unit in a Russian mine. The SM and conveyor belt combination provided the lower cost. In a third study, the comparison of the SM, hydraulic shovel, and front-end wheel loader was conducted to prepare a highwall for an auger mining operation. The SM was found to be the most economical method.

The studies by Schroder (2011) show various uses of the SM and evaluate where it is the most economical method. While the results are clearly presented, the methodology behind the calculations is not evident. The inclusion of rock parameters and mine site specifications would assist in understanding the calculations. While the data and calculations may not be stated, some of the SM's applications are. The SM does not only serve the purpose of the primary mining process but can perform supporting processes as well.

Designing and calculating costs for a mining project does not encompass all of the issues, the post-mining reclamation plans must also be designed. While economic evaluations can be performed for each scenario, the final reclamation design ultimately relies on the decision team. To aid in this group decision process Bascetin (2006) uses the Analytical Hierarchy Process (AHP) developed by Saaty (1980). In this study, the AHP was used to determine the optimal reclamation method for an open-pit coal mine in the Seyitomer region in Turkey. The AHP model developed by Bascetin (2006) considers capital cost, operating cost, natural factors, and cultural factors. Both natural and cultural factors have multiple sub-criteria that are included in the AHP. The end result of this study will be one of five different alternatives for a reclamation method. 
The study performed by Bascetin (2006) was to determine if the AHP would aid in the decision process for a particular reclamation method. The AHP model developed enabled decision makers to look at each of the possible reclamation methods and decide what their weaknesses and strengths were. The model was determined to be an improvement on the team's decision making process, as well as reducing the time and effort devoted the process. This model can be used for a basis when considering multiple reclamation methods with some variations to suit a specific project. 


\section{Chapter 3}

\section{Methodology}

\subsection{Introduction}

The objective of this research is to determine whether the Surface Miner mining method is a suitable option for surface coal mines in WV. The design and procedures used for achieving the objectives involve six interrelated modules. Module \#1 includes rock properties of sandstone, shale, and bituminous coal, which are the predominant overburden, interburden, and coal types in WV. Module \#2 considers drilling and blasting operations. Module \#3 includes digging and loading of overburden material and specifically addresses mining equipment such as the electric and hydraulic shovels and front-end wheel loaders. Two unit operations are involved with the removal of the interburden material: ripping and pushing by bulldozers and loading by hydraulic backhoe shovel. Module \#4 covers coal extraction by a hydraulic (backhoe) shovel and the coal crushing operation. Module \#5 focuses on the SM and its production, ownership, and operating costs for overburden, interburden, and coal. Module \#6 consists of a comparative analysis of all unit mining operations for overburden, interburden, and coal. It also presents the results for the production rates, ownership and operating costs. The production and cost models were developed in MS Excel. The analytical hierarchy process (AHP) is used for the selection of the optimal mining method based on both qualitative and quantitative factors. 
An algorithm was developed in order to determine the appropriate mining method for each rock unit in an organized fashion. This algorithm or one similar to it should be followed to insure all results are accurately calculated for the cost module comparison.

This algorithm can be seen in Figure 3.1.

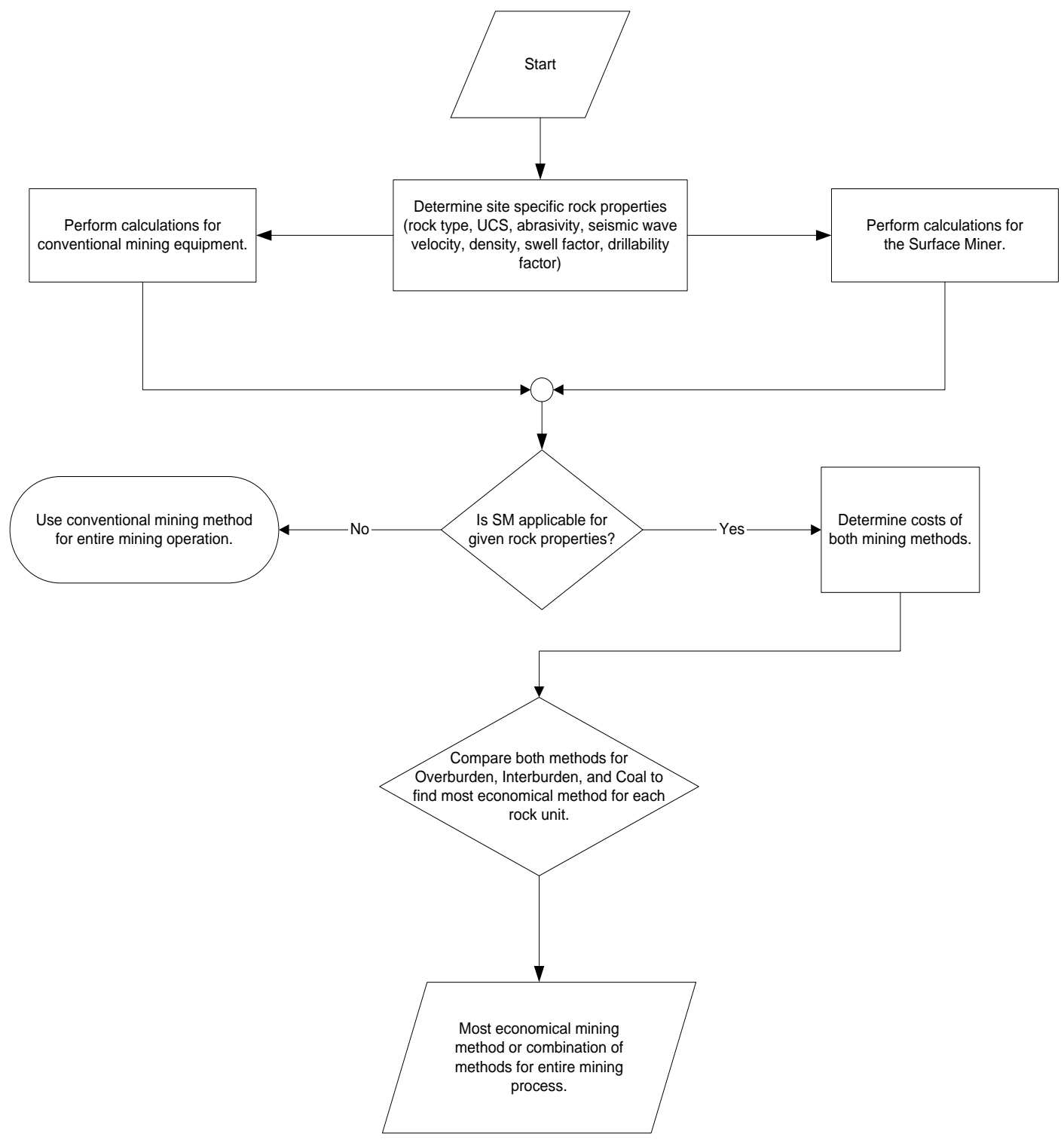

Figure 3-1 Mining Method Selection Algorithm 
The cost and production models for both the conventional and SM mining methods consider a medium-size surface coal mine in WV. For this study, the medium-size mine is defined with a production rate of 10 million bank cubic yards of overburden, 1 million bank cubic yards of interburden, and 1.5 million tons of coal to be excavated annually.

\subsection{Rock Properties (Module 1)}

Module \#1 contains the descriptions of possible rock types and properties within the state of WV. The typical rock units found in the surface coal mines of WV (generally the majority of the state excluding the eastern panhandle) are sandstone, shale, and bituminous coal (WVGES, 2011). The bituminous coal in WV and the surrounding area is found in varying thickness and in multiple seams. There may be instances where multiple seams of varied thickness exist in the same formation and are being mined or abandoned.

Properties such as bank \& loose density, unconfined compressive strength, abrasivity, seismic wave velocity, quartz content, and swell factor were compiled from Caterpillar (2010), Hartman (1992), Rusnak (2000), Schubert (2007), Mavko (2011), Plinninger (2010), Ingresoll-Rand (2003), Kecojevic (2010). Average values were generated for each property and applied to the conventional mining and SM equations. Table 3.1 shows the average values for the rock and coal properties in WV that are used in this study. 
Table 3-1 Average Values of Coal and Rock Properties in WV

\begin{tabular}{|c|c|c|c|}
\hline Rock type & Bituminous coal & Sandstone & Shale \\
\hline Bank density $\left(\mathrm{lb} / \mathrm{yd}^{3}\right)$ & 2,150 & 4,250 & 2,800 \\
\hline Loose density (lb/yd $\left.{ }^{3}\right)$ & 1,600 & 2,550 & 2,100 \\
\hline Specific gravity & 1.28 & 2.5 & 1.66 \\
\hline Swell factor & 1.35 & 1.6 & 1.45 \\
\hline Unconfined Compressive Strength (psi) & 2,901 & 14,500 & 10,875 \\
\hline Cerchar Abrasive Index (CAI) & 1 & 2 & 1.5 \\
\hline Seismic Wave Velocity (ft/sec) & - & 9,020 & 5,900 \\
\hline Equivalent Quartz Content (\%) & 5 & 75 & 45 \\
\hline Drillability factor & & 1.8 & 2.0 \\
\hline
\end{tabular}

\subsection{Drilling and Blasting Operations (Module 2)}

Equations developed by Atlas Copco (2006), Ingresoll-Rand (2003), Sandvik Tamrock (1999), Austin Powder (2009), Dyno Nobel (2010) and Kecojevic (2010) were used to calculate drilling and blasting parameters. These parameters include hole diameter, penetration rate, overall drilling rate, bench height, burden, spacing, sub-drilling, hole inclination, hole depth, hole length, stemming, particle size for stemming, hole charge length, hole charge concentration, total charge per hole, type of total amount of explosives, bottom and column charge concentration, volume of rock per foot of hole, volume of rock per hole, weight of rock per hole, number of required holes, specific drilling, total required drilling, powder factor, and delay times. Ammonium Nitrate + Fuel Oil (ANFO) and emulsions are the most common explosives agents used in WV surface coal mines and are used in this study. 
The total drilling cost is calculated and it is expressed in $\$ / \mathrm{yd}^{3}$ and $\$ /$ year. Blasting cost related to explosives, detonators, boosters, leadline, tubes, labor, and shot service is also determined. A total blasting cost is expressed in $\$ / \mathrm{yd}^{3}$ and $\$ /$ year.

\subsection{Digging and Loading (Module 3)}

This module pertains to the equipment used for digging and loading of the overburden and interburden. For this study, the production rate is defined to be 10 million bank cubic yards of overburden and 1 million bank cubic yards of interburden.

\subsubsection{Overburden}

In most WV surface coal mines several machines are used to dig and load overburden material. This equipment includes hydraulic shovels, electric (rope) shovels, front-end wheel loaders, and draglines (which are used mainly for stripping and disposal into the excavated area). Haulage costs are not considered in this research and therefore draglines are not included in the mining method comparison.

Production rates for these machines except for the dragline are calculated and ownership and operating costs are determined. Various sources such as Caterpillar (2010), Komatsu (2011), P\&H (2005), Hartman (1992), and Kecojevic (2010) are used to determine the production rates. Equations for ownership and operating costs are well documented in the sources stated previously and are used to calculate the costs in this research. Compiled cost data are obtained from InfoMine (2010). The total cost for each piece of equipment is expressed in $\$ / \mathrm{yd}^{3}, \$ / \mathrm{hr}$ and $\$ /$ year. 


\subsubsection{Interburden}

The interburden material in WV is typically, but not limited to, a sandstone or shale type rock. This material is interspersed between coal seams. The thickness and material properties of the interburden determines whether the rock is ripped, excavated, and loaded or the rock is to be blasted. It is assumed that interburden less than five feet thick can be ripped by a bulldozer.

The ability to rip interburden is dependent on the properties of the rock; specifically the seismic wave velocity. A bulldozer's specific capabilities are based on the machine's power, shank characteristics, and size. To insure the widest array of applications in varying thicknesses of interburden, the Caterpillar D11T CD or similar large size bulldozer was chosen for this study. Caterpillar (2009) provides the production rates for the bulldozers.

The interburden is first ripped by a bulldozer and then it is loaded by a hydraulic backhoe shovel. Production rates for these units are calculated and ownership and operating costs are determined. Compiled cost data are obtained from InfoMine (2010). The total cost for each unit is expressed in $\$ / \mathrm{yd}^{3}, \$ / \mathrm{hr}$ and $\$ /$ year. 


\subsection{Coal Extraction \& Crushing (Module 4)}

Module \#4 covers coal extraction by hydraulic (backhoe) shovel and the crushing operation. Once the coal is crushed it is transported to the processing facility in its fragmented form. In most cases, the coal needs to be reduced in size for its final use. The size and type of crusher is determined by the production rate, the feed and product sizes, the material characteristics such as lump factor, the number of drives, the drive efficiency, and the Bond's Work Index. The production rate and the feed and product sizes are values that will be generated by the specifications of the mine. The material lump factor is determined by the material composition, which can range from course to fine material. The drive efficiency depends on what type of motor is used in the crusher.

The ownership and operating costs are calculated based on production rate, crusher power requirement, and crusher settings. The total cost is expressed in $\$ /$ ton, $\$ / \mathrm{hr}$, and \$/year.

\subsection{Surface Miner Method (Module 5)}

This module describes the calculations of the SM in three different extraction scenarios; overburden, interburden, and coal extraction.

The first item to consider in the SM mining method is the mine design. The SM requires adequate room on both sides of the cut to turn the machine. An example of a mine design, where ramps are required on both ends of the row to allow the SM to turn around 
and re-enter the working area, is shown in Figure 3.2. This mine design is an example of one way to use the SM. There are multiple ways to use the machine depending on the orientation of the material being excavated.

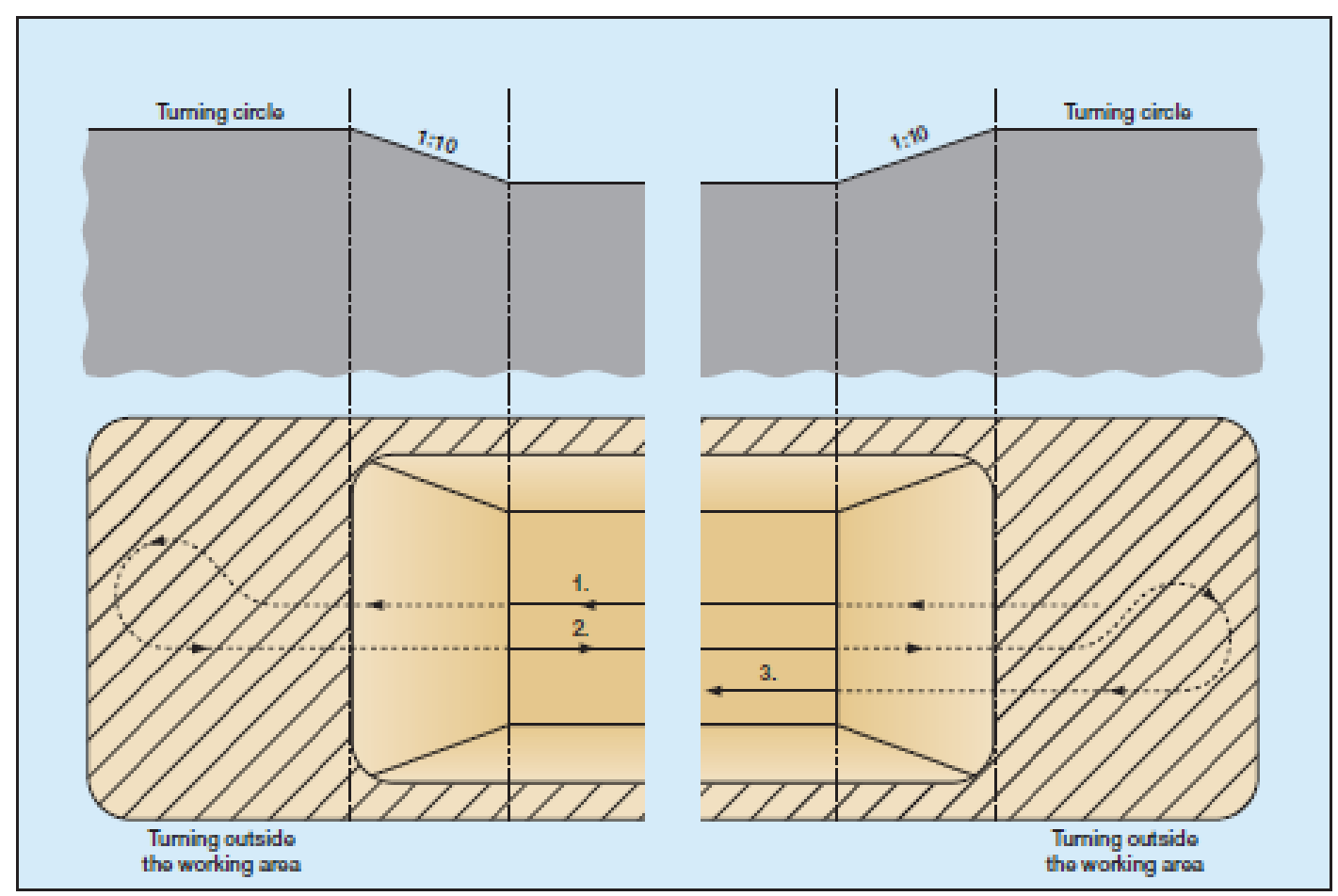

Figure 3-2 Example Mining Sequence of a Surface Miner (Wirtgen, 2008)

The SM mine design requires the cutting of long straight or curved rows. The rows that are cut are gradually stepped down to reach the desired depth or the bottom of the coal seam, as seen in Figure 3.3. When compared to a conventionally blasted highwall, the SM creates a cleaner and more stable highwall due to the step down cutting procedure as seen in Figure 3.3. 

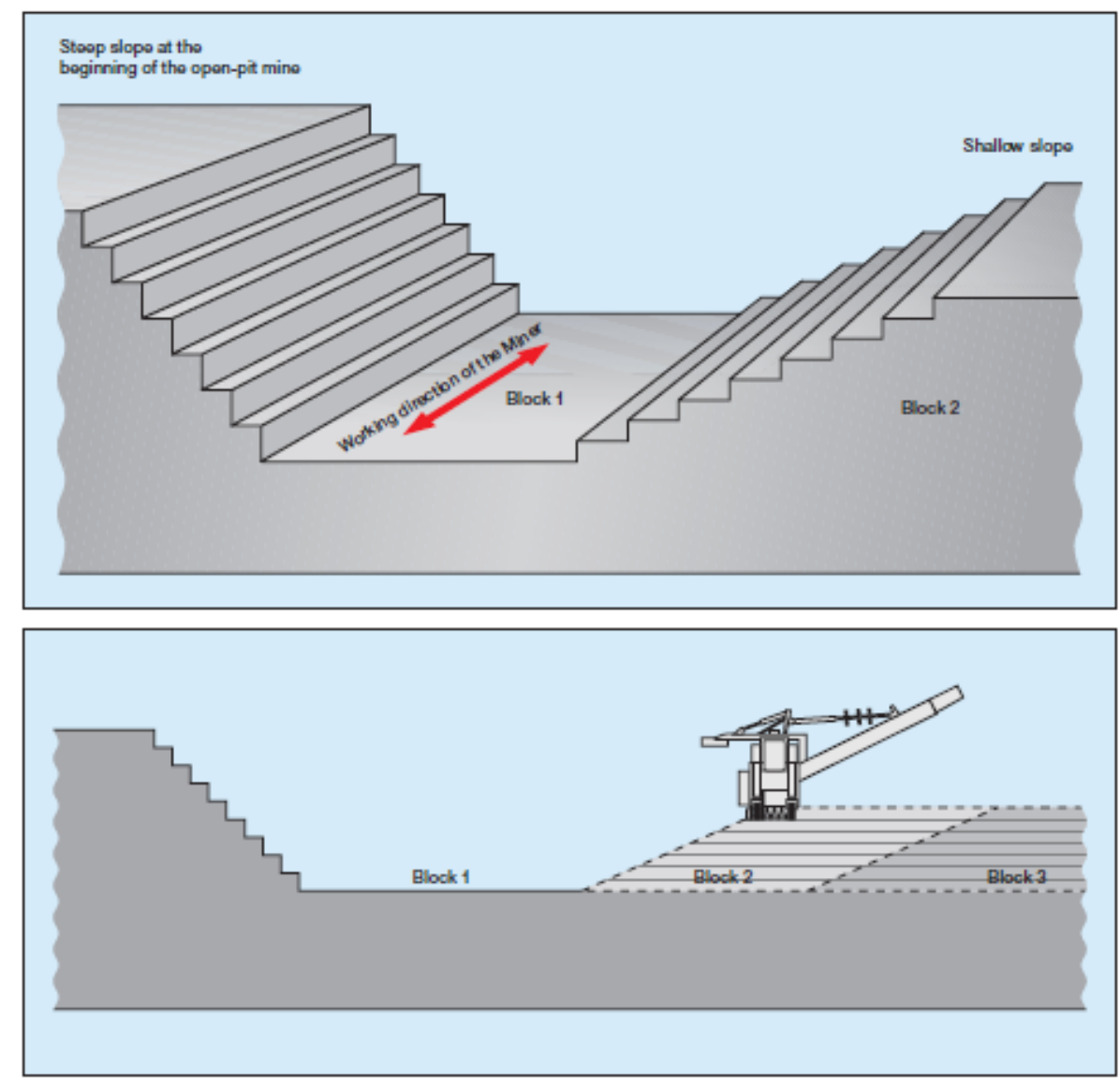

Figure 3-3 Typical Mining Sequence of a Surface Miner (Wirtgen, 2008)

A critical value that must be defined in the beginning of the SM calculations is the cutting performance, (Q) which is expressed in bank $\mathrm{ft}^{3} / \mathrm{hr}$. The Equation 3.1, developed by Wirtgen (2010), is used to determine the cutting performance in this thesis. The dimensions of the cut are dependent on the width, (W) in $\mathrm{ft}$, of the cutting drum and an average depth, (D) in $\mathrm{ft}$, of the cut. The cutting velocity, (V) in $\mathrm{ft} / \mathrm{min}$, is multiplied by the cutting dimensions to find the cutting performance as follows:

$$
Q=W * D * V * 60
$$


The depth and cutting velocity are dependent on the size of SM and the material being excavated. Material with higher compressive strength and abrasivity may require a shallow cut to prevent excessive pick wear. Equation 3.1 does not account for any delays that will be encountered in the cutting process.

Essentially, according to equation 3.1, the cutting performance is based on the size of the SM and the cutting velocity. The machine also has a travel (non-cutting) speed that will be used in other equations. The traveling speed is usually designated by the manufacturer, but the velocity at which the machine cuts is typically an empirically determined value. Because an experienced value is unavailable for every desired rock property scenario, another source for this information is needed. It is necessary to use an additional equation to determine the velocity of the SM while cutting. An equation developed by Origliasso (2011) calculates the cutting velocity, (V) in $\mathrm{m} / \mathrm{min}$, and uses the machine power, (P) in $\mathrm{kW}$, compressive strength, (UCS) in MPa, and cutting depth, (D) in $\mathrm{cm}$, as follows.

$$
V=\left(\frac{P *(59.6-12 \ln [U C S])}{D}\right)
$$

While this equation for cutting velocity is reliable, it is necessary to add an adjustment factor to accommodate for the different types of rock. The adjustment factor is generated based on the cutting velocities the SM will experience in the field for both coal and hard rock. Determination of the cutting velocity in both coal and hard rock is given by Equations 3.3 and 3.4, respectively, where the power, $(\mathrm{P})$ is in $\mathrm{kW}$, and cutting depth, (D) 
is in $\mathrm{cm}$. The adjustment factor allows the cutting velocity equation to calculate values more accurate to what will be experienced in the field. The conversion factor from meters per minute to feet per minute is 3.28 .

The adjustment factor, which is determined based on cutting velocity field values, is 1.35 for coal and 2.9 for hard rock. These cutting velocity equations are written as follows:

$$
\begin{gathered}
V=\left(\left(\frac{P *(59.6-12 \ln [U C S])}{D}\right) * 3.28\right) *(1.35) \\
V=\left(\left(\frac{P *(59.6-12 \ln [U C S])}{D}\right) * 3.28\right) *(2.9)
\end{gathered}
$$

One of the most influential variables when considering a SM is the amount of cutting tool (pick) wear that occurs during the cutting process. The reason for this high influence is not only the cost of replacement picks but also the time spent on replacing the worn picks. These additional factors affect the direct cost of operating the machine and its production capability. This is the why the SM becomes less economically feasible in the harder rock type situations.

Table 3.2 and 3.3 show the equations for the amount of pick wear expected in hard rock such as sandstone and shale, as well as coal. The equations in Table 3.2 and 3.3 were derived from pick wear data collected from a road header working in similar conditions. Best fit lines of the data were generated and the corresponding equations are displayed in 
the Tables 3.2 and 3.3. As both machines exert similar forces on the picks the amount of wear of a road header is fairly transferable to that of a SM (Bauer, 2011). 
Table 3-2 Pick Wear Equations for Hard Rock

\begin{tabular}{|c|c|c|c|c|c|}
\hline & \multicolumn{4}{|c|}{ Unconfined Compressive Strength $(x)$} \\
\hline & & 0-5 MPA & 5-30MPA & 30-70 MPA & $70 \mathrm{MPA}+$ \\
\hline \multirow{7}{*}{$\begin{array}{c}\text { Cerchar } \\
\text { Abrasivity } \\
\text { Index }\end{array}$} & 5.0 & $y=0.0138 x-0.0026$ & $y=0.0047 x^{1.4595}$ & $y=0.0326 x-0.2617$ & $y=-7 E-05 x^{2}+0.0202 x+1.1617$ \\
\hline & 4.0 & $y=0.0002 x^{2}+0.0043 x+0.0005$ & $y=0.0016 x^{1.568}$ & $y=0.0281 x-0.6017$ & $y=-0.0002 x^{2}+0.0547 x-1.5822$ \\
\hline & 3.0 & $y=1 E-04 x^{2}+0.0017 x+0.0011$ & $y=0.0006 x^{1.6334}$ & $y=0.0142 x-0.3167$ & $y=2 E-05 x^{2}+0.0197 x-0.9434$ \\
\hline & 2.0 & $y=0.0011 x+0.001$ & $y=6 E-05 x^{2}+0.0004 x+0.0014$ & $y=0.0071 x-0.1713$ & $y=0.0566 e^{0.0239 x}$ \\
\hline & 1.5 & $y=0.0006 x+0.0012$ & $y=3 E-05 x^{2}-8 E-05 x+0.0055$ & $y=0.0119 e^{0.0373 x}$ & $y=0.0186 e^{0.0308 x}$ \\
\hline & 1.0 & $y=0.0003 x+0.0013$ & $y=8 E-06 x^{2}+1 E-04 x+0.0024$ & $y=0.0035 e^{0.041 x}$ & $y=0.003 e^{0.0425 x}$ \\
\hline & 0.6 & $y=8 E-05 x+0.0013$ & $y=4 E-06 x^{2}-1 E-05 x+0.0018$ & $y=0.0013 e^{0.0462 x}$ & $y=0.001 e^{0.0489 x}$ \\
\hline
\end{tabular}

Table 3-3 Pick Wear Equations for Coal

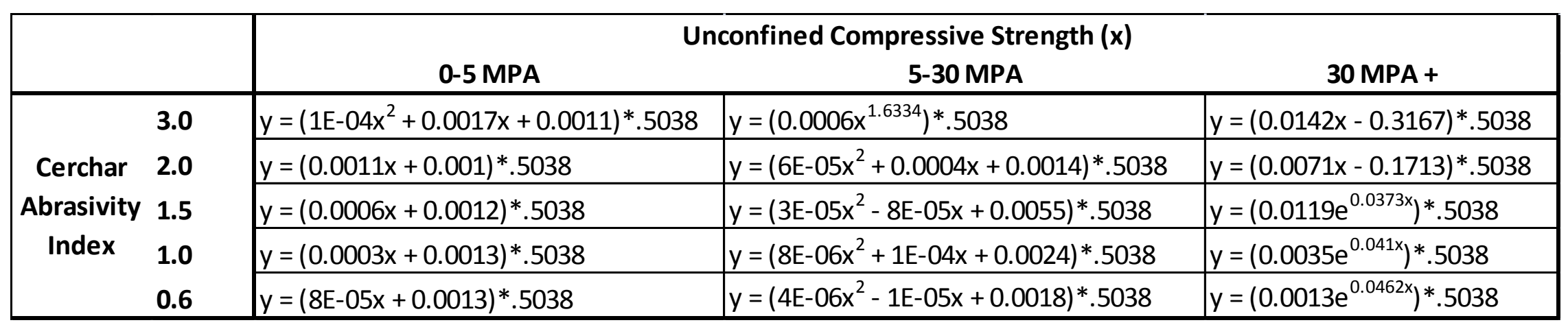


The equations shown in the Table 3.2 and 3.3 are dependent on the unconfined compressive strength (UCS), measured in $\mathrm{MPa}$, and the abrasivity of the rock, as measured by the Cerchar Abrasive Index, CAI. The " $x$ " variable in each equation refers to the unconfined compressive strength of the rock, while the " $y$ " variable is the amount of expected pick wear in picks per bank cubic meter. The pick wear, when plotted, shows an almost uniform wear as the UCS and abrasiveness increase. Because there are irregularities, equations have been derived for each value on the Cerchar Abrasive Index as well as for a range of unconfined compressive strengths.

Graphical representations of the equations in Tables 3.2 and 3.3 are displayed in the results section showing the relationship between pick wear and volume of material that can be cut until replacement is needed.

In addition to the pick wear in hard rocks, these values must also be obtained for wear in a softer material such as bituminous coal (Table 3.3). The pick wear value is determined by the characteristics, abrasivity and unconfined compressive strength, of the rock, which were described in module \#1. It is necessary to have a description of the softer bituminous coal because the unconfined compressive strength and abrasivity are not the only factors affecting the amount of pick wear. Rock properties, such as rock structure (solid, fractured, macro/micro seamy), and grain size are a few factors that cause vastly different pick wear values at the same unconfined compressive strengths and abrasiveness. 
The pick wear equations as stated previously are derived from the application of a road header in similar rock types. This among other factors cause the equations to generate pick wear values that are higher than what may actually be experienced. These values are acceptable but conservative.

With the known pick consumption per bank cubic meter, the amount of pick changes per row cut can be calculated. This value is needed to calculate the real cutting time of the SM. In the case of this research, the values for pick wear $\left(\mathrm{PW}_{\mathrm{SI}}\right)$ generated by the equations in Table 3.2 and 3.3, are stated in picks per bank cubic meter. To avoid conversions in all equations using pick wear, a simple conversion factor of $35.32 \mathrm{ft}^{3}$ per $\mathrm{m}^{3}$ will be used. The pick wear is represented in picks per bank cubic foot as follows:

$$
P W=P W_{S I} * 35.32
$$

In addition to calculating pick wear in terms of picks per bank cubic foot, it is good practice to find the pick wear per bank cubic yards and tons. The equations used to determine the various pick wear values are as follows:

$$
\begin{aligned}
& P W_{y d 3}=P W * 27 \\
& P W_{\text {ton }}=\frac{P W}{\text { Density }}
\end{aligned}
$$

The number of times the picks need to be changed is found by dividing the volume of material in the row length, $(\mathrm{RL})$ in $\mathrm{ft}$, by the pick wear $(\mathrm{PW})$. It is common practice to 
replace a minimum of five picks per change sequence. With the implementation of a pick changing tool, the time to change one pick has been reduced to approximately one minute. The equation for the number of pick changes per row (NPC) is as follows:

$$
N P C=\frac{R L * D * W}{P W * 5}
$$

The pick wear information in this research is provided in picks per bank cubic meter, which may not always be the case. Pick wear can also be measured in forward distance of the machine. For instance, the pick wear may be measured in the amount of picks per foot traveled while cutting. Equation 3.8 is slightly modified to accommodate the calculation of pick wear $\left(\mathrm{PW}_{\mathrm{ft}}\right)$ in feet traveled while cutting. Equation 3.9 represents the number of pick changes $\left(\mathrm{NPC}_{\mathrm{L}}\right)$ required when pick wear is calculated in cutting distance.

$$
N P C_{L}=\left(\frac{R L}{P W_{f t} * 5}\right)
$$

When the cutting performance has been determined, delays can be factored in to provide a practical cutting performance value. Delays such as time spent on sumping in and out of the cut (ST), turning (TT), pick changing (PCT), and other non-cutting time (NCT) lower the real cutting time. Truck haulage adds additional delay time in the calculations based on the time to change trucks after loading. The total time taken to process one row length, including all delays, is known as the total time per row (TTR). 
The first variable needed to find the total time per row is the time the SM is cutting material. The cutting time per row (CTR) is expressed in minutes as follows:

$$
C T R=\left(\frac{R L}{V}\right)
$$

The second variable in the total time equation is the time spent on changing picks. With the number of changes per row obtained from Equation 3.8, the time spent on pick changing, (PCT) in minutes, can be calculated as follows:

$$
P C T=N P C * 5
$$

The remaining delay time components are calculated in Equations 3.12, 3.13, and 3.14. When the SM starts a cut, there is a span of distance in which the cutting drum is being lowered until the appropriate depth is reached. This distance also exists at the end of a cut when the machine raises the cutting drum. When these two distances are combined the total sump length, (TSL) in $\mathrm{ft}$, is determined. The sumping segments are cut at a designated sumping speed, (SS) in $\mathrm{ft} / \mathrm{min}$. The sumping time is determined in minutes as follows:

$$
S T=\left(\frac{T S L}{S S} * \# \text { of Sumps per row }\right)
$$


The SM travels at higher rates of speed while not cutting. The travel speed, (TS) in $\mathrm{ft} / \mathrm{min}$, is applied to delays that do not involve cutting, such as turning time, (TT) in minutes, and other non-cutting time, (NCT) in minutes. The equations for these delays, calculated in minutes, are as follows:

$$
\begin{gathered}
T T=\left(\frac{\text { Turning Radius }}{T S}\right) \\
N C T=\left(\frac{\text { Non Cutting Length }}{T S}\right)
\end{gathered}
$$

When all of the delay components have been determined, the total time per row (TTR) is calculated in hours as follows:

$$
T T R=(C T R+P C T+S T+T T+N C T) / 60
$$

The Equation 3.1 must account for the delays in the cutting sequence to achieve an accurate cutting performance. The total operating hours that the SM is cutting material is known as the real cutting time (RCT), represented in hrs/year, which is a percentage (RCT\%) of the total operating hours per year (OHY). The RCT\% is a result of the amount of time spent cutting a row divided by the total time spent on cutting and noncutting time for that row as shown by equation 3.16 . 


$$
\begin{gathered}
R C T \%=\frac{C T R}{T T R} \\
R C T=R C T \% * O H Y
\end{gathered}
$$

The cutting performance value with applied delays is called the practical cutting performance, (PQ) in $\mathrm{bft}^{3} / \mathrm{hr}$, and is achieved by multiplying the cutting performance by the percentage of real cutting time as follows:

$$
P Q=R C T \% * Q
$$

This practical cutting performance value can be multiplied by the operating hours per year $(\mathrm{OHY})$ to show the maximum production (MP) of the SM in a specific scenario and is calculated in bank $\mathrm{yd}^{3} / \mathrm{year}$ as follows:

$$
M P=P Q * O H Y * 27
$$

The MP is a useful value when considering what size of SM and the number of SMs required to meet production goals. If more than one SM is needed to meet production requirements, the equations can be modified to calculate the number of required SMs. Multiple SMs are needed if the maximum production of the SM is less than the required production RP, i.e.

True or False $R P>M P$ 
If more than one machine is needed, the required production will be divided equally among all SMs. This defines a new required production per SM.

When the maximum production of the SM exceeds the required production, a variable called the real operating hours per year (ROHY) needs to be considered. To accurately compare both mining methods, their annual production must be the same. Therefore, if the ROHY is less than the OHY, the ROHY will be used for any calculations using the OHY.

There is an alternative option to calculate the practical cutting performance and it is used as a check to verify its validity. The practical cutting performance method is verified by multiplying the theoretical cutting performance, (TQ) in $\mathrm{ft} / \mathrm{hr}$, by the cutting dimensions. The TQ can be calculated without including the SM's cutting dimensions. It is measured in feet per hour instead of cubic feet per hour. This is done based on the time spent cutting. The TQ is calculated by dividing the RL by the TTR as follows:

$$
T Q=\frac{R L}{T T R}
$$

The theoretical cutting performance can then be multiplied by the operating hours per year to find the total distance cut per year. Although this is a theoretical value, the delay times experienced during the cutting process are considered because they are included in the total time per row variable. The distance cut per year is determined by: 


$$
T Q_{Y}=T Q * O H Y
$$

The theoretical cutting performance can be used to verify the practical cutting performance as stated previously. To do this, the theoretical cutting performance is multiplied by the dimensions of the cutting drum and the cutting depth to obtain the PQ.

$$
P Q=T Q * W * D
$$

An additional validation of the practical cutting performance is the maximum production, (MP) per year in $\mathrm{byd}^{3} / \mathrm{year}$. This is the yearly theoretical cutting performance multiplied by the cutting dimensions and a conversion factor, $27 \mathrm{ft}^{3} / \mathrm{yd}^{3}$, as follows:

$$
M P=T Q_{Y} * W * D * 27
$$

The TQ may also be necessary when pick wear is described in picks per distance cut.

The SM ownership and operating costs are calculated once the specifics and capabilities of the SM have been determined. The ownership cost equations come from Caterpillar (2009) and are used for every piece of equipment in this research. Variables used in these calculations are machine purchasing cost (PC) in dollars, ownership period (OP) in yrs, operating hours per year (OHY) in hrs, depreciation rate (DR) as a percentage, interest rate (INTR) as a percentage, insurance rate (INSR) as a percentage, tax rate (TXR) as a percentage, and the residual value rate (RV) as a percentage. The equations 
for depreciation value per year (DV) in $\$$ yr, the value to be recovered through work (VR) in dollars, capital cost (CC) in $\$ / h r$, interest cost (INT) in $\$ / h r$, insurance cost INS in $\$ / \mathrm{hr}$, and tax cost (TX) in $\$ / \mathrm{hr}$ are as follows:

$$
\begin{gathered}
D V=D R * P C \\
R V=R V \% * P C \\
V R=P C-R V \\
C C=(P C-R V) /(O P * O H Y) \\
I N T=\frac{\frac{O P+1}{2 * O P} * P C * \frac{I N T R}{100}}{O H Y} \\
I N S=\frac{\frac{O P+1}{2 * O P} * P C * \frac{I N S R}{100}}{O H Y} \\
T X=\frac{\frac{O P+1}{2 * O P} * P C * \frac{T X R}{100}}{O H Y}
\end{gathered}
$$

The ownership costs (OC) are calculated after all previous cost values have been determined. The ownership cost is the addition of all costs represented in $\$ / \mathrm{hr}$ as follows:

$$
O C=C C+I N T+I N S+T X
$$

The operating cost (OPC) is the summation of the repair (RC), fuel (FC), grease (GC), hydraulic oil (HO), water (WC), picks (PTC), and labor (LBC) stated $\$ / h r$. 


$$
O P C=R C+F C+G C+H O+W C+P T C+L B C
$$

The costs for every element except for the cost of picks can be seen in Equations 3.343.38, Caterpillar (2010) and Kecojevic (2010). The RC uses the machine purchasing cost and $\mathrm{OHY}$ as follows:

$$
R C=(8 \% * P C) / O H Y
$$

The fuel consumption rate, typically provided by the manufacturer, is used to calculate the fuel cost. The manufacturer provided fuel consumption rate generally describes the motor under full load capacity (FLC). The machine will not likely operate at full load capacity for long periods of time because of the risk of pushing the machine to its failure point. Therefore, a load coefficient factor (LCF) is used to estimate the average load on the motor. In the calculations for this research, a value of 70 percent is used for the LCF (Wirtgen, 2010). The equations used to calculate fuel and grease cost are as follows:

$$
\begin{gathered}
F C=F L C * L C F * \text { Fuel Cost } \\
G C=8 \% * F C
\end{gathered}
$$

The cost of hydraulic oil, (HO) in $\$ / \mathrm{hr}$, is calculated by the replacement time intervals in hrs of the oil (HCI) divided by the capacity of the hydraulic oil tank (VHO). The cost of water, (WC) in $\$ / \mathrm{hr}$, is determined by the consumption rate multiplied by the water cost. These equations are as follows: 


$$
\begin{array}{r}
H O=\frac{V H O}{H C I} * \text { Hydraulic Oil Cost } \\
\text { WC Consumption Rate } * \text { Water Cost }
\end{array}
$$

The pick cost is dependent on how the pick wear is described; per volume or distance cut. Before the cost of replacement picks can be found, the number of picks consumed yearly (PCY) must be calculated. Equation 3.24 calculates the SM's maximum production. As stated when explaining the ROHY, only the costs for achieving the exact required production needs to be calculated. This usable production (UP) value will be equal to the required production unless more than one SM is used to meet the requirement. If one SM is used, then Equation 3.39 is true; if multiple SMs are used, then Equation 3.40 is true.

$$
\begin{gathered}
U P=R P \\
U P=\frac{R P}{\# \text { of Surface Miners }}
\end{gathered}
$$

It is useful to define the amount of picks per set (PPS) for purchasing reasons. This value depends on the width of the cutting drum and the spacing between the picks on the drum. The spacing calculation is in SI units. The cutting drum width, (W) in meters, is based on the size of the SM and the pick spacing, (PS) in millimeters, is determined by the type of rock and the desired size of the product.

$$
P P S=\left(\frac{W * 1000}{P S * 1.1}\right)
$$


The amount of picks used to extract the exact amount of material is calculated after the usable production is determined, (the pick wear in this research is expressed as picks per volume). Time per set or per pick can also be calculated from the value found in Equation 3.42 by using simple arithmetic. The amount of picks consumed per year (PCY) is calculated by dividing the usable production (UP) by the pick wear. The conversion factor $27 \mathrm{ft}^{3} / \mathrm{yd}^{3}$ is applied to the equation for PCY and is as follows:

$$
P C Y=\frac{U P}{P W * 27}
$$

Multiplication of the values calculated in Equations 3.43 and 3.44 by the amount of material will yield the same result as calculated in Equation 3.42. The cost of pick consumption (PTC) is calculated from the amount of picks consumed per year. The equation can be varied to represent this value in the desired units, but it is calculated in $\$ / \mathrm{hr}$ to follow the previous cost calculations.

$$
P T C=\frac{P C Y * \text { Pick Cost }}{O H Y}
$$

The theoretical values are also used to verify the pick consumption and cost calculations. The pick wear, $\left(\mathrm{PW}_{\mathrm{L}}\right)$ in pick/ft, is used with the theoretical cutting performance to find the pick consumption per year.

$$
P C Y=T Q_{Y} * P W_{L}
$$


The value for pick consumption is based on the distance the SM cuts per year. The practical and theoretical pick consumption values are compared to check the validity of the pick consumption calculation. The pick consumption is correct if these two values are the same.

The calculations for the SM are broken down into three excavation scenarios; the overburden, interburden, and coal extraction. The same cost equations are used for the overburden, interburden, and coal extraction except for the different values for the pick wear, operating hours, and material characteristics. The costs for all three scenarios are calculated in $\$ / \mathrm{hr}$ and are converted to $\$ / \mathrm{yd}^{3}$ for overburden and interburden and $\$ /$ ton for coal for the mining method comparison. The $\mathrm{SM}(\mathrm{s})$ unit operation costs are compared to the conventional mining method costs to reveal the most economical mining method.

\subsection{Comparison of Mining Methods (Module 6)}

In this module, the conventional mining method is compared to the SM mining method. By comparing the overburden, interburden, and coal mining unit operations, the most economical method is determined. To insure both methods are comparable, all of the final costs are represented in dollars per cubic yard for overburden and interburden and in dollars per ton for coal. The comparison of methods uses the values derived by the calculations based on the material properties and characteristics described in module one. The results of the comparison module should not be taken as a rule-of-thumb for the entire state of WV. This comparison will provide results based on the average rock and material properties. In order to ultimately determine what method is the most 
economical, the site specific material properties must be known and then site specific calculations can be performed and provide a location specific result.

\subsubsection{Analytical Hierarchy Process for the Selection of the Optimal Mining Method}

This research uses the analytical hierarchy process (AHP), developed by Saaty (1980), to evaluate conventional mining methods with that of a surface miner. The AHP is suitable for this application because of its ability to evaluate the qualitative and quantitative values derived in this research. The AHP in this research breaks the problem of selecting the optimal mining method into four levels; goals, strategic issues, criterion, and alternatives. The AHP model developed for the selection of the optimal mining method can be seen in Figure 3.4. The problem is broken into levels based on the level of importance of a specific criterion. By defining the hierarchy of criteria the problem is analyzed in smaller more manageable problems. 


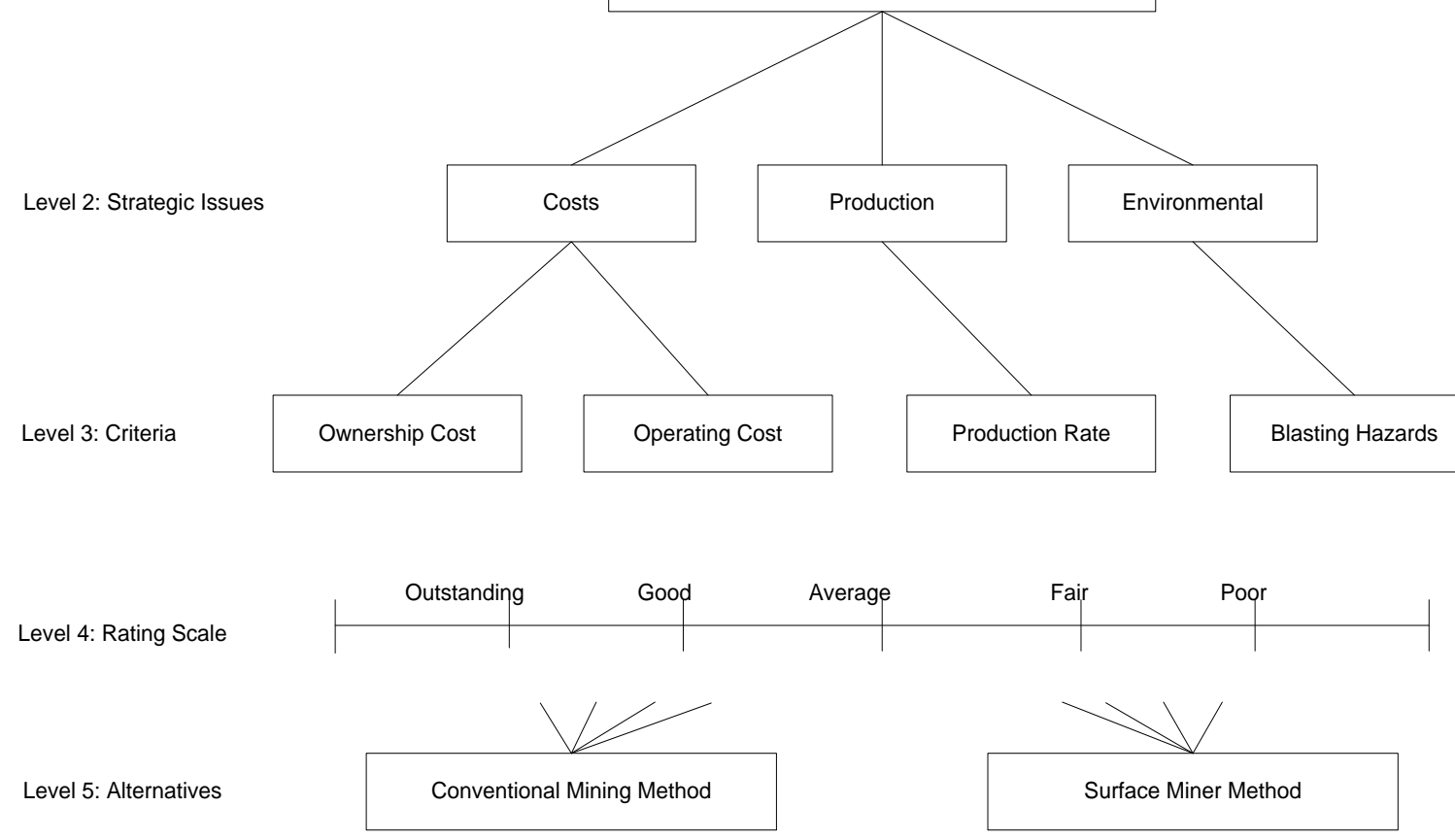

Figure 3-4 AHP Model for Selection of Optimal Mining Method

The optimal mining method can be selected when the levels have been defined and arranged into pairwise comparison matrices. The matrices are constructed based on the number of candidate requirements. For the model developed in this research, it uses two " $n \times n$ " matrices; one " $3 \times 3$ " matrix for the level two strategic issues and a " $2 \times 2$ " matrix for the level three criteria. No comparison matrix is needed for the production and environmental strategic issues because they only contain one criterion. With the matrices constructed, pairwise comparisons of all the requirements are performed. To assign a numerical value to each pair of requirements in the matrix, the scale created by Saaty (2008) is used to and can be seen in Table 3.4. 
Table 3-4 The Fundamental Scale of Absolute Numbers (Saaty, 2008)

\begin{tabular}{|c|c|c|}
\hline $\begin{array}{l}\text { Intensity of } \\
\text { Importance }\end{array}$ & Definition & Explanation \\
\hline 1 & Equal Importance & Two acitivities contribute equally to the objective \\
\hline 2 & Weak or Slight & \\
\hline 3 & Moderate Importance & $\begin{array}{l}\text { Experience and judgement slightly favour one } \\
\text { acitvity over another }\end{array}$ \\
\hline 4 & Moderate Plus & \\
\hline 5 & Strong Importance & $\begin{array}{l}\text { Experience and judgement strongly favour one } \\
\text { acitvity over another }\end{array}$ \\
\hline 6 & Strong Plus & \\
\hline 7 & $\begin{array}{l}\text { Very Strong or } \\
\text { Demonstrated Importance }\end{array}$ & $\begin{array}{l}\text { An activity is favoured very strongly over } \\
\text { another; its dominance demostrated in practice }\end{array}$ \\
\hline 8 & Very, Very Strong & \\
\hline 9 & Extreme Importance & $\begin{array}{l}\text { The evidence favouring one activity over } \\
\text { another is of the higherst possible order of }\end{array}$ \\
\hline $\begin{array}{l}\text { Reciprocals of } \\
\text { above }\end{array}$ & $\begin{array}{l}\text { If activity } i \text { has one of the } \\
\text { above non-zero numbers } \\
\text { assigned to it when } \\
\text { compared with activity } j \text {, } \\
\text { then } j \text { has the reciprocal } \\
\text { value when compared } \\
\text { with } i\end{array}$ & \\
\hline $1.1-1.9$ & $\begin{array}{l}\text { If the activities are very } \\
\text { close }\end{array}$ & $\begin{array}{l}\text { May be difficult to assign the best value but } \\
\text { when compared with other contrasting } \\
\text { activities the size of the small numbers would } \\
\text { not be too noticeable, yet they can still indicate } \\
\text { the relative importance of the acitivies. }\end{array}$ \\
\hline
\end{tabular}

Eigenvalues, a.k.a. the priority matrix, are generated from the comparison matrix when each criteria comparison has been given a value. The eigenvalues, or priority matrix, represent the weights of each criteria considered for the comparison matrix. The higher the weight of a criterion, the higher the influence it will have on the final selection. 
The priority matrix represents the weight of each criterion. This provides weights for each specific criterion but does not account for the weights of the other level's criteria for the same alternative. The last level of criteria/sub-criteria/etc. in an AHP model have Global Weights (GW) assigned to them. The GW considers each criterion, and its weight, from any previous level. For example, if Figure 3.5 would be the AHP model a GW would be assigned to the sub-criteria.

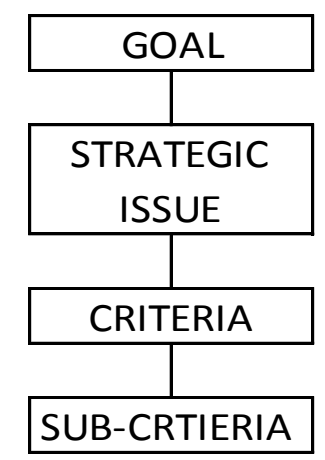

Figure 3-5 Example AHP Model

The GW calculated for the sub-criteria would account for the local weights of the strategic issue, the criteria, and the sub-criteria. A realistic AHP model will have more than one for the categories in Figure 3.5. Each alternative combines of all GW associated with it and finally the alternative with the highest value will be the best alternative.

To consider the differences between mining methods, it is necessary to rank the criteria for each mining method (level 4). A ranking system developed by Liberatore et al. (1992) uses five ratings: Outstanding (O), Good (G), Average (A), Fair (F), and Poor (P). 
This system was used by Bascetin (2006) in formulating a pairwise comparison judgment matrix to assign values to the five different ratings as seen in Table 3.5.

Table 3-5 Rank Values

\begin{tabular}{lc}
\hline \multicolumn{1}{c}{ Rank } & Nume rical Value \\
\hline Outstanding $(\mathrm{O})$ & 0.513 \\
Good $(\mathrm{G})$ & 0.261 \\
Average $(\mathrm{A})$ & 0.129 \\
Fair (F) & 0.063 \\
Poor (P) & 0.034 \\
\hline
\end{tabular}

A rating and score are assigned at the author's discretion to each of the criteria. By multiplying the score and the global weight and summing all these values for each mining method, a total score for the mining method is achieved. Finally, after normalizing each total score, the higher score is the determined to be the optimal mining method.

The Consistency Index (CI) is calculated to measure the errors in judgment by the user. This can be explained as the consistency of the user's judgments for each comparison in the matrix. An example of a user with consistent judgments would be as follows:

- A is deemed more important than B

- B is deemed more important than C

- A is therefore more important than $\mathrm{C}$

This type of input into a comparison matrix would display a consistent judgment making process and will likely provide valid results. An inconsistent judgment for the previous example would rate $\mathrm{C}$ more important than $\mathrm{A}$. 
To determine the CI, the maximum principle eigenvalue $\left(\lambda_{\max }\right)$ of the comparison matrix is needed. The equation developed by Saaty (1980) for the CI is dependent on the $\lambda_{\max }$ and the number or candidate requirements in the matrix " $n$ " as shown in Equation 3.45.

$$
C I=\frac{\lambda_{\max }-n}{n-1}
$$

Finally, Saaty (1980) proposed a method to determine if the matrix is acceptable, by the calculation of the Consistency Ratio (CR). The CR is based on the $\mathrm{CI}$ and the consistency indices of Randomly Generated Reciprocal Matrices (RI) developed by Saaty (1980). The RI values can be seen in Table 3.6.

Table 3-6 RI Values vs. "n" (Bascetin, 2006)

\begin{tabular}{lllllllllll}
\hline$n$ & 1 & 2 & 3 & 4 & 5 & 6 & 7 & 8 & 9 & 10 \\
\hline $\mathrm{RI}$ & 0.00 & 0.00 & 0.58 & 0.90 & 1.12 & 1.24 & 1.32 & 1.41 & 1.45 & 1.49 \\
\hline
\end{tabular}

The CR is calculated based on the " $n$ " value equivalent to the comparison matrix and its corresponding RI value displayed in Table 3.6. The equation for the CR is as follows:

$$
C R=\frac{C I}{R I[n]}
$$


A general rule for an acceptable matrix is a $\mathrm{CR}$ value less than or equal to 0.10 . The AHP can be determined quicker and more accurately by using software such as Expert Choice (2012), which uses the principles described here. This software is used to carry out the AHP in this research. 


\section{Chapter 4}

\section{Results and Analysis}

\subsection{Global Input Parameters}

Throughout this study, variables such as fuel price, hydraulic oil price, electricity price, insurance rate, interest rate, and tax rate will remain unchanged and therefore are considered to be global parameters. The values compiled from InfoMine (2011) and Kecojevic (2010) are displayed in Table 4.1 as global parameters.

Table 4-1 Global Parameters

\begin{tabular}{lrl}
\hline Parameters & $\underline{\text { Value }}$ & $\underline{\text { Units }}$ \\
\hline Fuel Price & 3.20 & $\$ /$ gal \\
Hydraulic Oil Price & 11.00 & $\$ /$ gal \\
Electricity Price & 0.07 & $\$ / \mathrm{kWh}$ \\
Insurance Rate & 6.00 & $\%$ \\
Interest Rate & 1.00 & $\%$ \\
Tax Rate & 1.00 & $\%$ \\
\hline
\end{tabular}

\subsection{Results and Analysis}

In this section, the results of the methodology described in chapter three is presented.

\subsubsection{Drilling and Blasting}

The cost assessment of the drilling and blasting operation was conducted for an annual

production of 10 million bank $\mathrm{yd}^{3}$ of overburden material. Drilling and blasting 
parameters are shown in Table 4.2. The drilling and blasting cost analysis are shown in Tables 4.3 and 4.4 respectively.

Table 4-2 Drilling and Blasting Parameters

\begin{tabular}{lrrl}
\hline Parameters & Sandstone & $\underline{\text { Shale }}$ & Units \\
Required production (RP) & $10,000,000$ & $10,000,000$ & bank $\mathrm{yd}^{3} / \mathrm{year}$ \\
Operating Hours per Year (OHY) & 4,600 & 4,600 & $\mathrm{hrs}$ \\
Bench height & 50 & 50 & $\mathrm{ft}$ \\
Hole diameter & 6 & 6 & $\mathrm{in}$ \\
Drillability Factor & 1.8 & 2.0 & \\
Overall Drilling Factor & 0.70 & 0.70 & \\
Explosive & ANFO & ANFO & \\
Detonation pressure & 31 & 31 & $\mathrm{kbars}$ \\
Density of explosive & 0.82 & 0.82 & $\mathrm{~g} / \mathrm{cc}$ \\
\hline
\end{tabular}


Table 4-3 Drilling Cost Analysis

\begin{tabular}{lrrl}
\hline Parameters & $\underline{\text { Sandstone }}$ & $\underline{\text { Shale }}$ & $\underline{\text { Units }}$ \\
\hline Burden & 12.90 & 14.93 & $\mathrm{ft}$ \\
Drill Hole Spacing & 16.78 & 19.41 & $\mathrm{ft}$ \\
Sub-drilling & 3.87 & 4.48 & $\mathrm{ft}$ \\
Hole Length & 54.70 & 55.32 & $\mathrm{ft}$ \\
Stemming & 12.90 & 14.93 & $\mathrm{ft}$ \\
Particle Size for Stemming & 0.50 & 0.50 & $\mathrm{in}$ \\
Hole charge length & 41.80 & 40.39 & $\mathrm{ft}$ \\
Penetration Rate & 89.59 & 98.99 & $\mathrm{ft} / \mathrm{hr}$ \\
Overall Drilling Rate & 62.71 & 69.30 & $\mathrm{ft} / \mathrm{hr}$ \\
Specific drilling & 0.14 & 0.10 & $\mathrm{ft} / \mathrm{yd}$ \\
Total Required Drilling & $1,364,499$ & $1,031,196$ & $\mathrm{ft}$ \\
Total drilling time & 22,903 & 15,664 & $\mathrm{hrs}$ \\
Number of required drills & 5 & 4 & \\
Machine Purchasing Cost (PC) & 598,200 & 598,200 & $\$$ \\
Depreciation Value per Year (DV) & 89,730 & 89,730 & $\$$ \\
Value to be Recovered Through Work (VR) & 538,380 & 538,380 & $\$$ \\
Residual Value (RV) & 59,820 & 59,820 & $\$$ \\
Capital Cost (CC) & 19.51 & 19.51 & $\$ / \mathrm{hr}$ \\
Interest Cost (INT) & 4.55 & 4.55 & $\$ / \mathrm{hr}$ \\
Insurance Cost (INSR) & 0.76 & 0.76 & $\$ / \mathrm{hr}$ \\
Tax Cost (TX) & 0.76 & 0.76 & $\$ / \mathrm{hr}$ \\
Ownership cost (OC) & 25.58 & 25.58 & $\$ / \mathrm{hr}$ \\
Fuel Cost (FC) & 33.60 & 33.60 & $\$ / \mathrm{hr}$ \\
Lube Cost (LC) & 4.62 & 4.62 & $\$ / \mathrm{hr}$ \\
Maintenance Cost & 23.93 & 23.93 & $\$ / \mathrm{hr}$ \\
Drill Accessory Cost & 18.81 & 13.86 & $\$ / \mathrm{hr}$ \\
Operating cost (OPC) & 100.96 & 96.01 & $\$ / \mathrm{hr}$ \\
Total drilling cost for all drills & 632.69 & 486.33 & $\$ / \mathrm{hr}$ \\
Total Drilling cost & $13,765,809$ & $7,237,047$ & $\$ / \mathrm{year}$ \\
Total Drilling cost & $\mathbf{0 . 7 2}$ & $\$ / \mathrm{bank} \mathbf{y d}$ \\
\hline & &
\end{tabular}


Table 4-4 Blasting Cost Analysis

\begin{tabular}{|c|c|c|c|}
\hline Parameters & $\underline{\text { Sandstone }}$ & $\underline{\text { Shale }}$ & Units \\
\hline Hole charge concentration & 10.04 & 10.04 & $\mathrm{lb} / \mathrm{ft}$ \\
\hline Total charge per hole & 419.52 & 405.40 & $\mathrm{lb}$ \\
\hline Volume of rock per $\mathrm{ft}$ of hole & 8.02 & 10.73 & $\mathrm{yd}^{3}$ \\
\hline Volume of rock per hole & 401 & 536 & $\mathrm{yd}^{3}$ \\
\hline Weight of Rock per Hole & 849.93 & 751.04 & ton \\
\hline Number of required holes & 24,944 & 18,641 & \\
\hline Total amount of explosive & $10,464,391$ & $7,556,998$ & $\mathrm{lb}$ \\
\hline Powder factor & 1.05 & 0.76 & $\mathrm{lb} / \mathrm{yd}^{3}$ \\
\hline Hole to Hole Delay Time & 50 & 50 & $\mathrm{~ms}$ \\
\hline Row to Row Delay Time & 125 & 150 & $\mathrm{~ms}$ \\
\hline Explosive cost & $5,441,483$ & $3,929,639$ & $\$$ \\
\hline Detonator Cost & 254,179 & 189,952 & $\$$ \\
\hline Booster Cost & 73,086 & 54,618 & $\$$ \\
\hline Leadline \& Tube Cost & 80,458 & 69,682 & $\$$ \\
\hline Time to Charge all Drill Holes & 968.93 & 699.72 & hrs \\
\hline Blaster Labor & 74,607 & 53,879 & $\$$ \\
\hline Delivery Driver & 59,686 & 43,103 & $\$$ \\
\hline Travel, delivery and shot service & 42,000 & 42,000 & $\$$ \\
\hline Total blasting cost per year & $6,025,500$ & $4,382,872$ & \$/year \\
\hline Total blasting cost & 0.60 & 0.44 & $\$ /$ bank yd ${ }^{3}$ \\
\hline Total drilling and blasting cost & 1.98 & 1.16 & $\$ /$ bank yd ${ }^{3}$ \\
\hline
\end{tabular}

Drilling costs for sandstone and shale are $\$ 1.38$ and $\$ 0.72$ per bank $\mathrm{yd}^{3}$, respectively, while blasting costs are $\$ 0.60$ and $\$ 0.44$ per bank $\mathrm{yd}^{3}$. Total drilling and blasting costs for sandstone and shale are $\$ 1.98$ and $\$ 1.16$ per bank $\mathrm{yd}^{3}$, respectively.

\subsubsection{Digging and Loading}

\section{Overburden}

The handling of sandstone and shale overburden material is considered for the following digging and loading equipment: hydraulic shovel, electric (rope) shovel and front-end 
wheel loader. The selection of the overburden removal machine is based on an annual production rate of 10 million bank $\mathrm{yd}^{3}$.

The parameters and cost analysis for the overburden hydraulic shovel is given in Tables 4.5 and 4.6.

Table 4-5 Overburden Hydraulic Shovel Parameters

\begin{tabular}{lrrl}
\hline Parameters & $\underline{\text { Sandstone }}$ & $\underline{\text { Shale }}$ & Units \\
\hline Required production per year (RP) & $10,000,000$ & $10,000,000$ & bank yd bear $^{3}$ year \\
Operating Hours per Year (OHY) & 6,000 & 6,000 & hrs \\
Number of Cycles & 122 & 122 & \\
Availability & 90.00 & 90.00 & $\%$ \\
Operating Efficiency & 83.00 & 83.00 & $\%$ \\
Fill Factor & 85.00 & 90.00 & $\%$ \\
Machine Purchasing Cost (PC) & $7,000,000$ & $6,100,000$ & $\$$ \\
Horsepower & 2,000 & 1,944 & $\mathrm{HP}$ \\
Labor & 35.00 & 35.00 & $\$ / \mathrm{hr}$ \\
\hline
\end{tabular}


Table 4-6 Overburden Hydraulic Shovel Cost Analysis

\begin{tabular}{|c|c|c|c|}
\hline Parameters & Sandstone & $\underline{\text { Shale }}$ & Units \\
\hline Hourly production & $1,666.67$ & $1,666.67$ & bank $\mathrm{yd}^{3} / \mathrm{hr}$ \\
\hline Bucket volume & 34.42 & 29.46 & $\mathrm{yd}^{3}$ \\
\hline Depreciation Value per Year (DV) & 787,500 & 686,250 & $\$$ \\
\hline Value to be Recovered Through Work (VR) & $6,300,000$ & $5,490,000$ & $\$$ \\
\hline Residual Value (RV) & 700,000 & 610,000 & $\$$ \\
\hline Capital Cost (CC) & 131.25 & 114.38 & $\$ / \mathrm{hr}$ \\
\hline Interest Cost (INT) & 39.38 & 34.31 & $\$ / \mathrm{hr}$ \\
\hline Insurance Cost (INSR) & 6.56 & 5.72 & $\$ / \mathrm{hr}$ \\
\hline Tax Cost (TX) & 6.56 & 5.72 & $\$ / \mathrm{hr}$ \\
\hline Ownership Cost (OC) & 183.75 & 160.13 & $\$ / \mathrm{hr}$ \\
\hline Fuel Cost (FC) & 243.20 & 236.39 & $\$ / \mathrm{hr}$ \\
\hline Maintenance, Wear Parts \& Labor & 175.00 & 152.50 & $\$ / \mathrm{hr}$ \\
\hline Operating Cost (OPC) & 453.20 & 423.89 & $\$ / \mathrm{hr}$ \\
\hline Total Digging and Loading Cost & 636.95 & 584.02 & $\$ / \mathrm{hr}$ \\
\hline Total Digging and Loading Cost & $3,821,700$ & $3,504,092$ & \$/year \\
\hline Total Digging and Loading Cost & 0.38 & 0.35 & $\$ /$ bank yd ${ }^{3}$ \\
\hline
\end{tabular}

The total loading costs for sandstone and shale overburden material are $\$ 636.95$ and $\$ 584.02$ per hour, respectively, or $\$ 3.82$-million and $\$ 3.50$-million on an annual basis, respectively. The costs of digging and loading per bank $\mathrm{yd}^{3}$ are $\$ 0.38$ for sandstone and $\$ 0.35$ for shale material.

The parameters and cost analysis for the electric (rope) shovel is given in Tables 4.7 and 4.8 . 
Table 4-7 Overburden Electric Shovel Parameters

\begin{tabular}{lrrl}
\hline Parameters & Sandstone & Shale & Units \\
\hline Required production per year (RP) & $10,000,000$ & $10,000,000$ & bank yd $\mathrm{yd}^{3} / \mathrm{year}$ \\
Operating Hours per Year (OHY) & 6,000 & 6,000 & $\mathrm{hrs}$ \\
Number of Cycles & 120 & 120 & \\
Availability & 90.00 & 90.00 & $\%$ \\
Operating Efficiency & 83.00 & 83.00 & $\%$ \\
Fill Factor & 90.00 & 95.00 & $\%$ \\
Machine Purchasing Cost (PC) & $8,802,000$ & $8,580,000$ & $\$$ \\
Horsepower & 3,000 & 2,700 & $\mathrm{HP}$ \\
Average Electric Draw & 32.6 & 34.6 & $\%$ \\
Labor & 35.00 & 35.00 & $\$ / \mathrm{hr}$ \\
\hline
\end{tabular}

Table 4-8 Overburden Electric Shovel Cost Analysis

\begin{tabular}{lrrl}
\hline Parameters & $\underline{\text { Sandstone }}$ & $\underline{\text { Shale }}$ & $\underline{\text { Units }}$ \\
\hline Hourly production & $1,666.67$ & $1,666.67$ & bank yd $^{3} / \mathrm{hr}$ \\
Bucket volume & 33.05 & 28.38 & $\mathrm{yd}^{3}$ \\
Depreciation Value per Year (DV) & 352,080 & 343,200 & $\$$ \\
Value to be Recovered Through Work (VR) & $7,041,600$ & $6,864,000$ & $\$$ \\
Residual Value (RV) & $1,760,400$ & $1,716,000$ & $\$$ \\
Capital Cost (CC) & 58.68 & 57.20 & $\$ / \mathrm{hr}$ \\
Interest Cost (INT) & 46.21 & 45.05 & $\$ / \mathrm{hr}$ \\
Insurance Cost (INSR) & 7.70 & 7.51 & $\$ / \mathrm{hr}$ \\
Tax Cost (TX) & 7.70 & 7.51 & $\$ / \mathrm{hr}$ \\
Ownership Cost (OC) & 120.29 & 117.26 & $\$ / \mathrm{hr}$ \\
Electricity Cost & 51.07 & 48.78 & $\$ / \mathrm{hr}$ \\
Maintenance, Wear Parts \& Labor & 220.05 & 214.50 & $\$ / \mathrm{hr}$ \\
Operating Cost (OPC) & 306.12 & 298.28 & $\$ / \mathrm{hr}$ \\
Total Digging and Loading Cost & 426.42 & 415.54 & $\$ / \mathrm{hr}$ \\
Total Digging and Loading Cost & $2,558,491$ & $2,493,264$ & $\$ / \mathrm{year}$ \\
Total Digging and Loading Cost & $\mathbf{0 . 2 6}$ & $\mathbf{0 . 2 5}$ & $\mathbf{\$} / \mathbf{b a n k} \mathbf{y d}$ \\
\hline
\end{tabular}

The total loading costs for sandstone and shale overburden material are $\$ 426.42$ and $\$ 415.54$ per hour, respectively, or approximately \$2.56-million and \$2.49-million on an annual basis, respectively. The costs of digging and loading per bank $\mathrm{yd}^{3}$ are $\$ 0.26$ for sandstone and $\$ 0.25$ for shale material. 
The parameters and cost analysis for the front-end wheel loader is given in Tables 4.9 and 4.10.

Table 4-9 Overburden Front-End Wheel Loader Parameters

\begin{tabular}{lrrl}
\hline Parameters & Sandstone & $\underline{\text { Shale }}$ & Units \\
\hline Required production per year (RP) & $10,000,000$ & $10,000,000$ & bank yd bear $^{3}$ year \\
Operating Hours per Year (OHY) & 6,000 & 6,000 & $\mathrm{hrs}$ \\
Number of Cycles & 90 & 90 & \\
Availability & 90.00 & 90.00 & $\%$ \\
Operating Efficiency & 83.00 & 83.00 & $\%$ \\
Fill Factor & 85.00 & 90.00 & $\%$ \\
Machine Purchasing Cost (PC) & $6,700,000$ & $6,500,000$ & $\$$ \\
Fuel Consumption Rate & 50.00 & 44.00 & $\mathrm{gal} / \mathrm{hr}$ \\
Labor & 35.00 & 35.00 & $\$ / \mathrm{hr}$ \\
\hline
\end{tabular}

Table 4-10 Overburden Front-End Wheel Loader Cost Analysis

\begin{tabular}{|c|c|c|c|}
\hline Parameters & Sandstone & Shale & Units \\
\hline$\overline{\text { Hourly production }}$ & $\overline{1,666.67}$ & $\overline{1,666.67}$ & $\overline{\text { bank } y d^{3} / \mathrm{hr}}$ \\
\hline Bucket volume & 46.66 & 39.94 & $\mathrm{yd}^{3}$ \\
\hline Depreciation Value per Year (DV) & $1,005,000$ & 975,000 & $\$$ \\
\hline Value to be Recovered Through Work (VR) & $6,700,000$ & $5,850,000$ & $\$$ \\
\hline Residual Value (RV) & 670,000 & 650,000 & $\$$ \\
\hline Capital Cost (CC) & 167.50 & 162.50 & $\$ / \mathrm{hr}$ \\
\hline Interest Cost (INT) & 39.08 & 37.92 & $\$ / \mathrm{hr}$ \\
\hline Insurance Cost (INSR) & 6.51 & 6.32 & $\$ / \mathrm{hr}$ \\
\hline Tax Cost (TX) & 6.51 & 6.32 & $\$ / \mathrm{hr}$ \\
\hline Ownership Cost (OC) & 219.61 & 213.06 & $\$ / \mathrm{hr}$ \\
\hline Fuel Cost (FC) & 160.00 & 140.80 & $\$ / \mathrm{hr}$ \\
\hline Tire Cost & 66.00 & 60.00 & $\$ / \mathrm{hr}$ \\
\hline Maintenance, Wear Parts \& Labor & 178.67 & 162.50 & $\$ / \mathrm{hr}$ \\
\hline Operating Cost (OPC) & 439.67 & 398.30 & $\$ / \mathrm{hr}$ \\
\hline Total Digging and Loading Cost & 659.28 & 611.36 & $\$ / \mathrm{hr}$ \\
\hline Total Digging and Loading Cost & $3,955,667$ & $3,668,133$ & \$/year \\
\hline Total Digging and Loading Cost & 0.40 & 0.37 & $\$ /$ bank yd $\mathbf{d}^{3}$ \\
\hline
\end{tabular}


The total loading costs for sandstone and shale overburden material are $\$ 659.28$ and $\$ 611.36$ per hour, respectively, or \$3.96-million and \$3.67-million on an annual basis, respectively. The costs of digging and loading per bank $\mathrm{yd}^{3}$ are $\$ 0.40$ for sandstone and $\$ 0.37$ for shale material.

\section{Interburden}

The bulldozer is designated for ripping and pushing interburden material. The bulldozer selected for this application is a Caterpillar D11T CD with a single shank or an equivalent machine of similar size and capability. The production rate is determined by referring to the production rate chart in Caterpillar (2009), which bases production on the seismic wave velocity of the material. If the thickness of interburden is larger than five feet or the seismic wave velocity increases, other methods for fracturing the rock, such as drilling and blasting, will be required.

The parameters and cost analysis for the bulldozer is given in Tables 4.11 and 4.12.

Table 4-11 Bulldozer Parameters

\begin{tabular}{lrrl}
\hline Parameters & $\underline{\text { Sandstone }}$ & $\underline{\text { Shale }}$ & Units \\
\hline Required production per year (RP) & $1,000,000$ & $1,000,000$ & bank yd bear $^{3}$ \\
Operating Hours per Year (OHY) & 3,000 & 3,000 & $\mathrm{hrs}$ \\
Machine Purchasing Cost (PC) & $1,870,000$ & $1,870,000$ & $\$$ \\
Seismic Wave Velocity & 9,020 & 5,900 & $\mathrm{ft} / \mathrm{sec}$ \\
Labor & 35.00 & 35.00 & $\$ / \mathrm{hr}$ \\
\hline
\end{tabular}


Table 4-12 Bulldozer Cost Analysis

\begin{tabular}{|c|c|c|c|}
\hline Parameters & Sandstone & Shale & $\underline{\text { Units }}$ \\
\hline Hourly production & 334 & 334 & bank $\mathrm{yd}^{3} / \mathrm{hr}$ \\
\hline Depreciation Value per Year (DV) & 336,600 & 336,600 & $\$$ \\
\hline Value to be Recovered Through Work (VR) & $1,683,000$ & $1,683,000$ & $\$$ \\
\hline Residual Value (RV) & 187,000 & 187,000 & $\$$ \\
\hline Capital Cost (CC) & 112.20 & 112.20 & $\$ / h r$ \\
\hline Interest Cost (INT) & 22.44 & 22.44 & $\$ / h r$ \\
\hline Insurance Cost (INSR) & 3.74 & 3.74 & $\$ / h r$ \\
\hline Tax Cost (TX) & 3.74 & 3.74 & $\$ / h r$ \\
\hline Ownership Cost (OC) & 142.12 & 142.12 & $\$ / h r$ \\
\hline Operating Cost (OPC) & 179.00 & 160.00 & $\$ / \mathrm{hr}$ \\
\hline Total Ripping and Pushing Cost & 321.12 & 302.12 & $\$ / \mathrm{hr}$ \\
\hline Total Ripping and Pushing Cost & 963,360 & 906,360 & $\$ /$ year \\
\hline Total Ripping and Pushing Cost & 0.96 & 0.91 & $\$ /$ bank yd $\mathrm{y}^{3}$ \\
\hline
\end{tabular}

The total ripping and pushing costs for sandstone and shale interburden material are $\$ 321.12$ and $\$ 302.12$ per hour, respectively, or $\$ 963,360$ and $\$ 906,360$ on an annual basis, respectively. The total cost per $\mathrm{yd}^{3}$ is $\$ 0.96$ and $\$ 0.91$ per $\mathrm{yd}^{3}$, respectively.

After the material has been ripped and pushed, a backhoe shovel is used for loading the material into haul trucks. The selection of a hydraulic backhoe is based on an hourly production rate of 334 bank $\mathrm{yd}^{3}$ of interburden material. The parameters and cost analysis for the backhoe shovel is given in Tables 4.13 and 4.14. 
Table 4-13 Interburden Backhoe Parameters

\begin{tabular}{lrrl}
\hline Parameters & Sandstone & Shale & Units \\
\hline Required production per year (RP) & $1,000,000$ & $1,000,000$ & bank yd bear $^{3}$.year \\
Operating Hours per Year (OHY) & 3,000 & 3,000 & hrs \\
Number of Cycles & 122 & 122 & \\
Availability & 85.00 & 85.00 & $\%$ \\
Operating Efficiency & 83.00 & 83.00 & $\%$ \\
Fill Factor & 85.00 & 90.00 & $\%$ \\
Machine Purchasing Cost (PC) & $1,600,000$ & $1,400,000$ & $\$$ \\
Horsepower & 760 & 730 & $\mathrm{HP}$ \\
Labor & 35.00 & 35.00 & $\$ / \mathrm{hr}$ \\
\hline
\end{tabular}

Table 4-14 Interburden Backhoe Cost Analysis

\begin{tabular}{|c|c|c|c|}
\hline Parameters & Sandstone & $\underline{\text { Shale }}$ & $\underline{\text { Units }}$ \\
\hline Hourly production & 334 & 334 & bank $\mathrm{yd}^{3} / \mathrm{hr}$ \\
\hline Bucket volume & 7.30 & 6.24 & $\mathrm{yd}^{3}$ \\
\hline Depreciation Value per Year (DV) & 240,000 & 210,000 & $\$$ \\
\hline Value to be Recovered Through Work (VR) & $1,440,000$ & $1,260,000$ & $\$$ \\
\hline Residual Value (RV) & 160,000 & 140,000 & $\$$ \\
\hline Capital Cost (CC) & 80.00 & 70.00 & $\$ / \mathrm{hr}$ \\
\hline Interest Cost (INT) & 18.67 & 16.33 & $\$ / \mathrm{hr}$ \\
\hline Insurance Cost (INSR) & 3.11 & 2.72 & $\$ / \mathrm{hr}$ \\
\hline Tax Cost (TX) & 3.11 & 2.72 & $\$ / \mathrm{hr}$ \\
\hline Ownership Cost (OC) & 104.89 & 91.78 & $\$ / \mathrm{hr}$ \\
\hline Fuel Cost (FC) & 92.42 & 88.77 & $\$ / \mathrm{hr}$ \\
\hline Maintenance, Wear Parts \& Labor & 80.00 & 70.00 & $\$ / \mathrm{hr}$ \\
\hline Operating Cost (OPC) & 207.42 & 193.77 & $\$ / \mathrm{hr}$ \\
\hline Total Digging and Loading Cost & 312.30 & 285.55 & $\$ / \mathrm{hr}$ \\
\hline Total Digging and Loading Cost & 936,915 & 856,637 & $\$ /$ year \\
\hline Total Digging and Loading Cost & 0.94 & 0.86 & $\$ /$ bank yd ${ }^{3}$ \\
\hline
\end{tabular}

The total loading costs for sandstone and shale interburden material are $\$ 312.30$ and $\$ 285.55$ per hour, respectively, or $\$ 936,915$ and $\$ 856,637$ on an annual basis, respectively. The cost of loading per bank $\mathrm{yd}^{3}$ is $\$ 0.94$ for sandstone and $\$ 0.86$ for shale material. 


\subsubsection{Conventional Coal Extraction and Crushing}

A hydraulic backhoe shovel is considered as the coal digging and loading equipment. An annual production of 1.5 million tons of bituminous coal is considered in this study. An overview of the parameters and cost assessment results for the hydraulic backhoe shovel is given in Tables 4.15 and 4.16 .

Table 4-15 Coal Extraction Parameters

\begin{tabular}{lrl}
\hline Parameters & Coal & Units \\
\hline Required production per year (RP) & $1,500,000$ & tons/year \\
Operating Hours per Year (OHY) & 3,000 & hrs \\
Number of Cycles & 115 & \\
Availability & 85.00 & $\%$ \\
Operating Efficiency & 83.00 & $\%$ \\
Fill Factor & 85.00 & $\%$ \\
Machine Purchasing Cost (PC) & $1,800,000$ & $\$$ \\
Horsepower & 760 & $\mathrm{HP}$ \\
Labor & 35.00 & $\$ / \mathrm{hr}$ \\
\hline
\end{tabular}


Table 4-16 Coal Extraction Cost Analysis

\begin{tabular}{lrl}
\hline Parameters & $\underline{\text { Coal }}$ & $\underline{\text { Units }}$ \\
\hline Hourly production & 500 & tons $/ \mathrm{hr}$ \\
Bucket volume & 9.06 & $\mathrm{yd}^{3}$ \\
Depreciation Value per Year (DV) & 231,429 & $\$$ \\
Value to be Recovered Through Work (VR) & $1,620,000$ & $\$$ \\
Residual Value (RV) & 180,000 & $\$$ \\
Capital Cost (CC) & 77.14 & $\$ / \mathrm{hr}$ \\
Interest Cost (INT) & 20.57 & $\$ / \mathrm{hr}$ \\
Insurance Cost (INSR) & 3.43 & $\$ / \mathrm{hr}$ \\
Tax Cost (TX) & 3.43 & $\$ / \mathrm{hr}$ \\
Ownership Cost (OC) & 104.57 & $\$ / \mathrm{hr}$ \\
Fuel Cost (FC) & 92.42 & $\$ / \mathrm{hr}$ \\
Maintenance, Wear Parts \& Labor & 96.00 & $\$ / \mathrm{hr}$ \\
Operating Cost (OPC) & 223.42 & $\$ / \mathrm{hr}$ \\
Total Digging and Loading Cost & 327.99 & $\$ / \mathrm{hr}$ \\
Total Digging and Loading Cost & 983,962 & $\$ / \mathrm{year}$ \\
Total Digging and Loading Cost & $\mathbf{0 . 6 6}$ & $\$ / \mathrm{ton}$ \\
\hline
\end{tabular}

The total digging and loading cost for bituminous coal is $\$ 327.99$ per hour or $\$ 936,962$ on an annual basis. The cost of digging and loading is $\$ 0.66$ per ton.

The selection of a crusher was based on the hourly production rate of 500 tons of coal being extracted by the backhoe shovel. The parameters and cost assessment results for the crusher is given in Tables 4.17 and 4.18. 
Table 4-17 Crushing Parameters

\begin{tabular}{lrl}
\hline Parameters & Coal & Units \\
\hline Required production per year (RP) & $1,500,000$ & tons/year \\
Operating Hours per Year (OHY) & 3,000 & hrs \\
Feed Size & 15.0 & in \\
Product Size & 4.0 & in \\
Material Lump Factor & 2.0 & \\
Bond's Work Index & 11.37 & $\mathrm{~kW} /$ tonne \\
Drive Efficiency & 0.85 & \\
Machine Purchasing Cost (PC) & 260,000 & $\$$ \\
Labor & 25.00 & $\$ / \mathrm{hr}$ \\
\hline
\end{tabular}

Table 4-18 Crushing Cost Analysis

\begin{tabular}{lrl}
\hline Parameters & $\underline{\text { Coal }}$ & $\underline{\text { Units }}$ \\
\hline Hourly production & 500 & tons/hr \\
Reduction Ratio & 3.8 & \\
Bond's Work per Tonne & 0.173 & $\mathrm{kWh} / \mathrm{tonne}$ \\
Power & 240 & $\mathrm{HP}$ \\
Depreciation Value per Year (DV) & 21,273 & $\$$ \\
Value to be Recovered Through Work (VR) & 234,000 & $\$$ \\
Residual Value (RV) & 26,000 & $\$$ \\
Capital Cost (CC) & 7.88 & $\$ / \mathrm{hr}$ \\
Interest Cost (INT) & 2.84 & $\$ / \mathrm{hr}$ \\
Insurance Cost (INSR) & 0.47 & $\$ / \mathrm{hr}$ \\
Tax Cost (TX) & 0.47 & $\$ / \mathrm{hr}$ \\
Ownership Cost (OC) & 11.66 & $\$ / \mathrm{hr}$ \\
Electricity Cost & 12.89 & $\$ / \mathrm{hr}$ \\
Wear Parts & 3.03 & $\$ / \mathrm{hr}$ \\
Spare Parts & 2.60 & $\$ / \mathrm{hr}$ \\
Operating Cost (OPC) & 43.52 & $\$ / \mathrm{hr}$ \\
Total Crushing Cost & 55.18 & $\$ / \mathrm{hr}$ \\
Total Crushing Cost & 165,537 & $\$ / \mathrm{year}$ \\
Total Crushing Cost & $\mathbf{0 . 1 1}$ & $\$ / \mathrm{ton}$ \\
\hline
\end{tabular}

The total crushing cost for bituminous coal is $\$ 55.18$ per hour or $\$ 165,537$ million on an annual basis, and $\$ 0.11$ per ton. 


\subsubsection{Surface Miner Method}

Two important parameters that need to be considered in the process of selection of SM are the unconfined compressive strength (UCS) and the abrasiveness of the rocks. The former is expressed in MPa or psi while the later by the Cerchar Abrasive Index (CAI). The CAI is used to describe the abrasiveness of a rock. The Cerchar Index was created in the 1970's by the Cerchar Institute in France (Rostami et al., 2005). The test consisted of scratching a rock surface with a steel pin and measuring the amount of wear, which defined the Cerchar Index. The amount of wear a pick experienced at varying values of abrasivity and UCS for both hard rock and coal can be seen in the Figure 4.1 and 4.2, respectively. These figures were obtained by plotting the pick wear equations described in chapter three. The equations and consequently the graphs are based on the pick wear data collected from a road header, which operated in similar conditions. Graphing the pick wear equations displays the amount of pick wear that can be expected based on the characteristics of the material. Referring to the pick wear graphs can provide and initial estimate of the cost of using the SM. It should be noted that the amount of wear caused by the hard rock and coal as calculated in Figures 4.1 and 4.2 may be higher than seen in the field. As expected, the more abrasive and the higher the compressive strength of the rock, the higher wear on the pick. 


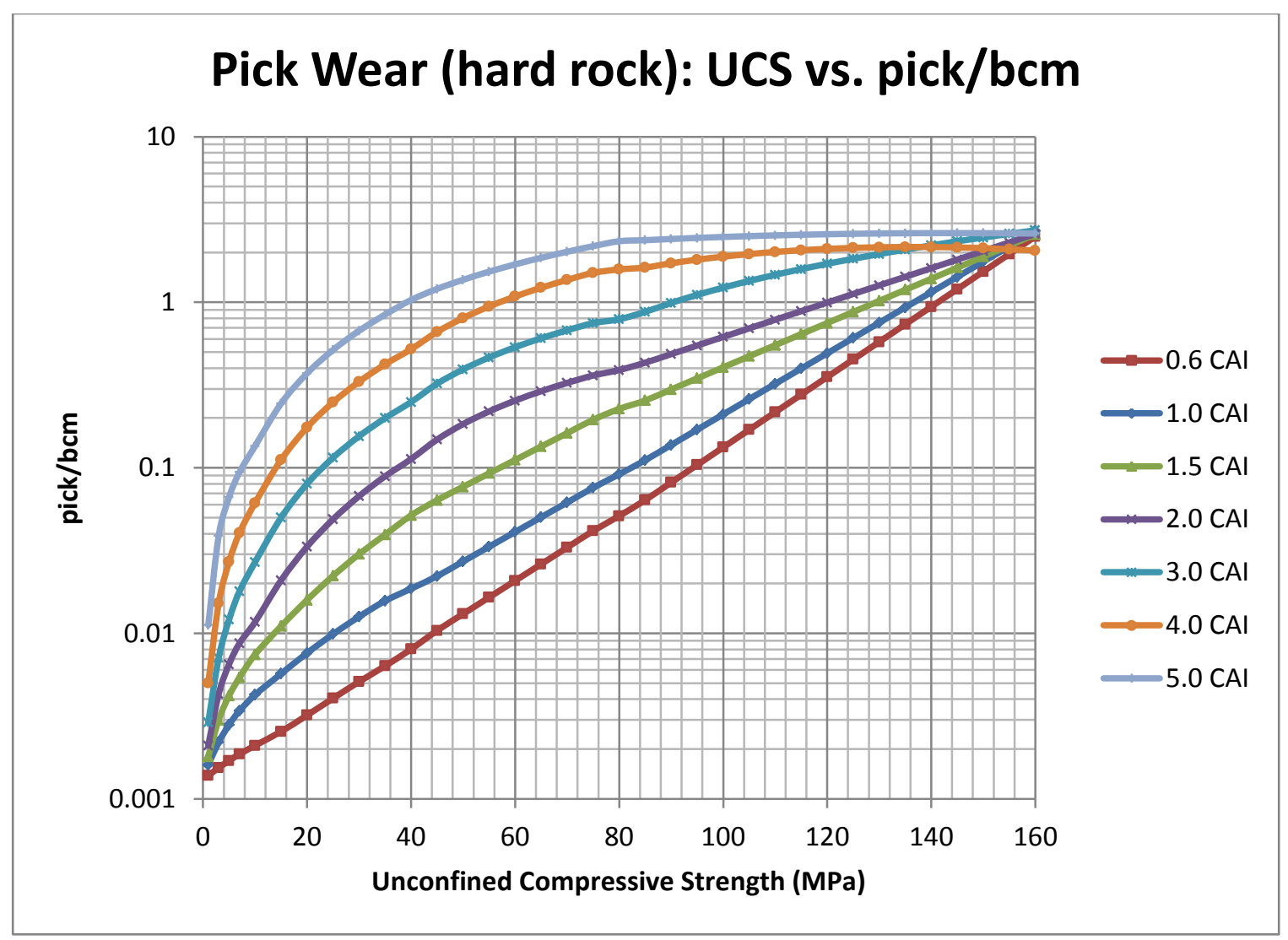

Figure 4-1 Pick Wear in Hard Rock 


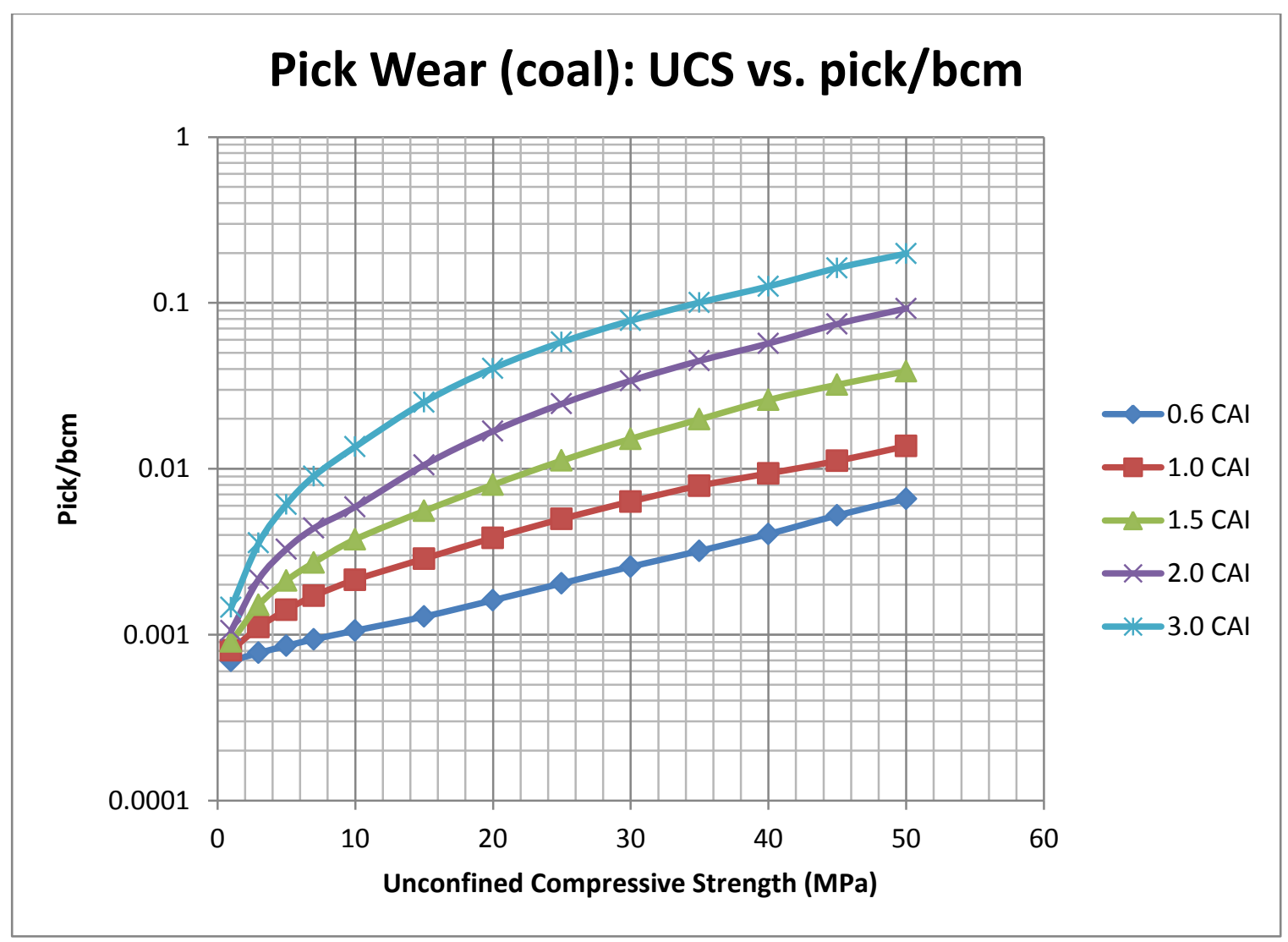

Figure 4-2 Pick Wear in Coal

Variations of practical cutting performance of the SM are given in Tables 4.19, 4.20, and 4.21 based on the compressive strength and abrasivity. These rates are given for the SM with the following properties: $8.2 \mathrm{ft}$ cutting drum and an engine output approximately $780 \mathrm{~kW}$. The practical cutting performance rates were calculated by using equation 3.18 described in chapter 3 . The figures are color-coded to show the ranges of production rates for this particular SM. 
Table 4-19 Surface Miner Performance in Sandstone (bank $\mathrm{yd}^{3} / \mathrm{hr}$ )

\begin{tabular}{|l|c|c|c|c|c|c|c|}
\hline & \multicolumn{8}{|c|}{ Sandstone (MPa) } \\
\hline & 60 & 70 & 80 & 90 & 100 & 110 & 120 \\
\hline $\mathrm{CAl}=.6$ & 630 & 495 & 383 & 287 & 207 & 143 & 93 \\
\hline $\mathrm{CAl}=1$ & 542 & 419 & 320 & 238 & 172 & 120 & 80 \\
\hline $\mathrm{CAl}=1.5$ & 364 & 273 & 206 & 160 & 120 & 89 & 63 \\
\hline $\mathrm{CAl}=2$ & 219 & 174 & 144 & 116 & 91 & 70 & 53 \\
\hline $\mathrm{CAl}=3$ & 123 & 98 & 83 & 66 & 53 & 44 & 36 \\
\hline $\mathrm{CAl}=4$ & 66 & 53 & 45 & 41 & 37 & 33 & 30 \\
\hline $\mathrm{CAl}=5$ & 44 & 37 & 32 & 30 & 29 & 27 & 26 \\
\hline
\end{tabular}

\begin{tabular}{|l|l|l|l|l|l|}
\hline Practical Cutting Performance (bank yd3/hr) & $>350$ & $350-250$ & $250-150$ & $150-50$ & $<50$ \\
\hline
\end{tabular}

Table 4-20 Surface Miner Performance in Shale (bank $\left.\mathrm{yd}^{3} / \mathrm{hr}\right)$

\begin{tabular}{|c|c|c|c|c|c|c|}
\hline & \multicolumn{6}{|c|}{ Shale (MPa) } \\
\hline & 60 & 70 & 80 & 90 & & 100 \\
\hline $\mathrm{CAl}=.6$ & 630 & 495 & 383 & 287 & & 207 \\
\hline $\mathrm{CAl}=1$ & 542 & 419 & 320 & 238 & & 172 \\
\hline $\mathrm{CAl}=1.5$ & 364 & 273 & 206 & 160 & & 120 \\
\hline$C A I=2$ & 219 & 174 & 144 & 116 & & 91 \\
\hline $\mathrm{CAI}=3$ & 123 & 98 & 83 & 66 & & 53 \\
\hline $\mathrm{CAl}=4$ & 66 & 53 & 45 & 41 & & 37 \\
\hline \multicolumn{3}{|c|}{ Practical Cutting Performance (bank yd3/hr) } & $350-250$ & $250-150$ & $150-50$ & $<50$ \\
\hline
\end{tabular}


Table 4-21 Surface Miner Performance in Coal (tons/hr)

\begin{tabular}{|l|c|c|c|c|c|}
\hline & \multicolumn{5}{|c|}{ Coal (MPa) } \\
\hline & 10 & 20 & 30 & 40 & 50 \\
\hline CAl=.6 & 1126 & 840 & 668 & 544 & 447 \\
\hline CAl=1 & 1110 & 821 & 648 & 526 & 430 \\
\hline CAl=1.5 & 1087 & 789 & 607 & 477 & 382 \\
\hline CAl=2 & 1058 & 729 & 535 & 406 & 307 \\
\hline CAl=3 & 965 & 606 & 418 & 305 & 222 \\
\hline
\end{tabular}

\begin{tabular}{|l|l|l|l|l|}
\hline Practical Cutting Performance (ton/hr) & $>800$ & $800-600$ & $600-400$ & $<400$ \\
\hline
\end{tabular}

The parameters and cost analysis for the SM in overburden material is given in Tables 4.22 and 4.23 .

Table 4-22 Surface Miner Parameters for Overburden

\begin{tabular}{lrrl}
\hline Parameters & $\underline{\text { Sandstone }}$ & $\underline{\text { Shale }}$ & $\underline{\text { Units }}$ \\
\hline Required production per year (RP) & $10,000,000$ & $10,000,000$ & bank yd bear $^{3}$ \\
Operating Hours per Year (OHY) & 6,000 & 6,000 & $\mathrm{hrs}$ \\
Cutting Depth (CD) & 1.48 & 1.48 & $\mathrm{ft}$ \\
Cutting Width (CW) & 8.20 & 8.20 & $\mathrm{ft}$ \\
Cutting Velocity (V) & 11.97 & 21.49 & $\mathrm{ft} / \mathrm{min}$ \\
Pick Wear (PW) & 0.017489 & 0.005527 & $\mathrm{pick} / \mathrm{bank} \mathrm{ft}^{3}$ \\
Machine Purchase Cost (PC) & $2,800,000$ & $2,800,000$ & $\$$ \\
Fuel Consumption at Full Load (FLC) & 50.6 & 50.6 & $\mathrm{gal} / \mathrm{hr}$ \\
Load Coefficient Factor (LCF) & 70.00 & 70.00 & $\%$ \\
Cutting Pick Cost & 17.04 & 17.04 & $\$ / \mathrm{pick}$ \\
Labor (LBC) & 35.00 & 35.00 & $\$ / \mathrm{hr}$ \\
\hline
\end{tabular}


Table 4-23 Surface Miner Cost Analysis for Overburden

\begin{tabular}{|c|c|c|c|}
\hline Parameters & Sandstone & Shale & Units \\
\hline Cutting Performance (Q) & 321.84 & 577.97 & bank yd ${ }^{3} / \mathrm{hr}$ \\
\hline Pick Changes per Row (NPC) & 84.67 & 26.76 & \\
\hline Pick Changing Time (PCT) & 423.34 & 133.78 & $\min$ \\
\hline Sump Time (ST) & 1.00 & 1.00 & $\min$ \\
\hline Turning Time (TT) & 0.92 & 0.92 & $\min$ \\
\hline Non-Cutting Time (NCT) & 0.00 & 0.00 & $\min$ \\
\hline Real Cutting Time (RCT) & 1,693 & 2,441 & hrs \\
\hline Practical Cutting Performance (PQ) & 90.80 & 235.14 & bank $\mathrm{yd}^{3} / \mathrm{hr}$ \\
\hline Maximum Production (MP) & 544,827 & $1,410,828$ & bank $\mathrm{yd}^{3} /$ year \\
\hline Number of Required Surface Miners & 19 & 8 & \\
\hline Usable Production (UP) & 526,316 & $1,250,000$ & bank yd $\mathrm{y}^{3} /$ year \\
\hline Real Operating Hours per Year (ROHY) & 5,796 & 5,316 & hrs \\
\hline Number of Picks Consumed (PCY) & 248,525 & 186,526 & picks/year \\
\hline Depreciation Value per Year (DV) & 252,000 & 252,000 & $\$$ \\
\hline Value to be Recovered Through Work (VR) & $2,520,000$ & $2,520,000$ & $\$$ \\
\hline Residual Value (RV) & 280,000 & 280,000 & $\$$ \\
\hline Capital Cost (CC) & 43.48 & 47.40 & $\$ / \mathrm{hr}$ \\
\hline Interest Cost (INT) & 15.94 & 17.38 & $\$ / \mathrm{hr}$ \\
\hline Insurance Cost (INS) & 2.66 & 2.90 & $\$ / \mathrm{hr}$ \\
\hline Tax Cost (TX) & 2.66 & 2.90 & $\$ / \mathrm{hr}$ \\
\hline Ownership Cost (OC) & 64.73 & 70.58 & $\$ / \mathrm{hr}$ \\
\hline Repair Cost (RC) & 38.65 & 42.14 & $\$ / \mathrm{hr}$ \\
\hline Fuel Cost (FC) & 113.32 & 113.32 & $\$ / \mathrm{hr}$ \\
\hline Grease Cost (GC) & 9.07 & 9.07 & $\$ / \mathrm{hr}$ \\
\hline Hydraulic Oil Cost (HO) & 1.45 & 1.45 & $\$ / \mathrm{hr}$ \\
\hline Water Cost (WC) & 0.00 & 0.00 & $\$ / \mathrm{hr}$ \\
\hline Pick Cost (PTC) & 730.63 & 597.89 & $\$ / \mathrm{hr}$ \\
\hline Operating Cost (OPC) & 928.12 & 804.71 & $\$ / \mathrm{hr}$ \\
\hline Total Cost per Surface Miner & 992.85 & 869.44 & $\$ / \mathrm{hr}$ \\
\hline Total Cost per Surface Miner & $5,754,720$ & $4,621,994$ & \$/year \\
\hline Total Surface Miner Cost & 10.93 & 3.70 & $\$ /$ bank yd ${ }^{3}$ \\
\hline
\end{tabular}


The total cost per SM for sandstone and shale are $\$ 992.85$ and $\$ 869.44$ per hour, or $\$ 5,754,720$ and $\$ 4,621,991$ on an annual basis, respectively. The overall total cost per bank $\mathrm{yd}^{3}$ is $\$ 10.93$ for sandstone and $\$ 3.71$ for shale material.

The parameters and cost analysis for the SM in interburden material is given in Tables 4.24 and 4.25 .

Table 4-24 Surface Miner Parameters for Interburden

\begin{tabular}{lrrl}
\hline Parameters & Sandstone & $\underline{\text { Shale }}$ & $\underline{\text { Units }}$ \\
\hline Required production per year (RP) & $1,000,000$ & $1,000,000$ & bank yd bear $^{3}$ \\
Operating Hours per Year (OHY) & 3,000 & 3,000 & $\mathrm{hrs}$ \\
Cutting Depth (CD) & 1.48 & 1.48 & $\mathrm{ft}$ \\
Cutting Width (CW) & 8.20 & 8.20 & $\mathrm{ft}$ \\
Cutting Velocity (V) & 11.97 & 21.49 & $\mathrm{ft} / \mathrm{min}$ \\
Pick Wear (PW) & 0.017489 & 0.005527 & $\mathrm{pick} / \mathrm{bank} \mathrm{ft}^{3}$ \\
Machine Purchase Cost (PC) & $2,800,000$ & $2,800,000$ & $\$$ \\
Fuel Consumption at Full Load (FLC) & 50.6 & 50.6 & $\mathrm{gal} / \mathrm{hr}$ \\
Load Coefficient Factor (LCF) & 70.00 & 70.00 & $\%$ \\
Cutting Pick Cost & 17.04 & 17.04 & $\$ / \mathrm{pick}$ \\
Labor (LBC) & 35.00 & 35.00 & $\$ / \mathrm{hr}$ \\
\hline
\end{tabular}


Table 4-25 Surface Miner Cost Analysis for Interburden

\begin{tabular}{|c|c|c|c|}
\hline Parameters & Sandstone & Shale & Units \\
\hline Cutting Performance $(\mathrm{Q})$ & 321.84 & 577.97 & bank yd ${ }^{3} / \mathrm{hr}$ \\
\hline Pick Changes per Row (NPC) & 84.67 & 26.76 & \\
\hline Pick Changing Time (PCT) & 423.34 & 133.78 & $\min$ \\
\hline Sump Time (ST) & 1.00 & 1.00 & $\min$ \\
\hline Turning Time (TT) & 0.92 & 0.92 & $\min$ \\
\hline Non-Cutting Time (NCT) & 0.00 & 0.00 & $\min$ \\
\hline Real Cutting Time (RCT) & 846 & 1,221 & hrs \\
\hline Practical Cutting Performance (PQ) & 90.80 & 235.14 & bank $\mathrm{yd}^{3} / \mathrm{hr}$ \\
\hline Maximum Production (MP) & 272,413 & 705,414 & bank $\mathrm{yd}^{3} /$ year \\
\hline Number of Required Surface Miners & 4 & 2 & \\
\hline Usable Production (UP) & 250,000 & 500,000 & bank yd $\mathrm{y}^{3} /$ year \\
\hline Real Operating Hours per Year (ROHY) & 2,753 & 2,126 & hrs \\
\hline Number of Picks Consumed (PCY) & 118,049 & 74,610 & picks/year \\
\hline Depreciation Value per Year (DV) & 252,000 & 252,000 & $\$$ \\
\hline Value to be Recovered Through Work (VR) & $2,520,000$ & $2,520,000$ & $\$$ \\
\hline Residual Value (RV) & 280,000 & 280,000 & $\$$ \\
\hline Capital Cost (CC) & 91.53 & 118.51 & $\$ / h r$ \\
\hline Interest Cost (INT) & 33.56 & 43.45 & $\$ / h r$ \\
\hline Insurance Cost (INS) & 5.59 & 7.24 & $\$ / \mathrm{hr}$ \\
\hline Tax Cost (TX) & 5.59 & 7.24 & $\$ / \mathrm{hr}$ \\
\hline Ownership Cost (OC) & 136.28 & 176.45 & $\$ / \mathrm{hr}$ \\
\hline Repair Cost (RC) & 81.36 & 105.34 & $\$ / \mathrm{hr}$ \\
\hline Fuel Cost (FC) & 113.32 & 113.32 & $\$ / \mathrm{hr}$ \\
\hline Grease Cost (GC) & 9.07 & 9.07 & $\$ / \mathrm{hr}$ \\
\hline Hydraulic Oil Cost (HO) & 1.45 & 1.45 & $\$ / \mathrm{hr}$ \\
\hline Water Cost (WC) & 0.00 & 0.00 & $\$ / \mathrm{hr}$ \\
\hline Pick Cost (PTC) & 730.63 & 597.89 & $\$ / h r$ \\
\hline Operating Cost (OPC) & $1,042.38$ & 973.79 & $\$ / \mathrm{hr}$ \\
\hline Total Cost per Surface Miner & $1,107.11$ & $1,038.52$ & $\$ / \mathrm{hr}$ \\
\hline Total Cost per Surface Miner & $3,048,072$ & $2,208,317$ & \$/year \\
\hline Total Surface Miner Cost & 12.19 & 4.42 & $\$ /$ bank yd ${ }^{3}$ \\
\hline
\end{tabular}


The total cost per SM for sandstone and shale are $\$ 1,107$ and $\$ 1,039$ per hour, or $\$ 2,048,072$ and $\$ 2,208,317$ on an annual basis, respectively. The overall total cost per bank $\mathrm{yd}^{3}$ is $\$ 12.19$ for sandstone and $\$ 4.42$ for shale material.

The parameters and cost analysis for the SM in bituminous coal is given in Tables 4.26 and 4.27.

Table 4-26 Surface Miner Parameters for Coal

\begin{tabular}{lrl}
\hline$\underline{\text { Parameters }}$ & $\underline{\text { Coal }}$ & $\underline{\text { Units }}$ \\
\hline Required production per year (RP) & $1,500,000$ & tons/year \\
Operating Hours per Year (OHY) & 3,000 & $\mathrm{hrs}$ \\
Cutting Depth (CD) & 1.48 & $\mathrm{ft}$ \\
Cutting Width (CW) & 8.20 & $\mathrm{ft}$ \\
Cutting Velocity (V) & 21.49 & $\mathrm{ft} / \mathrm{min}$ \\
Pick Wear (PW) & 0.000108 & $\mathrm{pick} / \mathrm{bank} \mathrm{ft}^{3}$ \\
Machine Purchase Cost (PC) & $2,800,000$ & $\$$ \\
Fuel Consumption at Full Load (FLC) & 50.6 & $\mathrm{gal} / \mathrm{hr}$ \\
Load Coefficient Factor (LCF) & 70.00 & $\%$ \\
Cutting Pick Cost & 17.04 & $\$ / \mathrm{pick}$ \\
Labor (LBC) & 35.00 & $\$ / \mathrm{hr}$ \\
\hline
\end{tabular}


Table 4-27 Surface Miner Cost Analysis for Coal

\begin{tabular}{|c|c|c|}
\hline Parameters & Coal & Units \\
\hline Cutting Performance (Q) & 878.12 & tons $/ \mathrm{hr}$ \\
\hline Pick Changes per Row (NPC) & 0.52 & \\
\hline Pick Changing Time (PCT) & 2.62 & $\min$ \\
\hline Sump Time (ST) & 1.00 & $\min$ \\
\hline Turning Time (TT) & 0.92 & $\min$ \\
\hline Non-Cutting Time (NCT) & 0.00 & $\min$ \\
\hline Real Cutting Time (RCT) & 2,807 & hrs \\
\hline Practical Cutting Performance (PQ) & 821.49 & bank $\mathrm{yd}^{3} / \mathrm{hr}$ \\
\hline Maximum Production (MP) & $2,464,477$ & tons/year \\
\hline Number of Required Surface Miners & 1 & \\
\hline Usable Production (UP) & $1,500,000$ & tons/year \\
\hline Real Operating Hours per Year (ROHY) & 1,826 & hrs \\
\hline Number of Picks Consumed (PCY) & 4,084 & picks/year \\
\hline Depreciation Value per Year (DV) & 252,000 & $\$$ \\
\hline Value to be Recovered Through Work (V & $2,520,000$ & $\$$ \\
\hline Residual Value (RV) & 280,000 & $\$$ \\
\hline Capital Cost (CC) & 138.01 & $\$ / \mathrm{hr}$ \\
\hline Interest Cost (INT) & 50.60 & $\$ / \mathrm{hr}$ \\
\hline Insurance Cost (INS) & 8.43 & $\$ / \mathrm{hr}$ \\
\hline Tax Cost (TX) & 8.43 & $\$ / \mathrm{hr}$ \\
\hline Ownership Cost (OC) & 205.48 & $\$ / \mathrm{hr}$ \\
\hline Repair Cost (RC) & 122.68 & $\$ / \mathrm{hr}$ \\
\hline Fuel Cost (FC) & 113.32 & $\$ / \mathrm{hr}$ \\
\hline Grease Cost (GC) & 9.07 & $\$ / \mathrm{hr}$ \\
\hline Hydraulic Oil Cost (HO) & 1.45 & $\$ / \mathrm{hr}$ \\
\hline Water Cost (WC) & 0.00 & $\$ / \mathrm{hr}$ \\
\hline Pick Cost (PTC) & 38.11 & $\$ / \mathrm{hr}$ \\
\hline Operating Cost (OPC) & 460.38 & $\$ / \mathrm{hr}$ \\
\hline Total Cost per Surface Miner & 525.11 & $\$ / \mathrm{hr}$ \\
\hline Total Cost per Surface Miner & 958,825 & \$/year \\
\hline Total Surface Miner Cost & 0.64 & $\$ /$ ton \\
\hline
\end{tabular}

The total cost for bituminous coal is $\$ 525.11$ per hour or $\$ 958,825$ on annual basis. The cost per ton of bituminous coal is $\$ 0.64$. The combination of the values determined in this section form a benchmark for the each of the mining methods to be compared in the following section. 


\subsubsection{Comparison of Mining Methods}

Figure 4.3 shows the cost of the extraction of sandstone overburden (UCS: $100 \mathrm{MPa}$, CAI: 2) for four different scenarios: drilling, blasting, and hydraulic shovel (scenario \#1); drilling, blasting, and electric shovel (scenario \#2); drilling, blasting, and front-end loader (scenario \#3); and SM (scenario \#4). Scenario \#2 yields the lowest cost of \$2.24 per bank $\mathrm{yd}^{3}$, followed by, in increasing order, scenario \#1 with the cost of $\$ 2.36$ per bank $\mathrm{yd}^{3}$, scenario \#3 with the cost of $\$ 2.38$ per bank $\mathrm{yd}^{3}$, and scenario \#4 with the cost of $\$ 10.93$ per bank cubic yard.

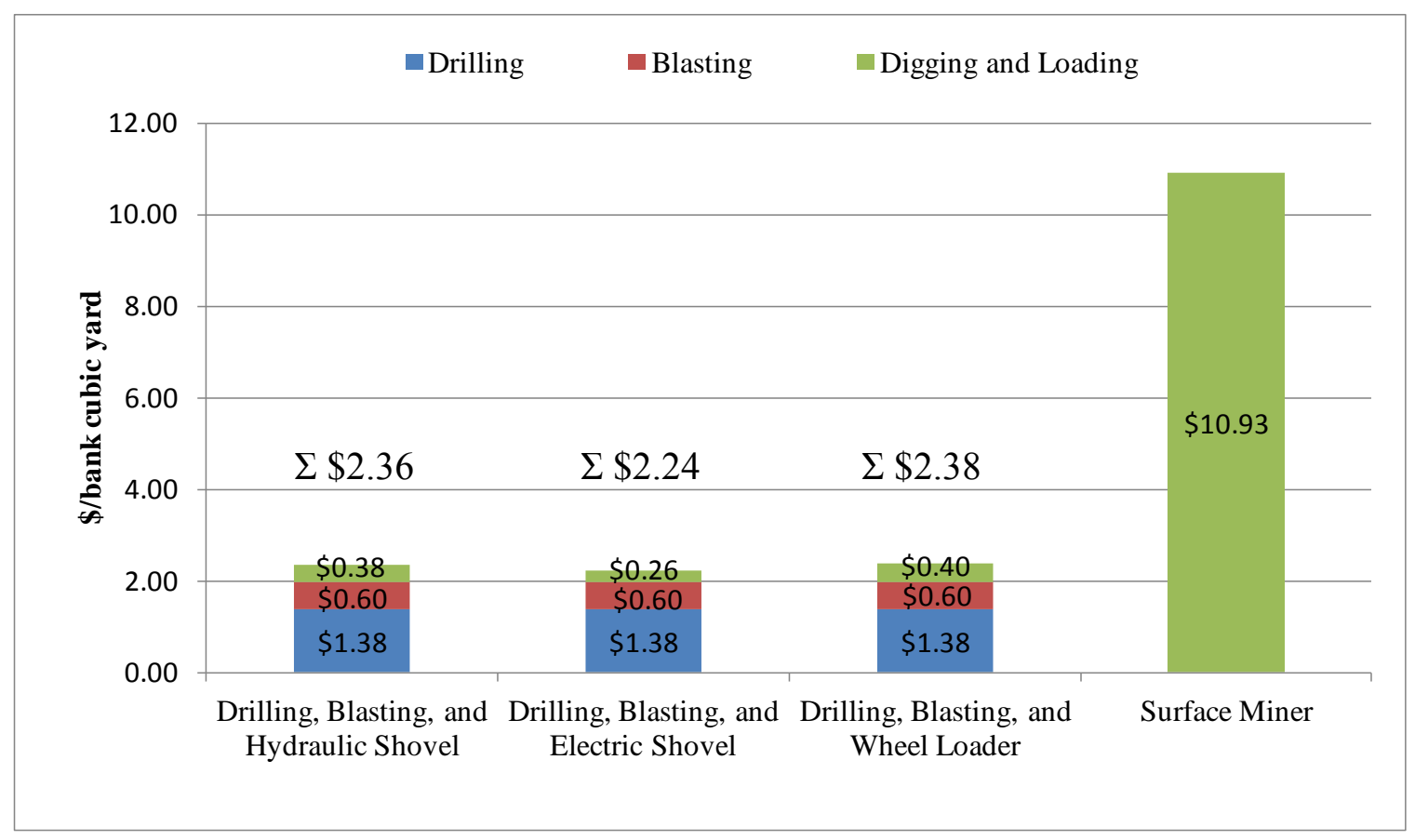

Figure 4-3 Conventional vs. SM Mining Method Comparison in Sandstone Overburden

Scenario \#4, which uses only the SM, is much less economical than each of the other scenarios for the considered rock properties. The costs for a varying range of rock properties have been calculated for each of the applications of the SM. The variances in 
costs based on the UCS and CAI of the material being extracted are displayed in Table 4.28. These values provide an idea for where the applicability of this machine could be. Table 4.28 shows that as the UCS and CAI decreases, the possible application of this machine increases. The material with higher UCS and CAI than what is shown results in costs that are obviously too high for any application and are disregarded.

Table 4-28 Total Cost of SM per Cubic Yard in Sandstone Overburden

\begin{tabular}{|l|c|c|c|c|c|c|}
\hline OB & \multicolumn{5}{|c|}{ Sandstone (MPa) } \\
\hline & 60 & 70 & 80 & 90 & 100 & 110 \\
\hline $\mathrm{CAl}=.6$ & $\$ 0.70$ & $\$ 0.99$ & $\$ 1.38$ & $\$ 1.97$ & $\$ 3.04$ & $\$ 4.66$ \\
\hline $\mathrm{CAl}=1$ & $\$ 1.07$ & $\$ 1.42$ & $\$ 2.05$ & $\$ 2.88$ & $\$ 4.26$ & $\$ 6.36$ \\
\hline $\mathrm{CAl}=1.5$ & $\$ 2.19$ & $\$ 3.11$ & $\$ 4.26$ & $\$ 5.52$ & $\$ 7.43$ & $\$ 10.10$ \\
\hline $\mathrm{CAl}=2$ & $\$ 4.52$ & $\$ 5.75$ & $\$ 6.90$ & $\$ 8.61$ & $\$ 10.93$ & $\$ 13.92$ \\
\hline
\end{tabular}

\begin{tabular}{|l|l|l|l|l|}
\hline Total Cost $\left(\$ / \mathrm{yd}^{3}\right)$ & $<\$ 1.50$ & $\$ 1.50-\$ 3.00$ & $\$ 3.00-\$ 4.50$ & $>\$ 4.50$ \\
\hline
\end{tabular}

Figure 4.4 shows the cost of extraction of shale overburden (UCS: 75 MPa, CAI: 1.5) for four different scenarios: drilling, blasting, and hydraulic shovel (scenario \#1); drilling, blasting, and electric shovel (scenario \#2); drilling, blasting, and wheel loader (scenario \#3); and SM (scenario \#4). Once again, scenario \#2 yields the lowest cost of $\$ 1.41$ per bank $\mathrm{yd}^{3}$, followed by, in increasing order, scenario \#1 with the cost of $\$ 1.51$ per bank $\mathrm{yd}^{3}$, scenario \#3 with the cost of $\$ 1.53$ per bank $\mathrm{yd}^{3}$, and scenario \#4 with the cost of $\$ 3.70$ per bank $\mathrm{yd}^{3}$. 


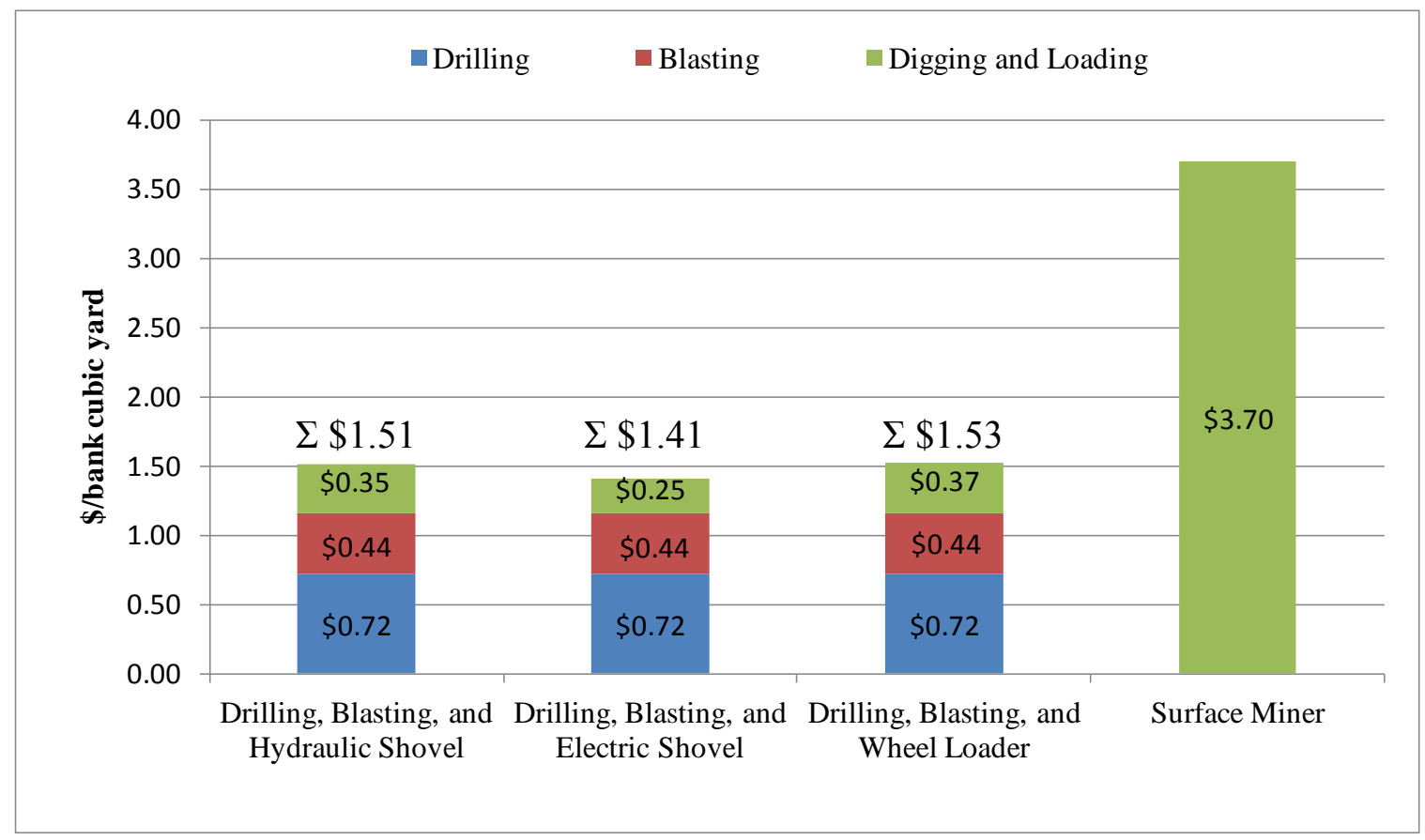

Figure 4-4 Conventional vs. SM Mining Method Comparison in Shale Overburden

Scenario \#4 is much higher in cost when compared to the remaining three scenarios. This is the situation created when calculating the costs based on the average property values as stated in module one. Table 4.29 shows the SM costs for various values of UCS and CAI in shale overburden. The same trend as seen in sandstone overburden exists in shale, the lower the UCS and CAI, the lower the costs will be.

Table 4-29 Total Cost of SM per Cubic Yard in Shale Overburden

\begin{tabular}{|l|c|c|c|c|c|c|}
\hline OB & \multicolumn{6}{|c|}{ Shale (MPa) } \\
\hline & 50 & 60 & 70 & 80 & 90 & 100 \\
\hline $\mathrm{CAl}=.6$ & $\$ 0.55$ & $\$ 0.70$ & $\$ 0.99$ & $\$ 1.38$ & $\$ 1.97$ & $\$ 3.04$ \\
\hline $\mathrm{CAl}=1$ & $\$ 0.76$ & $\$ 1.07$ & $\$ 1.42$ & $\$ 2.05$ & $\$ 2.88$ & $\$ 4.26$ \\
\hline $\mathrm{CAl}=1.5$ & $\$ 1.57$ & $\$ 2.19$ & $\$ 3.11$ & $\$ 4.26$ & $\$ 5.52$ & $\$ 7.43$ \\
\hline $\mathrm{CAl}=2$ & $\$ 3.30$ & $\$ 4.52$ & $\$ 5.75$ & $\$ 6.90$ & $\$ 8.61$ & $\$ 10.93$ \\
\hline
\end{tabular}

\begin{tabular}{|l|l|l|l|r|}
\hline Total Cost $\left(\$ / \mathrm{yd}^{3}\right)$ & $<\$ 1.00$ & $\$ 1.00-\$ 2.00$ & $\$ 2.00-\$ 3.00$ & $>\$ 3.00$ \\
\hline
\end{tabular}


The overburden calculations provide an estimated comparison that could be expected if the given conditions were encountered in the field. While the SM is more expensive in each type of overburden, it is much more expensive in the stronger and more abrasive sandstone than in shale. If the UCS and CAI are found to be lower, the likelihood of using the SM in shale will be higher than in sandstone.

Figure 4.5 shows the cost of extraction of sandstone interburden for two different scenarios: ripping and pushing by bulldozer and loading by backhoe shovel (scenario \#1); and SM (scenario \#2). Scenario \#1 yields the cost of $\$ 1.90$ per bank $\mathrm{yd}^{3}$, while the cost for scenario \#2 is $\$ 12.19$ per bank $\mathrm{yd}^{3}$.

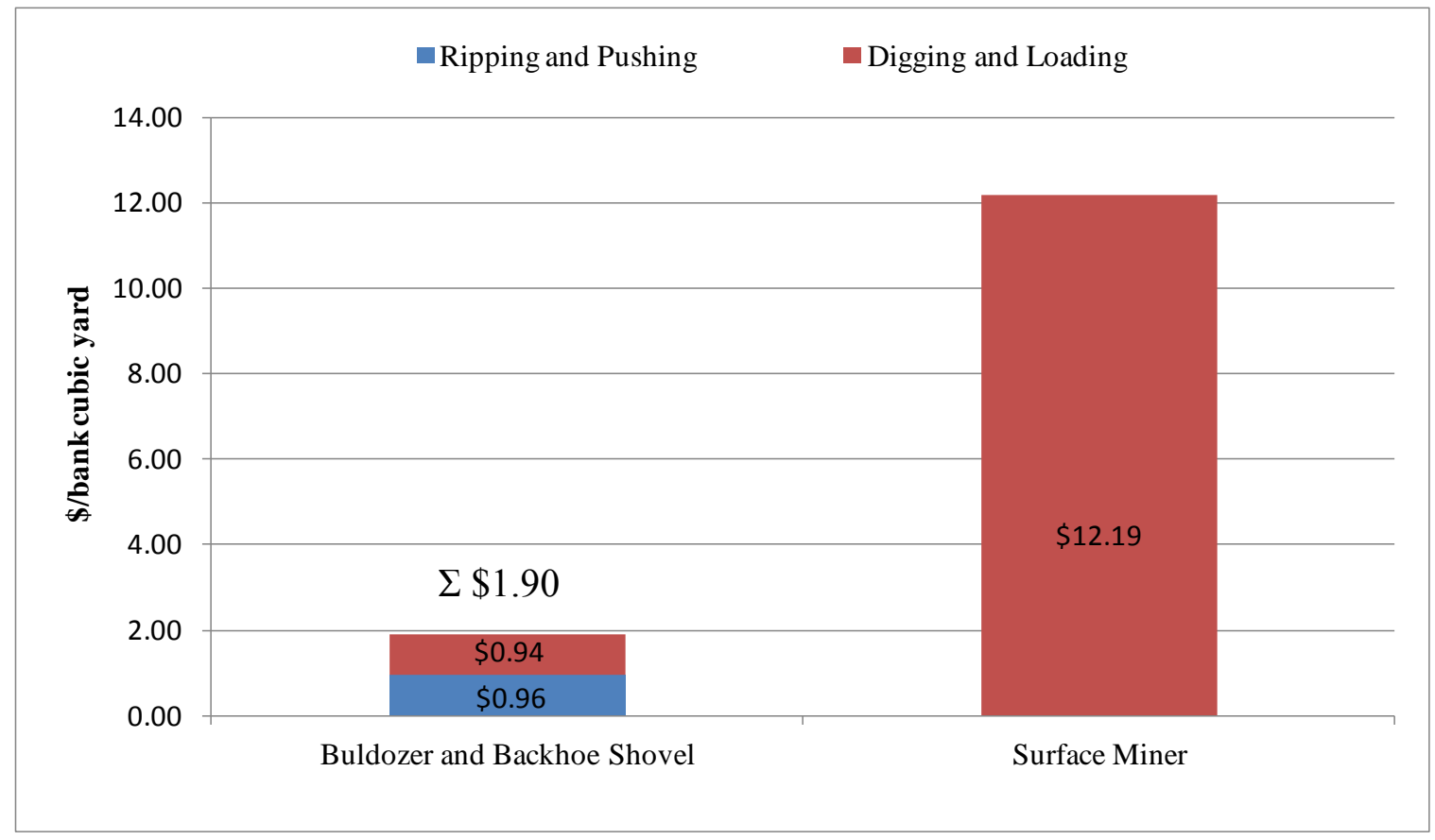

Figure 4-5 Conventional vs. SM Mining Method Comparison in Sandstone Interburden 
Table 4.30 shows the SM costs for various values of UCS and CAI in sandstone overburden. The same trend as seen in sandstone overburden can be observed for sandstone interburden.

Table 4-30 Total Cost of SM per Cubic Yard in Sandstone Interburden

\begin{tabular}{|l|c|c|c|c|c|c|}
\hline IB & \multicolumn{6}{|c|}{ Sandstone (MPa) } \\
\hline & 60 & 70 & 80 & 90 & 100 & 110 \\
\hline CAl=.6 & $\$ 1.12$ & $\$ 1.35$ & $\$ 1.68$ & $\$ 2.81$ & $\$ 3.70$ & $\$ 5.74$ \\
\hline CAl=1 & $\$ 1.43$ & $\$ 1.78$ & $\$ 2.89$ & $\$ 3.66$ & $\$ 4.86$ & $\$ 7.31$ \\
\hline CAl=1.5 & $\$ 2.49$ & $\$ 3.89$ & $\$ 4.92$ & $\$ 6.66$ & $\$ 8.39$ & $\$ 11.36$ \\
\hline CAl=2 & $\$ 5.24$ & $\$ 6.35$ & $\$ 7.98$ & $\$ 9.51$ & $\$ 12.19$ & $\$ 15.48$ \\
\hline
\end{tabular}

\begin{tabular}{|l|l|l|l|l|}
\hline Total $\operatorname{Cost}\left(\$ / \mathrm{yd}^{3}\right)$ & $<\$ 2.00$ & $\$ 2.00-\$ 3.00$ & $\$ 3.00-\$ 4.00$ & $>\$ 4.00$ \\
\hline
\end{tabular}

Figure 4.6 shows the cost of extraction of shale interburden material for two different scenarios: ripping and pushing by bulldozer and loading by backhoe shovel (scenario \#1); and SM (scenario \#2). Here, scenario \#1 yields the cost of $\$ 1.77$ per bank $\mathrm{yd}^{3}$, while the cost for scenario \#2 is $\$ 4.42$ per bank $\mathrm{yd}^{3}$. 


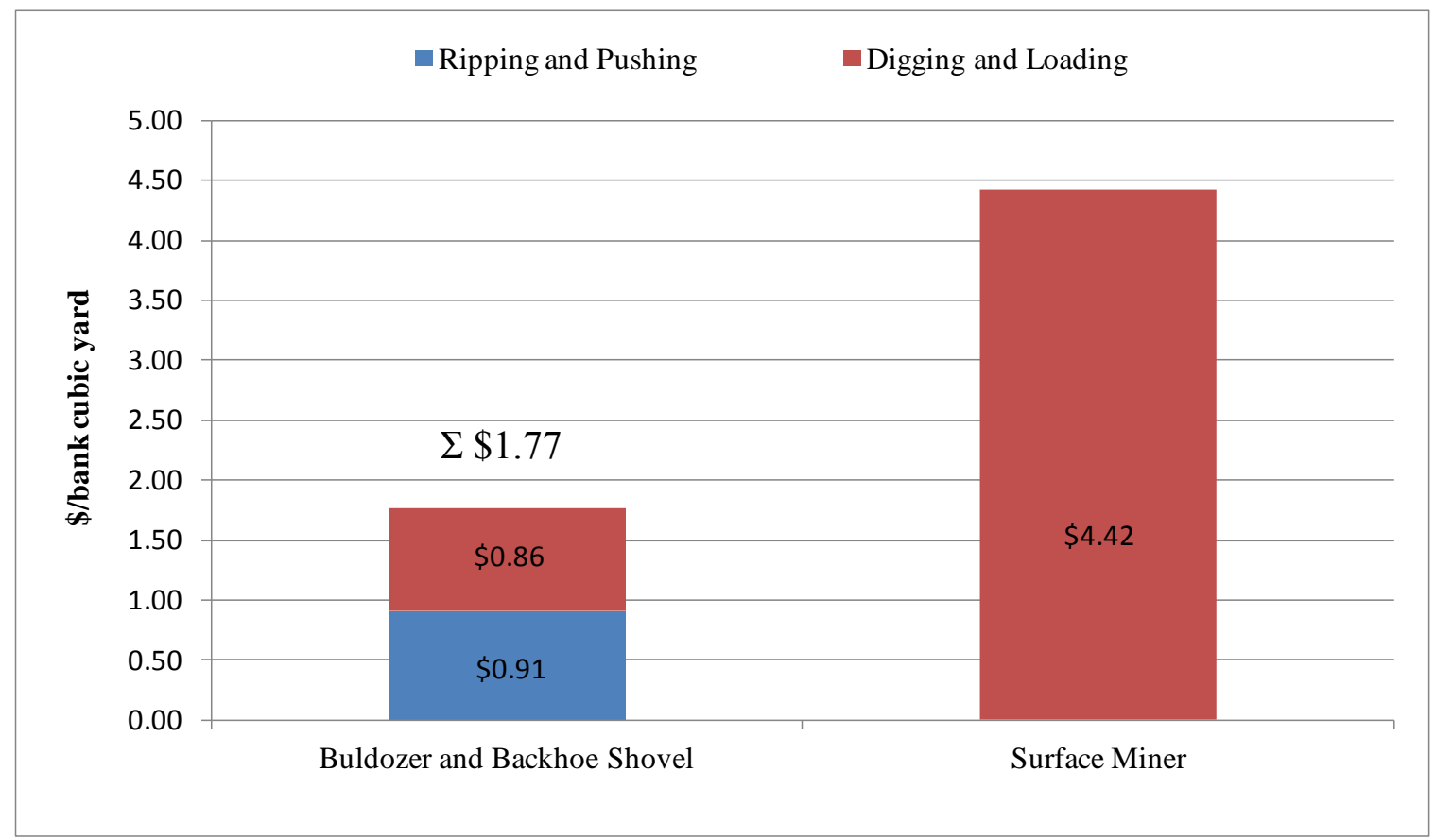

Figure 4-6 Conventional vs. SM Mining Method Comparison in Shale Interburden

Again, using the SM in a shale type interburden would be less economical than the conventional mining methods. The costs of the SM operating in shale interburden for various values of UCS and CAI are displayed in Table 4.31.

Table 4-31 Total Cost of SM per Cubic Yard in Shale Interburden

\begin{tabular}{|c|c|c|c|c|c|c|}
\hline \multirow[t]{2}{*}{ IB } & \multicolumn{6}{|c|}{ Shale (MPa) } \\
\hline & 50 & 60 & 70 & 80 & 90 & 100 \\
\hline $\mathrm{CAl}=.6$ & $\$ 0.97$ & $\$ 1.12$ & $\$ 1.35$ & $\$ 1.68$ & $\$ 2.81$ & $\$ 3.70$ \\
\hline $\mathrm{CAl}=1$ & $\$ 1.18$ & $\$ 1.43$ & $\$ 1.78$ & $\$ 2.29$ & $\$ 3.06$ & $\$ 4.26$ \\
\hline $\mathrm{CAl}=1.5$ & $\$ 1.93$ & $\$ 2.49$ & $\$ 3.89$ & $\$ 4.92$ & $\$ 6.66$ & $\$ 8.39$ \\
\hline $\mathrm{CAl}=2$ & $\$ 4.14$ & $\$ 5.24$ & $\$ 6.35$ & $\$ 7.98$ & $\$ 9.51$ & $\$ 12.19$ \\
\hline \multicolumn{3}{|c|}{ Total Cost $\left(\$ / y d^{3}\right)$} & $<\$ 1.00$ & $\$ 1.00-\$ 2.00$ & $\$ 2.00-\$ 3.00$ & $>\$ 3.00$ \\
\hline
\end{tabular}


The interburden calculations provide an estimated comparison that could be expected if the given condition were encountered. While the SM is more expensive in each type of interburden, it is much more expensive in the stronger and more abrasive sandstone than in shale. If the UCS and CAI are found to be lower, the likelihood of using the SM in shale would be higher than in sandstone.

Figure 4.7 shows the cost of extraction of bituminous coal for two different scenarios: digging and loading with backhoe shovel and crushing (scenario \#1); and SM (scenario $\# 2$ ). Here, scenario \#2 yields the lowest cost of $\$ 0.64$ per ton, while the cost for scenario $\# 1$ is $\$ 0.77$ per ton of coal.

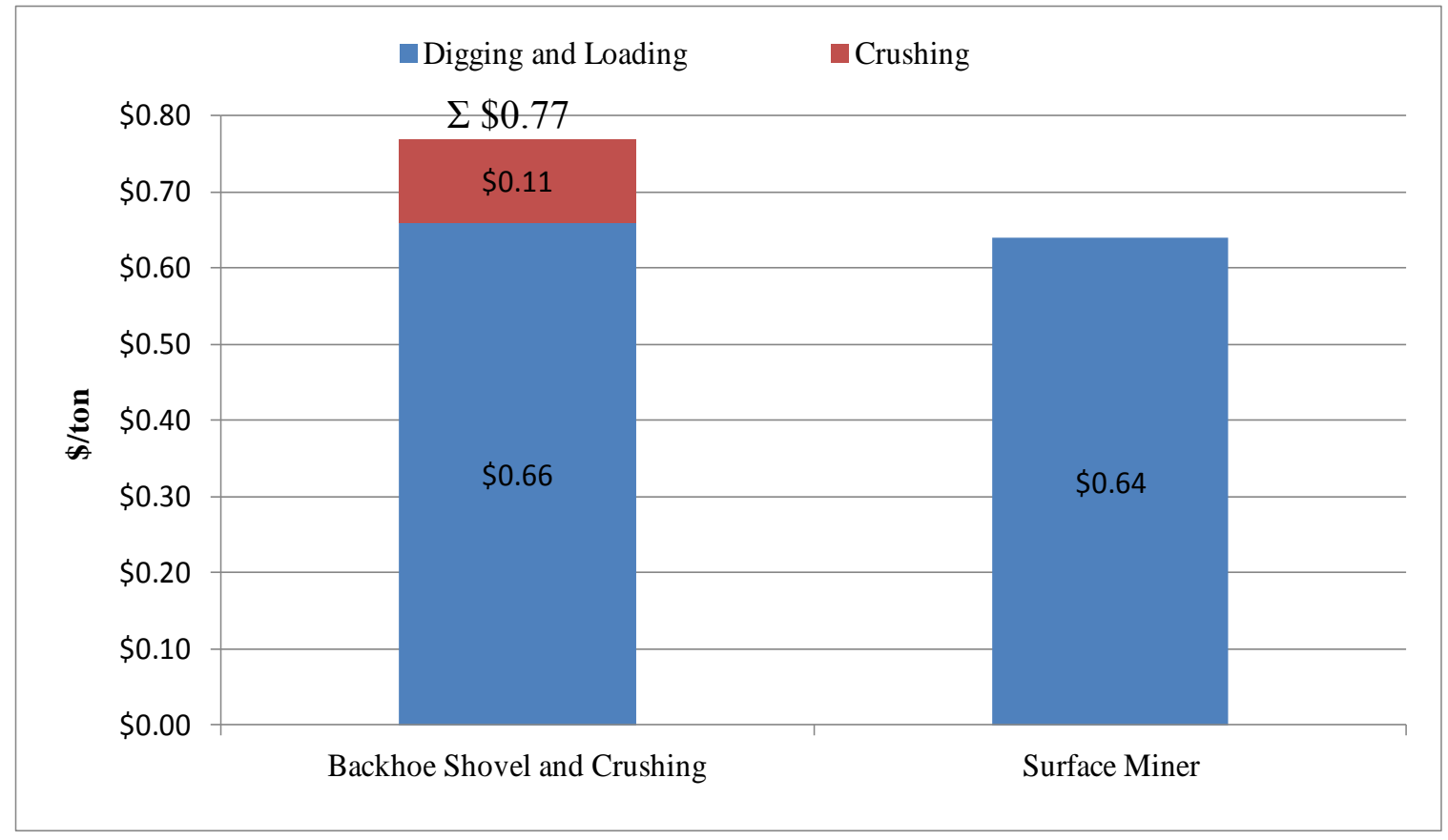

Figure 4-7 Conventional vs. SM Mining Method Comparison in Coal 
Unlike the previous comparison, the SM was calculated to be the most economical option for the extraction of bituminous coal. As the SM is less expensive than the conventional extraction method, a crushing unit could be added to the SM mining method if necessary and still be the more economical mining option. As with the previous comparison the values for costs of the SM in varying coal properties have been calculated and displayed in Table 4.32. This table shows much more favorable results than the previous ones. If the coal properties vary in either direction, the cost of the SM will likely still be lower than the conventional mining methods.

Table 4-32 Total Cost of SM per Ton in Bituminous Coal

\begin{tabular}{|l|c|c|c|c|c|}
\hline & \multicolumn{5}{|c|}{ Coal (MPa) } \\
\hline & 10 & 20 & 30 & 40 & 50 \\
\hline CAl=.6 & $\$ 0.55$ & $\$ 0.61$ & $\$ 0.67$ & $\$ 0.74$ & $\$ 1.23$ \\
\hline CAl=1 & $\$ 0.57$ & $\$ 0.64$ & $\$ 0.72$ & $\$ 0.85$ & $\$ 1.33$ \\
\hline CAl=1.5 & $\$ 0.59$ & $\$ 0.70$ & $\$ 0.84$ & $\$ 1.45$ & $\$ 1.68$ \\
\hline CAl=2 & $\$ 0.62$ & $\$ 0.82$ & $\$ 1.11$ & $\$ 1.88$ & $\$ 2.44$ \\
\hline CAl=3 & $\$ 0.73$ & $\$ 1.15$ & $\$ 2.13$ & $\$ 2.85$ & $\$ 4.32$ \\
\hline
\end{tabular}

\begin{tabular}{|l|l|l|l|l|}
\hline Total Cost $(\$ /$ ton) & $<\$ 1.00$ & $\$ 1.00-\$ 2.00$ & $\$ 2.00-\$ 3.00$ & $>\$ 3.00$ \\
\hline
\end{tabular}

The comparison of the conventional mining method and the SM mining method have shown that for the values tested in this research, the SM will only be more economical in the coal mining process. However, for overburden and interburden materials, the conventional mining methods are the more economical option. 


\subsubsection{Surface Miner Benefits}

A benefit of introducing SMs to surface coal mining in WV would be an environmental one. If the conditions are favorable and the SM can be applied, most of the blasting processes that concern communities can potentially be eliminated. Specifically, SM usage can eliminate the generation of flyrock, toxic fumes, ground vibration, and surface vibration created by air-blast. While these issues are not frequent when blasting, the possibility still exists and this is a tremendous opportunity to address these environmental issues. In addition, the application of SMs enables clean cut edges and benches and very stable benched highwalls as opposed to blasted edges. The crushing process provided directly by the machine generates an even grade $(96 \%<6$ ") of small particle sizes that can either be sold as secondary product (such as road base) or the material could also be used without further treatment for the reclamation process (Wirtgen, 2010).

The elevated grade control eliminates the need of at least the secondary crusher and possibly even (depending on the material) the need for a primary crusher. The SM creates a complete even and smooth surface, which leads to reduced damage to vehicles and tires. The mine operator has continuous control over drainage because the SM is able to cut a slope.

\subsubsection{AHP Results and Analysis}

The results of the cost and production analysis indicate that the SM would be applicable for the coal extraction phase. The cost comparison does not account for the negative or positive environmental factors created by either mining method. For this reason the use 
of the AHP for optimal mining method selection adds a vital piece of information to the overall judgment by considering these additional factors. The selection of the optimal mining method was developed by the author of this thesis. Since the AHP is based on the user-defined input values, the results will be subjective to the user's preferences. To combat the subjective nature of the AHP, a sensitivity analysis of the results was included.

The values in the comparison matrices were determined based on the user's knowledge and point of view in this case the user is the author of this thesis. The level of importance of each issue/criteria can be decided on when all aspects of surface coal mining in WV have been considered. When comparing production to cost it was decided that production is 1.2 times more important than cost. When comparing cost to environmental issues it was decided that environmental issues were 1.4 times more important than cost. When comparing production to environmental issues it was decided that environmental issues were 1.5 times more important than production. Finally, when comparing ownership cost to operating cost it was decided that operating cost is 1.1 times more important than ownership cost, due to the variations in operating cost over the life of the operation. The scale used for the comparison matrices ranges from 1 to 9 , as seen in Figure 3.4, with 9 representing an extremely important issue/criterion. The values decided on for these matrices represent small variations in the level of importance and still affect the outcome. These values are entirely biased to the user and will differ from user to user. To provide the most neutral outcome it is important to have multiple users 
input values. The pairwise comparison matrices for the mining method selection can be seen in Table 4.33 .

Table 4-33 Pairwise Comparison Judgment Matrices for the Selection of the Optimal Mining Method

\begin{tabular}{lcccl}
\hline Goal & Costs & Production & Environmental & Priority \\
\hline Costs & 1 & 0.8 & 0.7 & 0.275 \\
Production & 1.2 & 1 & 0.6 & 0.304 \\
Environmental & 1.4 & 1.5 & 1 & 0.420 \\
& & & $\mathrm{CR}=0.01$ \\
\hline Cost & Ownership Cost & Operating Cost & Priority \\
\hline Ownership Cost & 1 & 0.9 & 0.476 \\
Operating Cost & 1.1 & 1 & & 0.524 \\
& & & & $\mathrm{CR}=0.0$ \\
\hline
\end{tabular}

The values given to each comparison can be seen in Table 4.33. The eigenvalues, or priority matrix, of the comparison matrices yields the priority weights for costs, production, environmental, ownership cost, and operating cost. These values are 0.275 , 0.304, 0.420, 0.476, and 0.524, respectively. Finally, a Consistency Ratio (CR) is determined and for each comparison matrix. The CR is calculated to measure how consistent the judgments of the user have been when compared to large samples of random judgments (Coyle, 2004). They are considered acceptable because the CR is less than 0.10 .

The next step in the AHP was to generate the global weights for each criterion involved in the AHP model. The global weight combines all local weights from each level to achieve an overall weight. These global weights can be seen in Table 4.34. 
Table 4-34 Composite Priority Weights for Critical Factors

\begin{tabular}{lllll}
\hline Strategic Issues & Local Weights & Criteria & Local Weights & Global Weights \\
\hline Costs & 0.275 & Ownership Cost & 0.476 & 0.131 \\
& & Operating Cost & 0.524 & 0.144 \\
Production & 0.304 & Production Rate & 1.000 & 0.304 \\
Environmental & 0.420 & Blasting Hazards & 1.000 & 0.420 \\
\hline
\end{tabular}

The local weights for each strategic issue and criteria are displayed in Table 4.34. Global weights account for all of the local weights and the capital cost, operating cost, production rate, and blasting hazards are $0.131,0.144,0.304$, and 0.420 , respectively. Blasting hazards has the highest weight, as seen in Table 4.34, due to the level of importance placed on the environmental issues in the comparison matrices. A ranking of the highest to lowest global weights is shown in Table 4.35.

Table 4-35 Ranking of Critical Factors

\begin{tabular}{lll}
\hline Rank & Criteria & Global Weights \\
\hline 1 & Blasting Hazards & 0.420 \\
2 & Production Rate & 0.304 \\
3 & Operating Cost & 0.144 \\
4 & Ownership Cost & 0.131 \\
\hline
\end{tabular}


The Global Weights $(\mathrm{GW})$ show what criteria will have the most effect on the decision making process. Table 4.36 shows the ratings and scores applied to each of the criteria and the resulting adjusted global weight. The rating scores are as follows:

- Outstanding $(\mathrm{O})-0.513$

- $\operatorname{Good}(\mathrm{G})-0.261$

- Average (A) - 0.129

- $\quad$ Fair $(\mathrm{F})-0.063$

- $\operatorname{Poor}(\mathrm{P})-0.034$

Table 4-36 Application of the AHP Model to Mining Method Selection

\begin{tabular}{|c|c|c|c|c|c|c|c|}
\hline \multirow{2}{*}{$\begin{array}{l}\text { Strategic Issues } \\
\text { Criteria }\end{array}$} & \multirow{2}{*}{$\begin{array}{l}\text { Global } \\
\text { Weights }\end{array}$} & \multicolumn{3}{|c|}{ Conventional Mining Method } & \multicolumn{3}{|c|}{ Surface Miner Method } \\
\hline & & Rating & Score & $\mathrm{xGW}$ & Rating & Score & $x G W$ \\
\hline \multicolumn{8}{|l|}{ Cost } \\
\hline Ownership Cost & 0.131 & A & 0.129 & 0.0169 & A & 0.129 & 0.0169 \\
\hline Operating Cost & 0.144 & G & 0.261 & 0.0377 & $\mathrm{P}$ & 0.034 & 0.0049 \\
\hline \multicolumn{8}{|l|}{ Production } \\
\hline Production Rate & 0.304 & $\mathrm{O}$ & 0.513 & 0.1561 & $\mathrm{~A}$ & 0.129 & 0.0393 \\
\hline \multicolumn{8}{|l|}{ Environmental } \\
\hline Blasting Hazards & 0.420 & $\mathrm{P}$ & 0.034 & 0.0143 & $\mathrm{O}$ & 0.513 & 0.2156 \\
\hline Total Scores & & & & 0.2250 & & & 0.2767 \\
\hline Renormalized Scores & & & & 0.4485 & & & 0.5515 \\
\hline
\end{tabular}

The results shown in Table 4.36 indicate that the SM mining method is the better option due to the high weight associated with the environmental strategic issue. Figure 4.8 shows the results of the AHP with the global weights and scores in Table 4.36 as percentages. In Figure 4.8 each mining method has a designated color, red for the SM mining method and blue for the conventional mining method. As each line crosses a strategic issue (cost, production, or environment) it represents the level of importance for that issues. These are simply used to visually assist in understanding the strengths and 
weaknesses for each mining method. For example, the conventional mining method is more important in terms of cost and production as seen by the blue line being higher than the red in those two categories. The results of performing the AHP provide the global weights for each criterion and the final weight or priority of the alternatives.

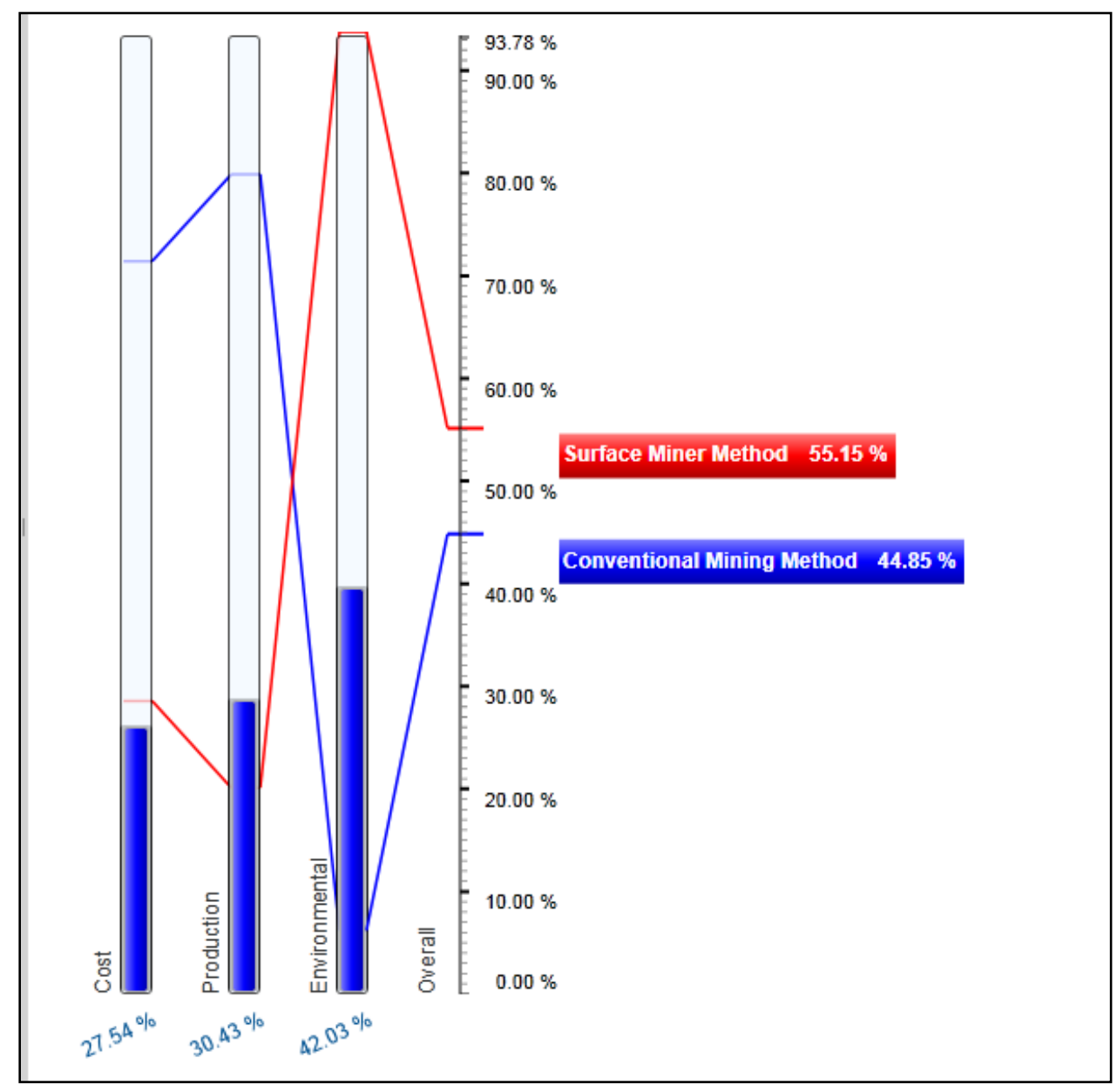

Figure 4-8 Performance Sensitivity Analysis

Figure 4.8 displays the global weights of each criterion for cost, production, and environmental as $27.54 \%, 30.43 \%$, and $42.03 \%$, respectively. After applying a rating score to each of the criteria the optimal mining method is determined by the highest 
priority. In this case the SM mining method with $55.15 \%$ is the optimal method compared to $44.85 \%$ for the conventional mining method.

\subsubsection{AHP Sensitivity Analysis}

As the presented AHP results are obtained based on user-defined input values; this approach requires sensitivity analyses to be performed. For this purpose, the Expert Choice (2012) is used to adjust the criteria's priority, while simultaneously adjusting the remaining criteria relative to one other. Three separate sensitivity analyses were conducted; the first on the level of importance assigned to a criteria in the comparison matrix, the second on the final priority percentages of the criteria, and thirdly on the rating given to blasting hazards.

The first sensitivity analyses consider the level of importance given to a criterion when compared to another in a comparison matrix. An example of decreasing the level of importance by 10 percent is shown below.

- Production is 1.2 time more important than cost is decreased to 1.1 times more important than cost.

This is an analysis of the level of importance only and does not consider the ratings and scores. Tables $4.37-4.39$ display the results of these analyses. The check mark displays the optimal mining method for each scenario. The optimal mining method remains the same in each case regardless of the importance level varying by 20 percent in both the 
positive and negative direction. This analysis shows that variations of the criteria's importance do not have the largest effect on the outcome of the AHP.

Table 4-37 Production and Cost Sensitivity Analysis

\begin{tabular}{|c|c|c|c|c|c|}
\hline \multicolumn{6}{|c|}{ Production and Cost Comparis on Matrix } \\
\hline $\begin{array}{l}\text { Sensitivity } \\
\text { Analysis }\end{array}$ & $\begin{array}{l}\text { Production } \\
\text { Importance }\end{array}$ & \multicolumn{2}{|c|}{$\begin{array}{l}\text { Conventional } \\
\text { Mining Method }\end{array}$} & \multicolumn{2}{|c|}{$\begin{array}{l}\text { SM Mining } \\
\text { Method }\end{array}$} \\
\hline$-20 \%$ & 1.0 & 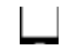 & $44.29 \%$ & $\underline{V}$ & $55.71 \%$ \\
\hline$-10 \%$ & 1.1 & $\sqcup$ & $44.58 \%$ & 以 & $55.42 \%$ \\
\hline $0 \%$ & 1.2 & L & $44.85 \%$ & $\boldsymbol{V}$ & $55.15 \%$ \\
\hline $10 \%$ & 1.3 & 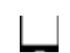 & $45.11 \%$ & $\underline{v}$ & $54.89 \%$ \\
\hline $20 \%$ & 1.4 & $L$ & $45.36 \%$ & $\checkmark$ & $54.64 \%$ \\
\hline
\end{tabular}

Table 4-38 Environmental and Cost Sensitivity Analysis

\begin{tabular}{|c|c|c|c|c|c|}
\hline \multicolumn{6}{|c|}{ Environmental and Cost Comparison Matrix } \\
\hline $\begin{array}{l}\text { Sensitivity } \\
\text { Analysis }\end{array}$ & $\begin{array}{c}\text { Environmental } \\
\text { Importance }\end{array}$ & \multicolumn{2}{|c|}{$\begin{array}{c}\text { Conventional } \\
\text { Mining Method }\end{array}$} & \multicolumn{2}{|c|}{$\begin{array}{l}\text { SM Mining } \\
\text { Method }\end{array}$} \\
\hline$-20 \%$ & 1.0 & L & $45.96 \%$ & $\checkmark$ & $54.04 \%$ \\
\hline$-10 \%$ & 1.1 & L & $45.38 \%$ & $\checkmark$ & $54.62 \%$ \\
\hline $0 \%$ & 1.2 & L & $44.85 \%$ & $\checkmark$ & $55.15 \%$ \\
\hline $10 \%$ & 1.3 & L & $44.35 \%$ & $\checkmark$ & $55.65 \%$ \\
\hline $20 \%$ & 1.4 & L & $43.88 \%$ & $\underline{v}$ & $56.12 \%$ \\
\hline
\end{tabular}


Table 4-39 Environmental and Production Sensitivity Analysis

\begin{tabular}{|c|c|c|c|c|c|}
\hline \multicolumn{6}{|c|}{ Environmental and Production Comparison Matrix } \\
\hline $\begin{array}{l}\text { Sensitivity } \\
\text { Analysis }\end{array}$ & $\begin{array}{l}\text { Environmental } \\
\text { Importance }\end{array}$ & \multicolumn{2}{|c|}{$\begin{array}{c}\text { Conventional } \\
\text { Mining Method }\end{array}$} & \multicolumn{2}{|c|}{$\begin{array}{l}\text { SM Mining } \\
\text { Method }\end{array}$} \\
\hline$-20 \%$ & 1.0 & $L$ & $46.34 \%$ & $\checkmark$ & $53.66 \%$ \\
\hline$-10 \%$ & 1.1 & 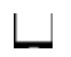 & $45.57 \%$ & $\checkmark$ & $54.43 \%$ \\
\hline $0 \%$ & 1.2 & $L$ & $44.85 \%$ & $\checkmark$ & $55.15 \%$ \\
\hline $10 \%$ & 1.3 & $L$ & $44.17 \%$ & $\underline{v}$ & $55.83 \%$ \\
\hline $20 \%$ & 1.4 & $L$ & $43.54 \%$ & $\checkmark$ & $56.46 \%$ \\
\hline
\end{tabular}

The second sensitivity analysis adjusts the criteria (cost, production, and environmental) in increments of approximately 10 percent in both the positive and negative directions. This is a sensitivity analysis of the criteria only and does not include variations in rating scores. The optimal mining method has the highest priority percentage and is displayed in red font. The results of these adjustments for the cost criteria can be seen in Table 4.40 .

Table 4-40 Sensitivity Analysis on Final Criteria

\begin{tabular}{|l|cccccccccccc|}
\hline Sensitivity Analysis & \multicolumn{4}{|c}{ Cost } & \multicolumn{4}{c}{ Production } & \multicolumn{4}{c|}{ Environment } \\
& $\underline{\mathbf{- 1 0 \%}}$ & $\underline{\mathbf{0}}$ & $\underline{\mathbf{+ 1 0 \%}}$ & $\underline{\mathbf{+ 2 0 \%}}$ & $\underline{\mathbf{- 1 0 \%}}$ & $\underline{\mathbf{0}}$ & $\underline{\mathbf{+ 1 0 \%}}$ & $\underline{\underline{\mathbf{1 0 \%}}}$ & $\underline{\mathbf{0}}$ & $\underline{\mathbf{+ 1 0 \%}}$ \\
\hline Cost \% & 17.44 & 27.54 & 37.52 & 47.50 & 31.53 & 27.54 & 23.63 & 32.24 & 27.54 & 22.76 \\
\hline Production \% & 34.67 & 30.43 & 26.24 & 22.05 & 20.36 & 30.43 & 40.32 & 35.62 & 30.43 & 25.15 \\
\hline Environment \% & 47.88 & 42.03 & 36.24 & 30.45 & 48.11 & 42.03 & 36.05 & 32.14 & 42.03 & 52.10 \\
\hline Surface Miner Method \% & 56.79 & 54.67 & 52.30 & 49.60 & 61.33 & 54.67 & 48.63 & 47.29 & 54.67 & 61.95 \\
\hline Conventional Mining Method \% & 43.21 & 45.33 & 47.70 & 50.40 & 38.67 & 45.33 & 51.37 & 52.71 & 45.33 & 38.05 \\
\hline
\end{tabular}

Table 4.40 displays the global weights of each criterion for cost, production, and environmental as well as the optimal mining method (displayed in red font). The optimal mining method selection continues to be the SM mining method until the of cost priority 
percentage is increased by $20 \%$. This result was expected as the SM has a lower score for costs. A similar trend exists when adjusting the production priority percentage. The optimal mining method remains the SM mining method until the production priority is increased by $10 \%$. This was expected as the SM has a lower score for production and will affect the optimal method at some point. Conversely, as the environmental priority percentage decreases $(-10 \%)$ the optimal mining method becomes the conventional mining method. This was expected as the SM has a higher score for environmental issues and at a point in lowering its priority the optimal mining method will change.

As mentioned previously this sensitivity analysis does not account for variations in rating score input values. Since blasting hazards is the highest weighted criteria, a sensitivity analysis of the rating score was performed on it. In this sensitivity analysis the global weights of the three strategic issues will remain unchanged, while the influence of the rating scores will vary and impact the decision accordingly. Figure 4.9 shows that the conventional mining method score for blasting hazards rise to "fair" with all remaining scores unchanged. 


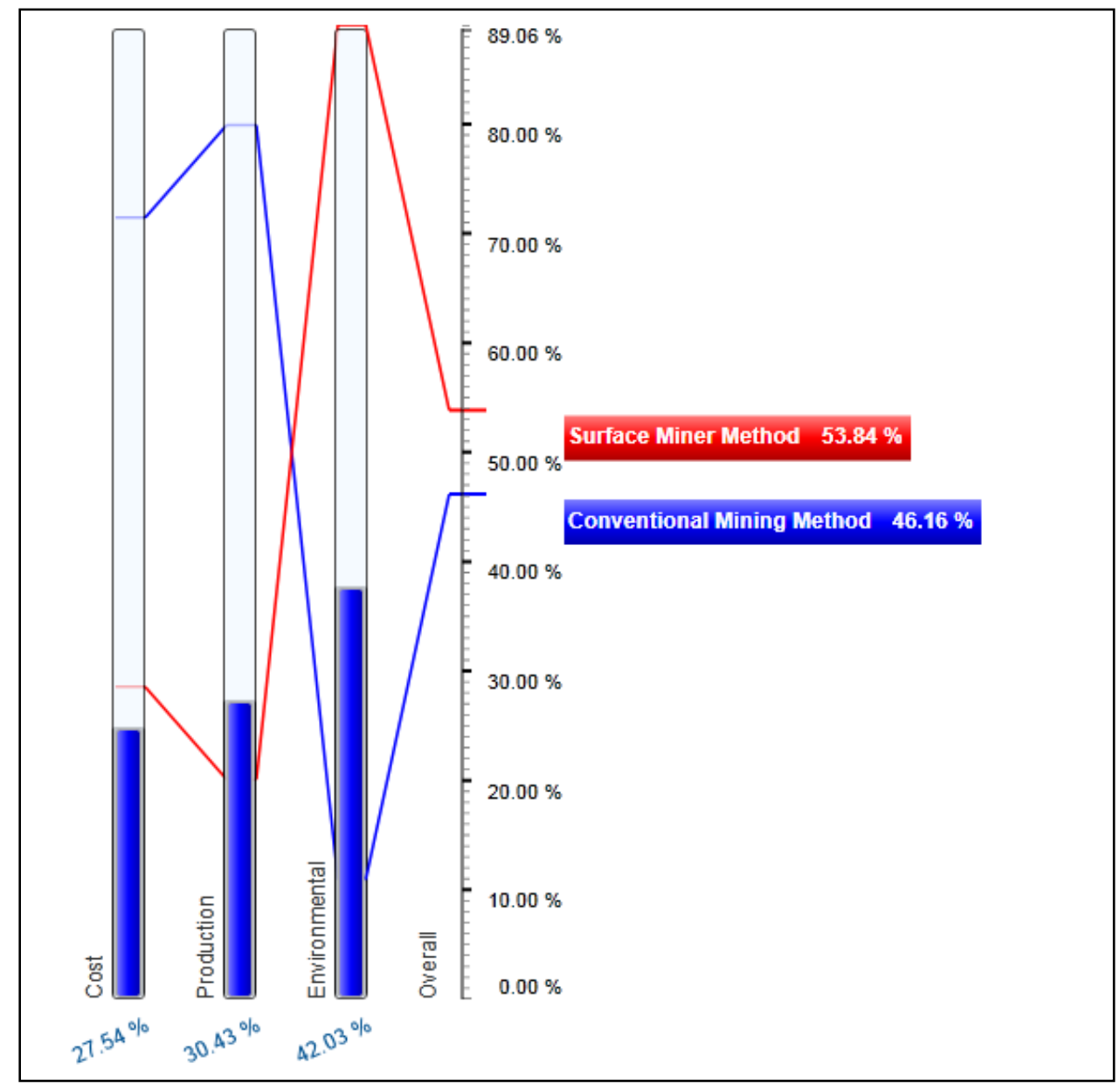

Figure 4-9 Sensitivity Analysis (Conventional Blasting Rating: Fair)

Raising the blasting hazards score for the conventional mining method to "fair" will not affect the selection of the optimal mining method as the priority of the SM mining method is $53.84 \%$ compared to $46.16 \%$ for the conventional mining method.

Figure 4.10 shows the SM mining method score for blasting hazards dropping to "good" with all remaining scores unchanged. 


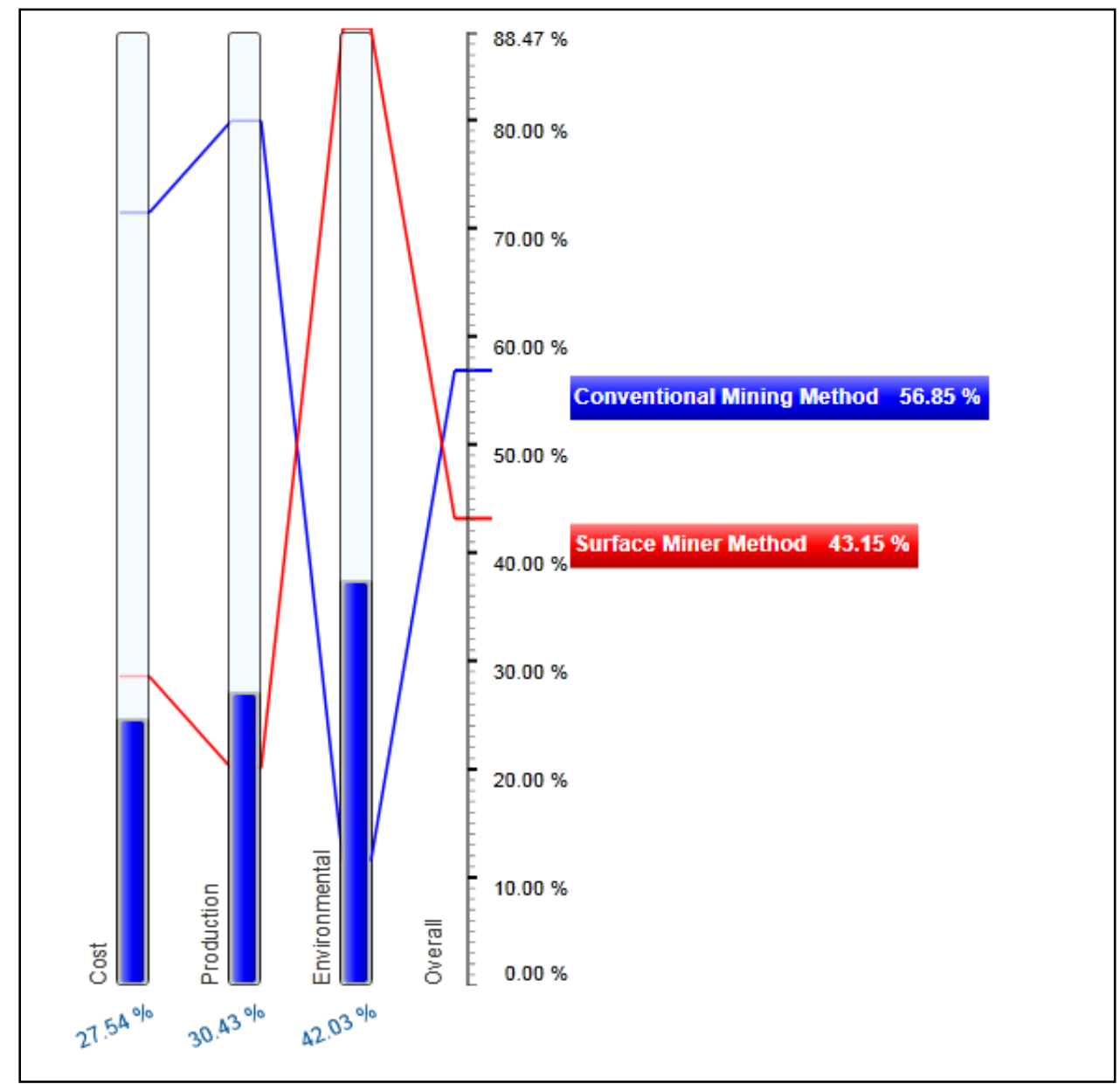

Figure 4-10 Sensitivity Analysis (SM Blasting Rating: Good)

Lowering the blasting hazards score for the SM mining method to "good" will affect the selection enough to change the optimal mining method to the conventional mining method with a priority of $56.85 \%$ compared to $43.15 \%$ for the SM mining method.

Finally, Figure 4.11 shows the conventional mining method rising to "fair" and the SM mining method dropping to "good" with all remaining scores unchanged. 


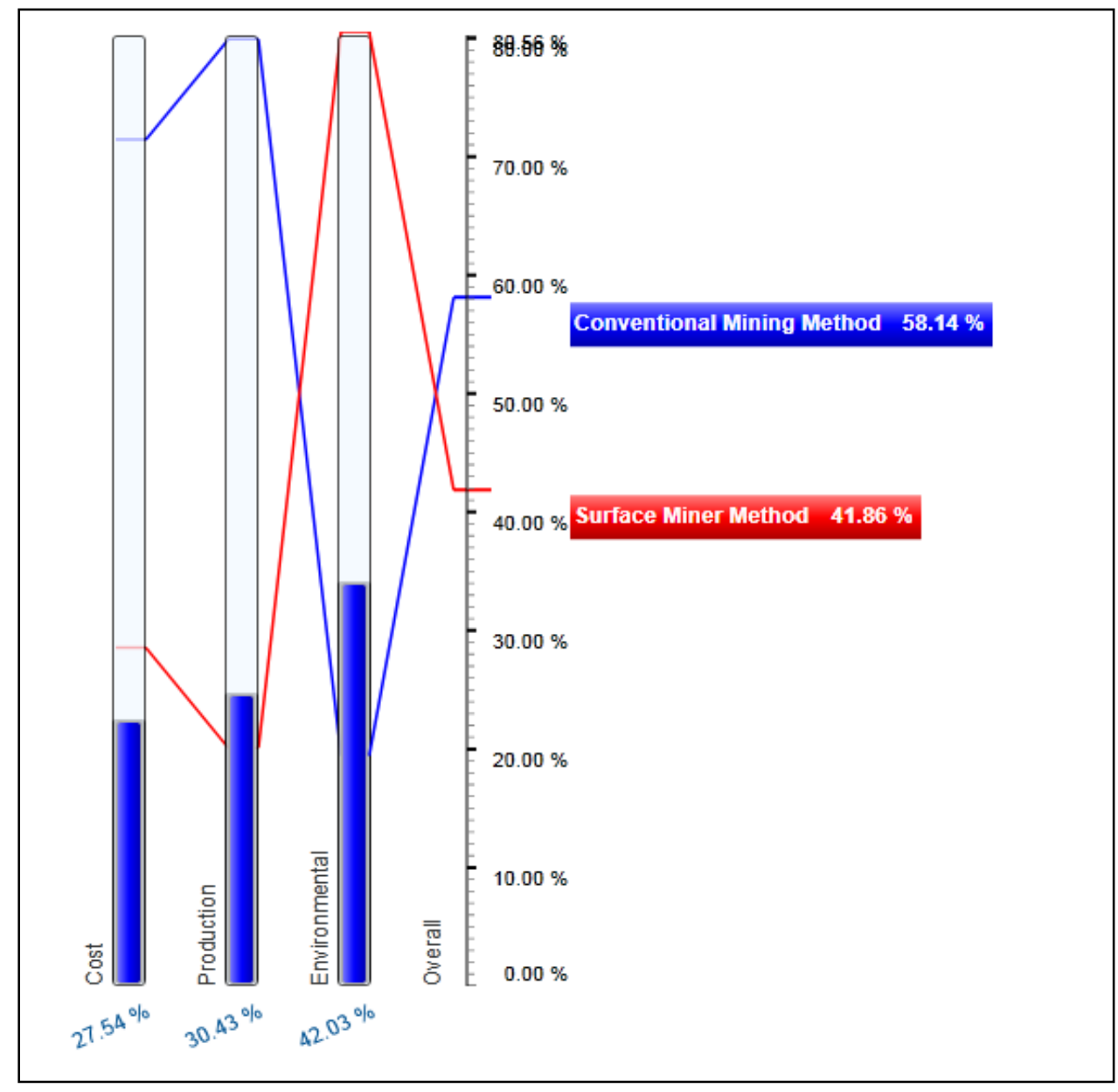

Figure 4-11 Sensitivity Analysis (Conventional Blasting Rating: Fair, SM Blasting Rating: Good)

Lowering the blasting hazards score for the SM mining method to "good" and raising the conventional to "fair" will affect the selection to the conventional mining method with a priority of $58.14 \%$ compared to $41.86 \%$ for the SM mining method.

The results of the sensitivity analysis for the blasting hazards score are to be expected as it is the only rating were the SM mining method is superior. By performing these sensitivity analyses, it can be seen how dependent the selection of the optimal mining 
method is on environmental factors. The combination of the results produced by the cost and production analysis and the application of the AHP, allows for an informed decision on the optimal mining method to be made. 


\section{Chapter 5}

\section{Conclusions and Recommendations for Future Research}

\subsection{Conclusions}

Based on the results of the study it can be concluded that the application of the SM would benefit surface coal mining operations in WV. These benefits include: lower costs of extraction of bituminous coal when compared with conventional mining unit operations; improved selective mining where thin coal seams, overburden, and interburden can be mined separately, thus preventing dilution of coal; generates an even grade of coal which reduces costs of further processing; and a more environmentally friendly mining method.

The downside of using the SM in surface mining operations begins with the limited quantity of the overburden and interburden material being extracted. An application problem arises with higher values of unconfined compressive strength and abrasivity of overburden and interburden material. Picks on the cutting drum will wear out faster and require more changes. At a certain point this method becomes unfeasible due to the slower advance rate and cost involved in a high amount of pick changes. New pick changing tools have accelerated this process, but it still remains one of the main factors of the operating cost. The negative aspects of using the SM are: a lower production rate when compared with conventional mining units; a high operating cost or inability to work in rocks with a very high value of unconfined compressive strength of overburden/interburden material. 
As governmental regulations become more stringent and public pressure increases, future coal mining operations will need to achieve "low impact" mining. Incorporating new design features and practices that can substantially reduce negative impacts is one of many steps that will need to be taken. New mining technologies and systems can also minimize environmental disturbances while improving coal recovery. The SM is one such technology that can eliminate blasting, which is one of the major public concerns. These types of changes are necessary to ensure that the coal industry can continue to operate safely and economically in the changing atmosphere.

\subsection{Recommendations for Future Research}

Some of the limitations in this research include the lack of data from any specific mine in WV; absence of the haulage considerations (specifically haul trucks) in the model; and the absence of dragline consideration as a digging and disposal mining unit. These three limitations should be included and addressed in future research.

To confirm the results of this research, it is necessary to test a SM in one of the existing surface coal mines in WV. Data collected from the testing should be focused on the engine load factor, the amount of pick wear, cutting depth, and cutting velocity in sandstone and shale overburden and interburden. This would greatly help determine the fuel consumption and maintenance costs involved with the SM. The formulas used for calculation of pick wear would be confirmed or determined to need revision given the data generated from an experimental trial in a material with the known properties. 


\section{References}

1. Atlas Copco, 2009. Blasthole Drilling in Open Pit Mining. Atlas Copco, $1^{\text {st }}$ ed. Garland, TX. pp. 206.

2. Bascetin, A. 2006. A Decision Support System Using Analytical Hierarchy Process (AHP) for the Optimal Environmental Reclamation of an Open-pit Mine. Environmental Geology. Springer-Verlag. Vol .52. Issue 4. pp. 663-672.

3. Bauer, R. 2011. Pick Wear of A Road Header. Internal Documentation by Wirtgen. pp. 1.

4. Brahma, K.C. 2007. A Study on Application of Strategic Planning Models and Operations Research Techniques in Opencast Mining. Department of Mining Engineering. National Institute of Technology. Rourkela. pp. 224.

5. Caterpillar, 2009. Caterpillar Performance Handbook, $40^{\text {th }}$ ed. Peoria, IL: Caterpillar Inc. pp. 1442.

6. Coyle, G. 2004. The Analytical Heirarchy Process (AHP). Practical Strategy, Pearson Education Limited. pp. 11.

7. Dev, K., Ghose, A.K. 2008. Predicting "Cuttability" with Surface Miners - A Rockmass Classification Approach. National Institute of Technology. Rourkela. Indian School of Mines University. Dhanbad. Journal of Mines, Metals and Fuels. Vol. 56. Issue 5-6. pp. 85-91.

8. Dyno Nobel, 2010. Cost of Explosives. Salt Lake City, UT: Dyno Noble. pp. 2.

9. Expert Choice, 2012. Expert Choice Software. Arlington, VA. http://www.expertchoice.com.

10. Ghosh, A., Mondal, S., Singh, S., Sinha, A. 2010. Application of Surface Miner in Nongtrai Limestone Mine of Lafarge Umiam Mining PVT. LTD. in Meghalaya, India. Central Institute of Mining \& Fuel Research. Department of Science \& Technology. Government of India. Jharkhand, India. pp. 66.

11. Hartman, H. 1990. SME Mining Engineering Handbook. Society for Mining, Metallurgy, and Explorations Inc. Littleton, CO. pp. 727-744. 
12. InfoMine, 2010. Mine and Mill Equipment Costs. Spokane Valey, WA: InfoMine USA Inc. pp. [SU-2]-[SU-43].

13. Ingersoll-Rand, 1998. Bench Drilling Techniques and Equipment Selection Manual. $1^{\text {st }}$ ed. Roanoke, VA: Ingersoll-Rand. pp. 85.

14. Kecojevic, V. 2010. Surface Mining: Lectures 4-14. West Virginia University. Morgantown, WV.

15. Komatsu, 2011. Application Principles. $2^{\text {nd }}$ ed. Peoria, IL: Komatsu America Co. pp. [G-1]-[16-4].

16. Liberatore, M., Nydick, R., Sanchez, P. 1992. The Evaluation of Research Papers (Or How to Get an Academic Committee to Agree on Something). Interfaces 22:2. pp. 92-100.

17. Mavko, G. 2011. Parameters That Influence Seismic Velocity. Conceptual Overview of Rock and Fluid Factors that Impact Seismic Velocity and Impedance. Stanford Rock Physics Laboratory. pp. 73-112.

18. Origliasso, C. 2011. Surface Miners: Design Features and New Approaches for Performance Prediction and Costs Calculation. Politechnico Di Torino. Tesi di laurea magistrale. Ingegneria per I'Ambiente e il Territorio. pp. 87.

19. Plinninger, R. 2010. Hardrock Abrasivity Investigation Using the Rock Abrasivity Index (RAI). Taylor \& Francis Group. London. pp. 3445-3452.

20. Pradhan, P., Dey, K. 2009. Rock Cutting with Surface Miner: A Computational Approach. Department of Mining Engineering. National Institute of Technology. Rourkela, India. Journal of Engineering and Technology Research. Vol. 1. pp. 115121.

21. Rostami, J., Ozdemir, L., Bruland, A., Dahl, F. 2006. Review of Issues Related to Cerchar Abrasivity Testing and Their Implications on Geotechnical Investigations and Cutter Cost Estimates. Department of Mining Engineering. University of Tehran. Earth Mechanics Institute. Colorado School of Mines. Norwegian University of Science and Technology at Trondheim. SINTEF Technology and Society. Ch. 57. pp. 738-741. 
22. Rusnak, J., Mark, C. 2000. Using the Point Load Test to Determine the Uniaxial Compressive Strength of Coal Measure Rock. Peabody Group. NOISH. In proceedings of the $19^{\text {th }}$ International Conference on Ground Countrol in Mining. Morgantown, WV: West Virginia University. pp. 362-371.

23. Saaty, T. 1980. The Analytic Hierarchy Process: Planning, Priority Setting, Resource Allocation. McGraw-Hill International Book Co. New York. pp. 287.

24. Saaty, T. 2008. Decision Making with the Analytical Hierarchy Process. Katz Graduate School of Business. University of Pittsburgh, PA. International Journal Services Science. Vol. 1. No. 1.pp. 83-98.

25. Schimm, B. 1997. Mining of Medium Hard Rock Without Blasting by Means of Cutting. Experience and Economics of the Wirtgen Surface Miner. Wirtgen GmbH. Windhagen, Germany. Denver, CO: Society for Mining, Metallurgy, and Exploration, Inc. pp. 5.

26. Schroder, D. n.d. Large Surface Miners - Applications and Cost Calculations. Krupp Fordertechnik GmbH. Essen, Germany. Accesed 2011. pp. 6.

27. Schroder, D., Schwier, E. 1996. Selection of Mining Systems for Large Open Pits. Braunkohle, Surface Mining. pp. 8.

28. Schubert. 2007. Rock Excavation by Drill and Blast. Lecture 10. Institute for Rock Mechanics and Tunneling. Graz University of Technology.

29. Apodaca. L.E. 2010. Explosives. In Minerals Yearkbook 2010. U.S. Geological Survey. pp. 6.

30. Wirtgen. 2008. Wirtgen Surface Mining Manual. Germany: Wirtgen Group. pp. 172.

31. Wirtgen. 2010. Wirtgen Surface Mining Manual. Germany: Wirtgen Group. pp. 172.

32. WV Coal. 2011. Coal Facts-West Virginia Coal: Fueling an American Renaissance. Publication of West Virginia Coal Association. WV. pp. ?.

33. WVGE. 2011. Geologic Map of West Virginia. Mont Chateau Research Center. Morgantown, WV: West Virginia Geological and Economical Survey. 